\title{
Expression profiling of oocyte specific genes, transcription factors and microRNAs during early embryonic development in rainbow trout (Onchorhyncus mykiss)
}

\author{
Raghuveer K. Ramachandra \\ West Virginia University
}

Follow this and additional works at: https://researchrepository.wvu.edu/etd

\section{Recommended Citation}

Ramachandra, Raghuveer K., "Expression profiling of oocyte specific genes, transcription factors and microRNAs during early embryonic development in rainbow trout (Onchorhyncus mykiss)" (2007). Graduate Theses, Dissertations, and Problem Reports. 2595.

https://researchrepository.wvu.edu/etd/2595

This Dissertation is protected by copyright and/or related rights. It has been brought to you by the The Research Repository @ WVU with permission from the rights-holder(s). You are free to use this Dissertation in any way that is permitted by the copyright and related rights legislation that applies to your use. For other uses you must obtain permission from the rights-holder(s) directly, unless additional rights are indicated by a Creative Commons license in the record and/ or on the work itself. This Dissertation has been accepted for inclusion in WVU Graduate Theses, Dissertations, and Problem Reports collection by an authorized administrator of The Research Repository @ WVU.

For more information, please contact researchrepository@mail.wvu.edu. 
Expression profiling of oocyte specific genes, transcription factors and microRNAs during early embryonic development in rainbow trout (Onchorhyncus mykiss)

\title{
Raghuveer K Ramachandra
}

Dissertation submitted to the Davis College of Agriculture, Forestry and Consumer Sciences at West Virginia University in partial fulfillment of the requirements for the degree of

\author{
Doctor of philosophy \\ in
}

Animal and Food Sciences

\author{
Jianbo Yao, Ph.D., Chair \\ Kenneth Blemings, Ph.D. \\ Dale Karlson, Ph.D. \\ Caird Rexroad III, Ph.D. \\ Janet Tou, Ph.D. \\ Michael Vernon, Ph.D.
}

\section{Division of Animal and Nutritional Sciences}

\section{Morgantown, WV}

\section{7}
Keywords: Oocyte specific genes, embryonic development, embryonic genome activation, Transcription factors, microRNAs, microRNA library construction




\title{
Expression profiling of oocyte specific genes, transcription factors and microRNAs during early embryonic development in rainbow trout (Onchorhyncus mykiss)
}

\author{
Raghuveer K Ramachandra
}

\section{Abstract}

Genes specifically expressed in oocytes are important for the development of oocytes and early embryos. By analyzing ESTs from a rainbow trout oocyte cDNA library, we identified a novel EST sequence that does not show homology to any sequences in the GenBank. Analysis of tissue distribution by RT-PCR revealed that this gene was only expressed in unfertilized oocytes. Sequencing of the EST clone identified a cDNA of $3163 \mathrm{bp}$. Northern blot analysis showed the novel gene has a single transcript of $3.4 \mathrm{~kb}$. Additional 5' sequence was obtained by 5' RACE, extending the novel cDNA to $3333 \mathrm{bp}$. Analysis of the full length cDNA identified an open reading frame encoding a protein of 564 amino acids. The novel protein contains a conserved oxysterol binding protein (OSBP) domain at the $\mathrm{C}$ terminus that is characteristic of OSBP-related proteins implicated in lipid metabolism. Therefore, we named the novel gene as Oocyte-specific Oxysterol binding protein Related-Protein of Trout (OORP-T). In situ hybridization showed that the OORP-T mRNA appears to be confined to the cytoplasm of vitellogenic oocytes. Transcription of OORP-T appears to start during pre-vitellogenesis and increases steadily, reaching its peak in the late vitellogenic stage. OORP-T transcript is abundantly present in unfertilized eggs but the level drops significantly in day 2 embryos and continues to decline in day 7 embryos after which it remains low. It is proposed that OORP-T may play an important role in the utilization of yolk derived lipid products during oocyte development and early stages of embryonic development in rainbow trout.

Maternal-zygotic transition (MZT) is the first major transition in early development leading to the activation of embryonic genome. Effective transcription machinery including transcription factors must be in place during MZT for it to occur. Therefore, measuring the transcript abundance of key transcription factors prior to and after MZT can give important clues about the roles of transcription factors during this process. In this study, we quantitatively measured mRNA abundance of 9 selected transcription factors (Figla, P300, YY1, HMGA1, HMGB1, HMGN1, ATF-1, TEAD2 and OCT-4) in unfertilized eggs and early stage embryos from day 1 through day 7 post fertilization using quantitative real time PCR. Our results demonstrate that significant amounts of mRNA for all transcription factors studied are present in unfertilized eggs and day 1 embryos, and the expression of all transcription factors reaches minimum levels in day 2 embryos. While some transcription factors remain at low levels of expression throughout late stage development, others show significant increase of expression following embryonic genome activation. The expression patterns of these transcription factors are suggestive of their roles in MZT as well as in early development in rainbow trout.

Current literature and our results on expression patterns of oocyte specific genes and transcription factors suggest global but highly regulated maternal mRNA degradation 
at the time of embryonic genome activation (EGA). We hypothesized that microRNAs (miRNAs), naturally occurring 19-21bp long post-transcriptional regulators, are involved in this degradation process. We analyzed the expression pattern of dicer, an enzyme required for the processing of microRNAs. Dicer is abundantly expressed until 24 hours post-fertilization and gets down-regulated afterwards. This supports the hypothesis that dicer processes mature miRNAs during these stages and these miRNAs in turn degrade maternal mRNAs. To identify candidate microRNAs involved in this process, we constructed a miRNA library from a pool of oocytes and early stage embryos $(0$ hour post-fertilization through 96 hours post-fertilization). Sequencing analysis of clones showed that there are at least 15 miRNAs expressed during these stages, 4 of which are novel to rainbow trout. We carried out quantitative real-time PCR to learn more about their expression pattern. Our results show that several microRNAs are up-regulated when maternal RNAs are degraded. Stat3, a transcription factor which is involved in activating the transcription of miR-21 is also abundantly expressed in early rainbow trout embryos. Taken together, these results indicate that up-regulated microRNAs, some induced by stat3, could be responsible for degradation of maternal mRNAs in early embryos.

Identification and characterization of a novel oocyte specific gene with a conserved domain that is involved in oxysterol (a metabolite of cholesterol, a precursor molecule of all steroid hormones) metabolism is described here. Expression pattern of OORP-T follows the pattern of estrogen during oogenesis indicating its unique role in oogenesis and early embryonic development although the functions of OORP-T remain to be discovered. None the less, the OORP-T can potentially be used as a marker in selecting for high growth, better nutritional efficiency, disease resistance etc. Based on the results of studies on expression pattern of transcription factor mRNAs and microRNAs, it appears that microRNAs may be involved in maternal mRNAs degradation before EGA. The microRNAs identified and characterized here might also serve as markers for above mentioned economically important traits especially because microRNA might be regulating several target genes involved in any of the above mentioned phenotypes. 


\section{Dedication}

to the dreams of appa, amma and virochana

and

to the love and prayers of veenu 


\section{Acknowledgements}

I acknowledge the support and encouragement rendered by Dr Jianbo Yao, chair of my advisory committee. The freedom I got in terms of choosing the project, designing experiments and executing them was just amazing and I truly cherish it.

I acknowledge the support by advisory committee members Drs Kenneth Blemings, Michael Vernon, Caird Rexroad III, Janet Tou and Dale Karlson in going through my dissertation and critically evaluating it. Certainly their suggestions have made me a better writer and a better thinker.

Colleagues in the lab, Diana, Moh, Brandon, Qiu, Jyothsna, Sarah and Angela made the lab environment very friendly and helped me in every way they could. I thank them for their friendship, help and support.

Faculty in the department has been very kind and supportive of me. I am indebted to Drs Paul Lewis, Bob Daily, Keith Inskeep, Bob Cochrane and Brett Kenny for their encouragement and goodwill.

Colleagues in the department, Ida, O, Justin, Fernando, Jill, Dan, EZ, Aimee \& Beth were all a great help when I needed them most. I can't thank them enough for their friendship, timely help and expertise they shared with me.

Staffs in the department Bonnie, Gretchen, Lindsey, Kim, Sarah (Beamer) were nice to me and helped me in every way they could. I thank them for bearing with me.

Financial support by USDA is gratefully acknowledged.

Last but the most important, dreams and expectations of my parents and brother have taken me this far. Nothing can replace the love and prayers of Veenu. I have no words to explain their role in my life and thank them. 


\section{Table of contents}

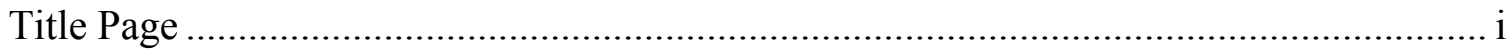

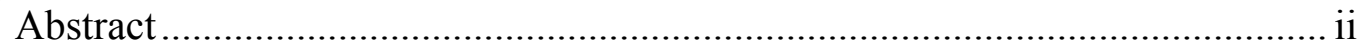

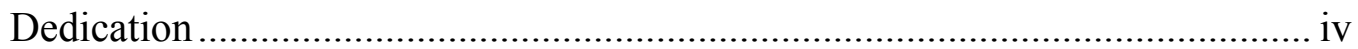

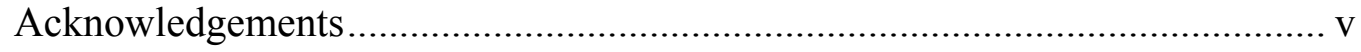

Table of contents........................................................................................ vi

List of figures............................................................................................ vii

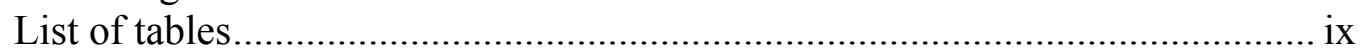

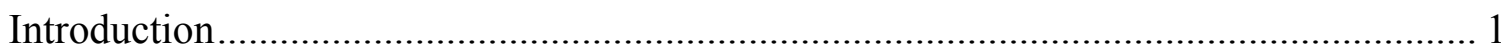

Review of literature

Oocyte-somatic interactions.......................................................................... 3

Formation and early development of primordial follicles ...................... 3

Proliferation and differentiation of granulosa cells ................................. 5

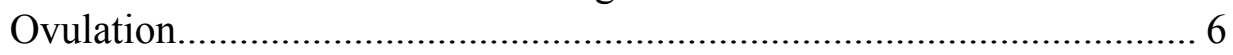

Fertilization and early embryonic development ................................... 8

Embryonic genome activation ............................................................ 9

Chromatin remodeling .................................................................. 10

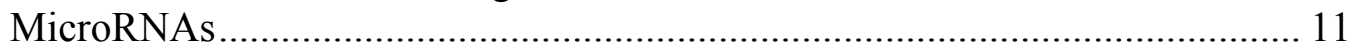

Introduction.................................................................................. 11

Synthesis and mechanism of action ................................................... 13

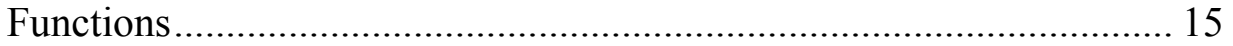

Roles in early development............................................................... 15

Chapter 1 : Identification of OORP-T, a novel oocyte-specific gene in rainbow trout ... 18

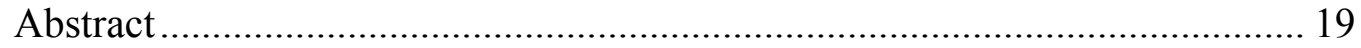

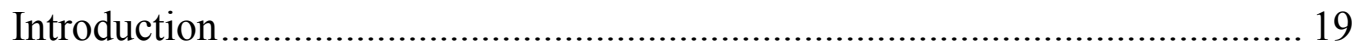

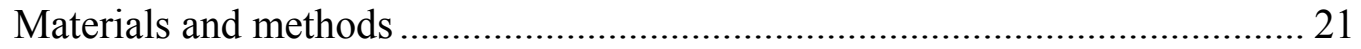

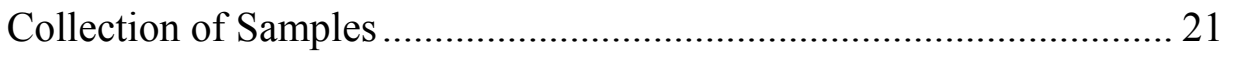

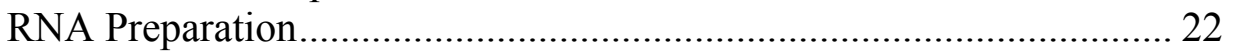

RT-PCR

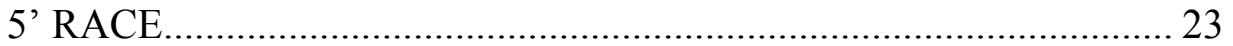

Preparation of Digoxigenin (DIG)-Labeled RNA Probe ........................ 23

Northern Blot Analysis ........................................................................ 23

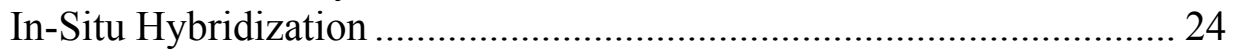

Quantitative Real Time PCR ………………………………......... 25

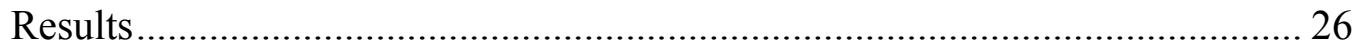

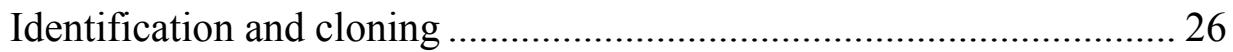

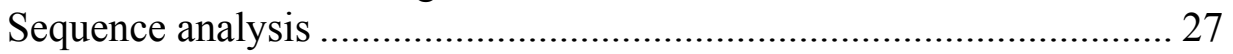

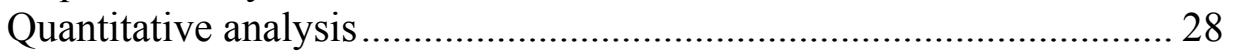

Cellular localization .................................................................... 28

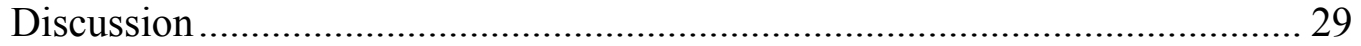

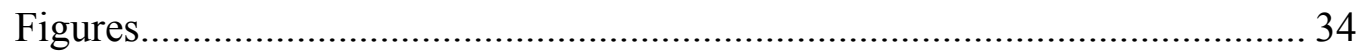

Chapter 2: Expression of key transcription factors during early embryogenesis ........... 39

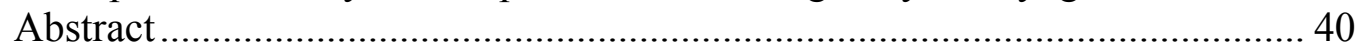

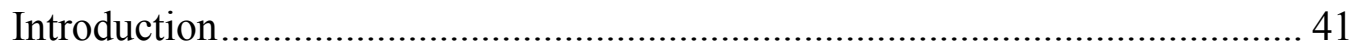

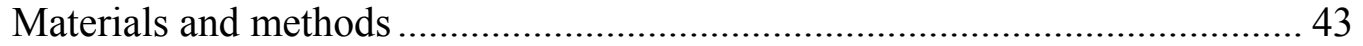

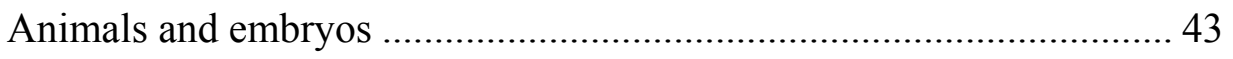




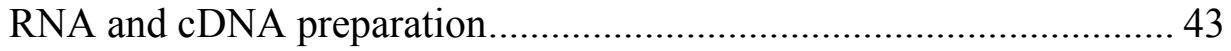

Quantitative real time PCR …………………….............................. 43

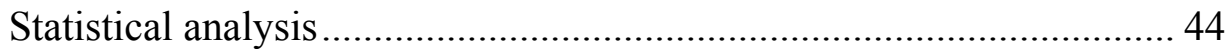

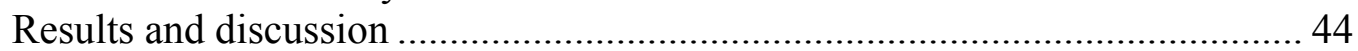

Tables and figures ..................................................................................... 48

Chapter 3 : Cloning and characterization of microRNAs in rainbow trout ...................... 52

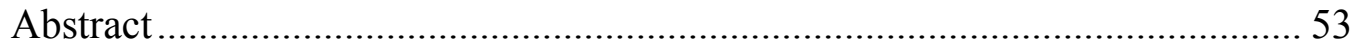

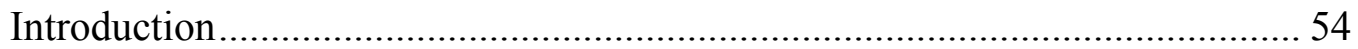

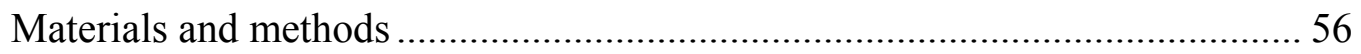

Animals and embryos .................................................................. 56

Quantitative Real-time PCR for dicer and stat3 …………………....... 56

MicroRNA Cloning ……................................................................ 57

Quantitative Real-time PCR for microRNAs ...................................... 58

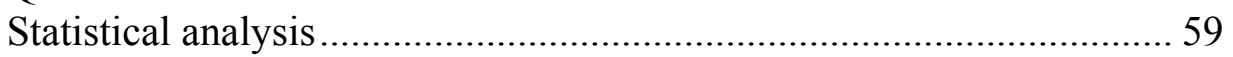

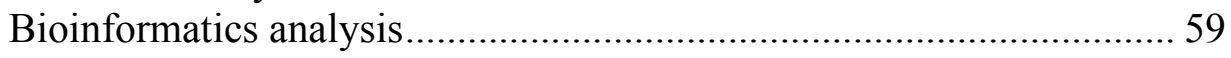

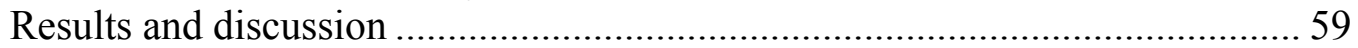

Expression pattern of Dicer ................................................................ 59

MicroRNA library construction and sequencing .................................. 61

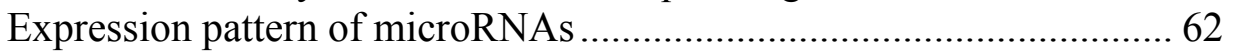

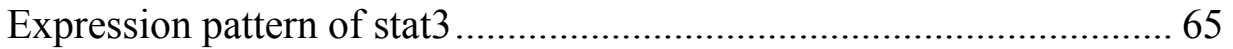

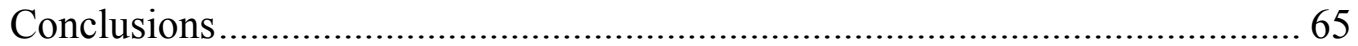

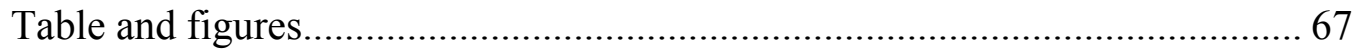

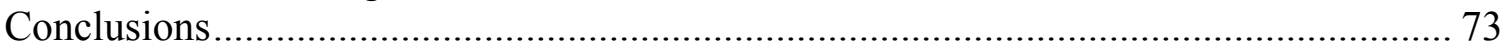

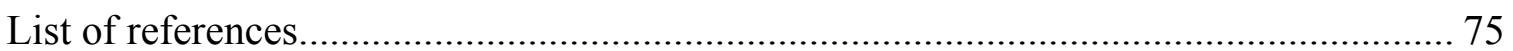




\section{List of figures}

Figure I Mechanism of synthesis and procession of microRNAs.....................14

Chapter 1

Figure 1-1 Expression of OORP-T mRNA in rainbow trout tissues. 34

Figure 1-2 Full-length cDNA and amino acid sequences of rainbow trout OORP-T.. ... 35

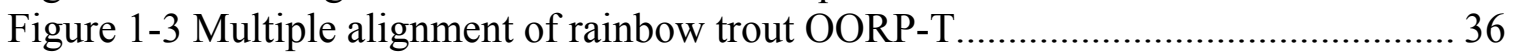

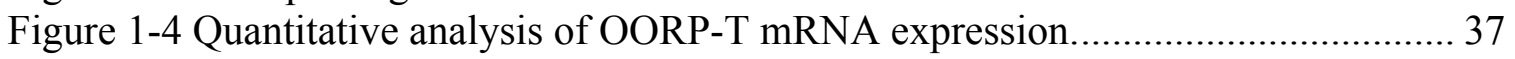

Figure 1-5 Localization of OORP-T by in situ hybridization........................................ 38

Chapter 2

Figure 2-1 Relative abundance of Figla, P300 and YY1, HMGA1, OCT-4 and ATF-1.. 50

Figure 2-2 Relative abundance of HMGN1, HMGB1 and TEAD2.

Chapter 3

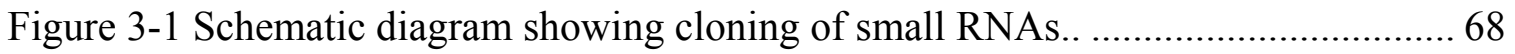

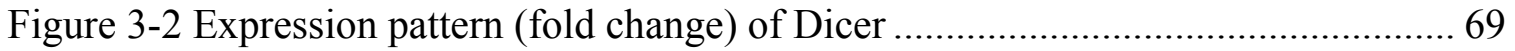

Figure 3-3 Alignment of novel rainbow trout microRNAs. ...................................... 70

Figure 3-4 Expression patterns (fold change) of microRNAs ........................................ 71

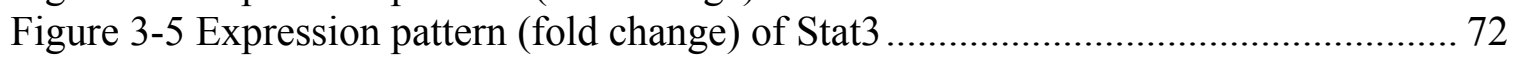




\section{List of tables}

Table 2-1 Relevant information about transcription factors evaluated........................... 48

Table 2-2 Primers used for quantitative real time PCR ........................................... 49

Table 3-1 Rainbow trout microRNAs. Sequences, length, primers and conservation across species. 


\section{INTRODUCTION}

Aquaculture is increasingly becoming the focus for assuring food security for the growing world population given the limited land resources. The rainbow trout (Oncorhynchus mykiss) is a commercially important aquaculture species. It is a native of North America and Russia and is one of the most studied model fishes in wide areas of research. Extensive information on basic biology is available for rainbow trout as a result of widespread culture as food and sport fish (Thorgaard et al. 2002). Since they are closely related to other salmonid species like Atlantic and Pacific salmon and chars, they can serve as a surrogate for research on these economically important species. Over the last 20 years, rainbow trout is featured in over 20,000 scientific reports dealing with physiology, ecology and behavior. Because of its large size, it is amenable to surgical manipulations, experiments that need large amounts of specific tissues and cell types. The rainbow trout are well suited for toxicological and carcinogenesis studies because of its sensitivity to low concentrations of toxic materials (Bailey et al. 1996). Unlike other fish models, elaborate information is available on natural populations of rainbow trout to aid answering evolutionary questions (Hershberger 1992). Various other branches of science where rainbow trout are being used as a model include comparative immunology, disease ecology, physiology of sensory systems, circulation, respiration, osmoregulation, muscle structure \& function and reproduction (Thorgaard et al. 2002).

The ability of rainbow trout to produce a large number of gametes throughout the year, the transparency of their eggs, external fertilization, ease of egg incubation and manipulation make rainbow trout an ideal model for studies on early embryonic 
development. Areas where rainbow trout is used as a model include gamete physiology, sex determination, vitellogenesis, and reproductive endocrinology.

These studies were conducted after assessing the importance of rainbow trout embryonic development from the points of view of understanding basic biology of early embryonic development using trout as a model and potentially identifying molecular markers to aid selection of quality broodstock. Three approaches were used in this study. Several oocyte specific genes have proven to be missing links in our understanding on oogenesis, oocyte-somatic interactions and early embryonic development (see review). Therefore the first project was designed to identify and characterize novel genes specifically expressed in rainbow trout oocytes and early embryos. Embryonic genome activation is the most important landmark and the first major transition in embryo's life. The aim of the second project was to characterize the existence \& distribution of transcription machinery during embryonic genome activation. Degradation of maternally inherited messenger RNAs at the time of embryonic genome activation is essential for normal development. A similar pattern of degradation was observed in the first two projects leading to the third project. The objective of the third project was to identify and characterize potentially involved microRNAs in degradation of maternal mRNAs during embryonic genome activation in rainbow trout. 


\section{REVIEW OF LITERATURE}

\section{Oocyte-somatic interactions}

The physical proximity of the oocyte and surrounding somatic cells prompted biologists to hypothesize that oocyte growth is supported by granulosa cells. As early as 1935, Pincus and Enzmann hypothesized that somatic cells surrounding the oocyte maintain the oocyte in meiotic arrest based on the observation that fully grown oocytes separated from antral follicles underwent spontaneous gonadotrophin-independent resumption of meiosis (Pincus and Enzmann 1935). But role of oocyte in signaling its surrounding cells was not realized until 1970 when el-Fouly et al. showed that rabbit follicles undergo precocious luteinization when the oocyte-cumulus complex was removed (el-Fouly et al. 1970). Since that pioneering study, there has been a great interest in characterizing the interaction between oocyte, cumulus cells and granulosa cells. This interaction is thought to be in place from recruitment of primordial follicles until after ovulation. Extensive information is available on hormonal and non-hormonal interactions between oocytes and somatic cells (Buccione et al. 1990a; Combelles et al. 2004).

\section{Formation and early development of primordial follicles}

Presence of an oocyte is essential for the structural and functional identity of a follicle (Eppig 2001). An oocyte specific basic-helix-loop-helix transcription factor called factor in germline alpha (figla) is expressed early in the embryo's life and is required for this process. Because of its transcription factor nature, Figla controls expression of zona pellucida genes and probably other genes (Soyal et al. 2000). Other basic-helix-loophelix transcription factors that are germline specific and required for folliculogenesis are 
Sohlh1 and Shohlh2. Transcription factor Sohlh1 and its downstream target Lhx8 are required for oogenesis and mice lacking Sohlh1 are sterile (Pangas et al. 2006). Female mice lacking another oocyte specific homeobox gene nobox have severe deformities in primordial follicle growth and transition from primordial to primary follicles (Rajkovic et al. 2004). Taken together, germ line specific transcription factors Figla, Sohlh1, Sohlh2, Lhx8 and Nobox control the expression of each other and possibly other transcription factors and play crucial roles in folliculogenesis in mice (Zheng and Dean 2007).

The germ cell specific RNA binding protein Dazla (deleted in azoospermia-like autosomal) is implicated in RNA transport and protein synthesis in oocytes and is required for development and survival of germ cells and hence causes infertility in mice lacking it (Cooke et al. 1996; Padmanabhan and Richter 2006; Ruggiu et al. 1997). Msy2 also known as $Y b x 2$ is another germline specific RNA/DNA binding protein important in stability and translation of cytoplasmic transcripts and a possible transcription regulator (Yu et al. 2001). Post-fertilization degradation of Msy2 suggests a role for this gene in the oocyte-embryo transition (embryonic genome activation) (Zheng and Dean 2007). Cytoplasmic polyadenylation element binding protein 1 (Cpeb1) binds to polyadenylation elements in the 3' untranslated regions of mRNAs and controls their translation. Temporally controlled expression of cpeb1 controls expression of several targets including Dazla and GDF9 (see below) (Vasudevan et al. 2006). Mice lacking cpeb1 are sterile and no germ lines are observed in postnatal ovaries (Tay and Richter 2001).

The mechanism by which follicles are activated for entry into the growing cohort is not well understood. However, two oocyte specific TGF $\beta$ family members, namely bone morphogenetic protein-15 (BMP15) and growth and differentiation factor-9 
(GDF9), are thought to act as paracrine controls produced by oocytes (Elvin et al. 2000b; Otsuka et al. 2000). Mutations in either of these genes causes failure to develop beyond primary follicle stage and results in infertility (Davis et al. 1992; Dong et al. 1996; Galloway et al. 2000). Oocyte derived GDF-9 represses expression of a kit ligand gene (Kitl) in granulosa cells (Joyce et al. 2000; Joyce et al. 1999) and oocytes possess receptors for Kitl (Yoshida et al. 1997) thus completing a loop of oocyte-granulosa cells mutual signaling. Bone morphogenetic protein 15 acts synergistically with GDF9 in development of granulosa cells, ovulation and fertility (Dong et al. 1996; Su et al. 2004; Yan et al. 2001) and a 50\% reduction in natural BMP-15 concentration causes increased ovulation; possibly because of the disruption in the feedback between the ovary and pituitary by the action of increased gonadotrophins and augmented follicular development showing that oocyte derived factors have important but indirect roles in follicles recruitment (Galloway et al. 2000).

\section{Proliferation and differentiation of granulosa cells}

Hirshfield (1986) observed that granulosa cells close to the oocyte proliferate faster than those further away from it. Oocytes control the proliferation of granulosa cells by secreting multiple paracrine factors ( $\mathrm{Li}$ et al. 2000). Since both recombinant GDF9 and BMP15 promote proliferation of granulosa cells, they are considered oocyte derived mitogens (Hayashi et al. 1999; Otsuka et al. 2000; Vitt et al. 2000). After the formation of the antrum, mural granulosa cells and cumulus cells are different both in terms of their morphology and gene expression patterns and this differentiation is influenced by the oocyte to a great extent (Furman et al. 1986; Joyce et al. 1999). For example, Kitl and FSH-induced Lhcgr are expressed by cumulus cells detached from the oocyte and are 
suppressed by paracrine factors secreted by the oocyte (Eppig et al. 1997). Further, expression of these genes is influenced by GDF9 in the same way as in mature oocyte, supporting the hypothesis that oocyte acts on granulosa cells through GDF9 and/or BMP15 (Elvin et al. 1999; Joyce et al. 2000). However, not-fully grown oocytes fail to induce this action in spite of their production of GDF9 indicating the involvement of other factors (Eppig 2001). Apart from contributing to normal development of oocyte and embryos, these oocyte specific genes are attributed to commercially important traits in farm animals. Mutations on BMP-15 and GDF-9 are associated with both increased ovulation rate and infertility in sheep (Galloway et al. 2000; Hanrahan et al. 2004).

\section{Ovulation}

Follicles are termed primordial follicles once encompassed by a squamous layer of somatic follicular cells. This large pool of primordial follicles serves as the reservoir from which follicles are recruited for ovulation (Eppig 2001). Oocytes resume meiosis once they receive external signals to grow. However not all oocytes gain the competence to pass the metaphase-I stage if they don't receive signals from growing antral follicles (Handel and Eppig 1998). Resumption of meiosis requires a surge of gonadotrophins which also stimulates cumulus cells to secrete hyaluronic acid in turn helping in cumulus expansion (Chen et al. 1993; Salustri et al. 1989). Germinal vesicle breakdown causes activation of mitogen-activated protein kinase in cumulus cells. This activation requires signals from the oocyte and a somatic cell signal downstream of the pre-ovulatory LH surge. Cumulus cell differentiation is caused by the factors secreted by oocyte including growth and differentiation factor 9 (GDF-9) (Eppig 2001). 
Pre-ovulatory surges in gonadotrophins levels cause series of reactions leading to ovulation. Gonadotrophins induce cumulus cells to produce hyaluronic acid, a nonsulphated glycosaminoglycon, which is bound to the cumulus cells by linker proteins. Upon hydration of hyaluronic acid, the space between cumulus cells becomes enlarged and filled with a sticky mucified matrix (Chen et al. 1996; Salustri et al. 1989). However, removal of the oocyte-cumulus from the follicle results in no FSH-induced hyaluronic acid production but, co-culture of FSH-stimulated oocytectemized complexes with denuded fully grown oocytes enables the expansion of the complex (Buccione et al. 1990b; Eppig 2001). Hence, Eppig (2001) hypothesized that the oocytes secrete a cumulus expansion enabling factor (CEEF) to enable the granulosa cells to respond to the FSH surge by producing hyaluronic acid. This CEEF is not secreted by not-fully grown oocytes, but secreted to some extent by GV stage oocytes and is not detected in 2 cell embryos. Prostaglandin-endoperoxide synthase 2 (ptgs2 or Cox2) is an enzyme required for the synthesis of prostaglandins. Expression of this gene and in turn production of prostaglandin is orchestrated by thecal cells and augmented by oocyte (Joyce et al. 2001). So oocytes influence granulosa cells in ways essential for ovulation by enhancing prostaglandin production and cumulus expansion (Eppig 2001). GDF9 participates in the production of prostaglandin by stimulating expression of Ptgs 2 and by augmenting expression of Ptgerep2, a receptor of prostaglandin (Elvin et al. 2000a).

Before the pre-ovulatory LH surge, the oocytes suppress expression of urokinase plasminogen activator (Plau or uPA) by cumulus cells and prevent protease-mediated tissue modification. After ovulation, cumulus cells are insensitive to the oocyte suppression and hence secrete uPA and participate in disassembly of the cumulus cell- 
oocyte complex (Canipari et al. 1995; D'Alessandris et al. 2001). Reasons for this differential receptivity are unknown indicating a role of several unknown factors.

\section{Fertilization and early embryonic development}

Formation of the zona pellucida, a three-dimensional extra-cellular matrix surrounding oocytes and early embryos, is required for fertilization (Familiari et al. 2006). Three glycoproteins secreted by the oocyte form this complex namely ZP (zona pellucida)1, ZP2 and ZP3 (Bleil and Wassarman 1980). These three oocyte specific genes basically form the egg membrane, possess receptors for sperm and control fertilization. Disruption of any of these three genes results in infertility/reduced fecundity (Liu et al. 1996; Rankin et al. 1996; Rankin et al. 1999; Rankin et al. 2001). It was observed in humans and mice that $\mathrm{ZP} 2$ is cleaved by a presumptive protease thereby changing the three-dimensional structure to produce a non-permissive structure for sperm binding irrespective of fertilization (Bauskin et al. 1999; Bleil et al. 1981; Rankin et al. 2003).

Maternal effect genes are those that are stored in the oocyte before ovulation but not required until late in development (Zheng and Dean 2007). Several oocyte specific maternal effect genes are identified and characterized. Zygote arrest 1 (zar1) is one such gene that is expressed during folliculogenesis and persistent until the two cell stage in mice (Wu et al. 2003) and up to 24 hours in rainbow trout (Ramachandra et al., data unpublished). Zar1 null mouse oocytes can be fertilized but the two pronuclei do not fuse thereby affecting the oocyte to embryo transition (Wu et al. 2003).

Nucleoplasmin2 (Npm2) is another oocyte specific gene thought to play a very important role during post-fertilization nuclear modifications. This nuclear protein is conserved in several species but was first identified in Xenopus (Philpott and Leno 1992; 
Philpott et al. 1991). Mice lacking npm2 are fertile but show severe heterochromatin and acetylation defects (Burns et al. 2003).

Nalp5 (NACHT, leucine-rich repeat and PYD containing 5) or mater (maternal antigen that embryos require) is a cytoplasmic protein required for development of mice embryos beyond the 2 cell stage. Nalp5 null mice mimic phenotypes caused by treatment of $\alpha$-amanitin, a chemical that blocks transcription by RNA polymerase II and inhibits progression of embryos beyond the 2 cell stage suggesting that it is required for transcription (Tong et al. 2000).

It was famously hypothesized by Eppig (2001) that if oocytes were absent from the follicles, granulosa cells would continue to be mural granulosa cells as a default pathway and that only oocytes can develop a cumulus cell phenotype. Hence, there has been great interest in identifying and characterizing oocyte specific factors in farm animals and animal models (Hanrahan et al. 2004; Soyal et al. 2000; Tong et al. 2000). Identification and characterization of novel oocyte specific factors have proved to be a very important task in filling gaps of our understanding about the interaction between the oocyte and its surroundings. So it was the objective of project I (chapter 1) to identify novel oocyte specific genes in rainbow trout.

\section{Embryonic genome activation}

Embryonic genome activation (EGA), also known as the maternal-zygotic transition (MZT) is the activation of the zygotic genome at a point when the embryonic genome is ready to meet the transcriptional needs of the zygote. EGA occurs at different time points depending on the species (Kanka 2003; Telford et al. 1990). In mice, it occurs at the 1-2 cell stage (Bolton et al. 1984), 4-8 cell stage in humans (Telford et al. 1990), 8- 
16 cell stage in bovine (Memili and First 1999) and at mid-blastula stage in Xenopus (Etkin and Balcells 1985) and zebrafish (Kane and Kimmel 1993) (hence the name midblastula transition- MBT). Initiation of transcription is a complex process and there could be at least three reasons why EGA does not take place earlier: 1) chromatin mediated repression, 2) rapid cell cycles and 3) insufficient transcription machinery (Schier 2007). The fact that EGA occurs in some species (mice, humans and bovine) even when the embryo is beginning to divide, undermines the hypothesis that active division is the only reason for the absence of transcription before EGA. However, it could contribute along with the other two factors mentioned above in mediating the transcriptionally repressed state (Vigneault et al. 2004). Epigenetic imprinting including chromatin mediated repression, is believed to make a major contribution to the process (Schier 2007). So the transcriptionally repressive state could be due to the non-permissive chromatin structure and/or absence/insufficiency of transcription machinery before EGA (Vigneault et al. 2004).

\section{Chromatin remodeling}

Histone acetyltransferases (HAT) are enzymes that acetylate histone tails of nucleosomes and relax the chromatin structure making the genomic DNA more accessible to transcription factors (Marmorstein 2001). Some studies have demonstrated the importance of histones in the process of embryonic genome activation (Stein et al. 1997; Worrad et al. 1995). Chromatin structure and conformation is also determined by another class of transcription factors called architectural proteins (Bewley et al. 1998). These high mobility group (HMG) proteins produce chromatin conformations favorable for transcription (Bianchi and Beltrame 2000). There are at least three main groups of 
HMG proteins and they are classified based on the conserved domain (systematic nomenclature on this website http://www.informatics.jax.org/mgihome/ nomen/genefamilies/hmgfamily.shtml) (HMG-Homepage 2007).

Apart from chromatin structure, transcription factors play a very important role in transcription (Vigneault et al. 2004). There are several sequence-specific transcription factors that initiate/facilitate recruitment of general transcription factors like TATA box binding protein and RNA polymerase II (Nikolov and Burley 1997; Woychik and Hampsey 2002). One study investigated the presence of sufficient transcription machinery at the time of EGA and found that transcription factors are present during the time of EGA in cows (Vigneault et al. 2004). Project II (chapter 2) investigates mRNA expression patterns of 9 transcription factors (Figla, P300, YY1, HMGA1, HMGB1, HMGN1, ATF-1, TEAD2 and OCT-4) to evaluate the presence of sufficient transcription machinery at the time of embryonic genome activation in rainbow trout.

\section{MicroRNAs}

\section{Introduction}

MicroRNAs (miRNAs) are a class of naturally occurring 19-23 base pair long RNAs that bind to specific recognition sequences on the 3'untranslated regions (UTR) of their target messenger RNAs and regulate protein production (Pillai 2005). If the homology between the recognition sequence and the microRNA is high, the mRNA is directed to deadenylation ( $\mathrm{Wu}$ et al. 2006) and subsequent degradation, and if the homology is low, translation is repressed (Brennecke et al. 2005). Each mRNA could have recognition sequence for more than one miRNA and each miRNA can control up to 200 genes (Brennecke et al. 2005). 
MicroRNAs were first identified as an isolated oddity in worms. Lin-4 was the first member to be identified and was shown to be involved in developmental timing in Caenorhabditis elegans (C. elegans) (Lee et al. 1993b). Currently there are 5,071 (version 10.0 last updated August 2007) miRNAs in the microRNA database managed by the Sanger Institute (Griffiths-Jones 2004). Initial discoveries were results of forward genetics and were identified based on their mutant phenotypes (Lee et al. 1993b; Reinhart et al. 2000). Since then several labs have adopted cloning-sequencing and bioinformatics strategies to bypass the rare discovery of forward genetics (Berezikov et al. 2006; Chen et al. 2005; Hikosaka et al. 2007; Omoto and Fujii 2006; Takada et al. 2006). Cloning and sequencing has been the choice strategy for identifying novel microRNAs expressed in a cell type/developmental stage because cDNA cloning needs little/no genomic sequence information (Wienholds and Plasterk 2005). Computational methods were developed so that if the genomic sequence were available the disadvantages of cloning could be avoided. The specific disadvantages are that cDNA cloning might miss miRNAs that are in low copy numbers or expressed in a small window of developmental timing or some microRNAs could be difficult-to-clone because of their sequence composition (Bentwich 2005; Bentwich et al. 2005; Grad et al. 2003; Lai et al. 2003). However only a portion of predicted miRNAs have been experimentally confirmed (Wienholds and Plasterk 2005). Distribution of microRNAs in the genome is not random, about half of the microRNAs are arranged within introns of host genes and they are co-expressed with each other. Majority of the rest of the microRNAs are arranged as clusters which are co-expressed (Baskerville and Bartel 2005; Rodriguez et al. 2004). Several of these microRNAs have 
tissue/cell type specific expression as shown by cloning or northern blot or microarray techniques (Barad et al. 2004; Baskerville and Bartel 2005; Lagos-Quintana et al. 2002).

\section{Synthesis and mechanism of action}

MicroRNA processing is a stepwise and compartmentalized process which is not well characterized (Lee et al. 2002). Schematic representation of their synthesis and processing is depicted in figure 0.1 . MicroRNAs are transcribed as primary-miRNAs (pri-miRNAs) by RNA polymerase II (Lee et al. 2004) and hence possess 5'cap and 3'poly A tails (Cai et al. 2004). These pri-miRNAs are processed into 70-80bp premiRNAs by the RNase III enzyme Drosha (Lee et al. 2003). Pri-miRNA hairpins are exported out of the nucleus into the cytoplasm by exportin 5 with Ran-GTP as a cofactor (Bohnsack et al. 2004; Lund et al. 2004). Primary miRNAs are then processed into premiRNAs by another RNase III enzyme Dicer (Hutvagner et al. 2001) which was initially identified as an enzyme that processes long double stranded RNA molecules into small interfering RNAs (siRNAs) (Hammond 2005). These processed double stranded RNA molecules unwind and form miRNA. The strand that has the 5 'end where initialization of this unwinding begins (lowest thermodynamic stability) is called the lead strand and is the future miRNA (Hutvagner 2005). This RNA strand is incorporated into a ribonucleoprotein complex on the target mRNA (Hutvagner and Zamore 2002) and directs the target to (i) degradation if complimentarity is high or to (ii) translational repression if the complimentarity is low (Wienholds and Plasterk 2005). In animals 
mRNA degradation is less common than translation repression (Yekta et al. 2004).

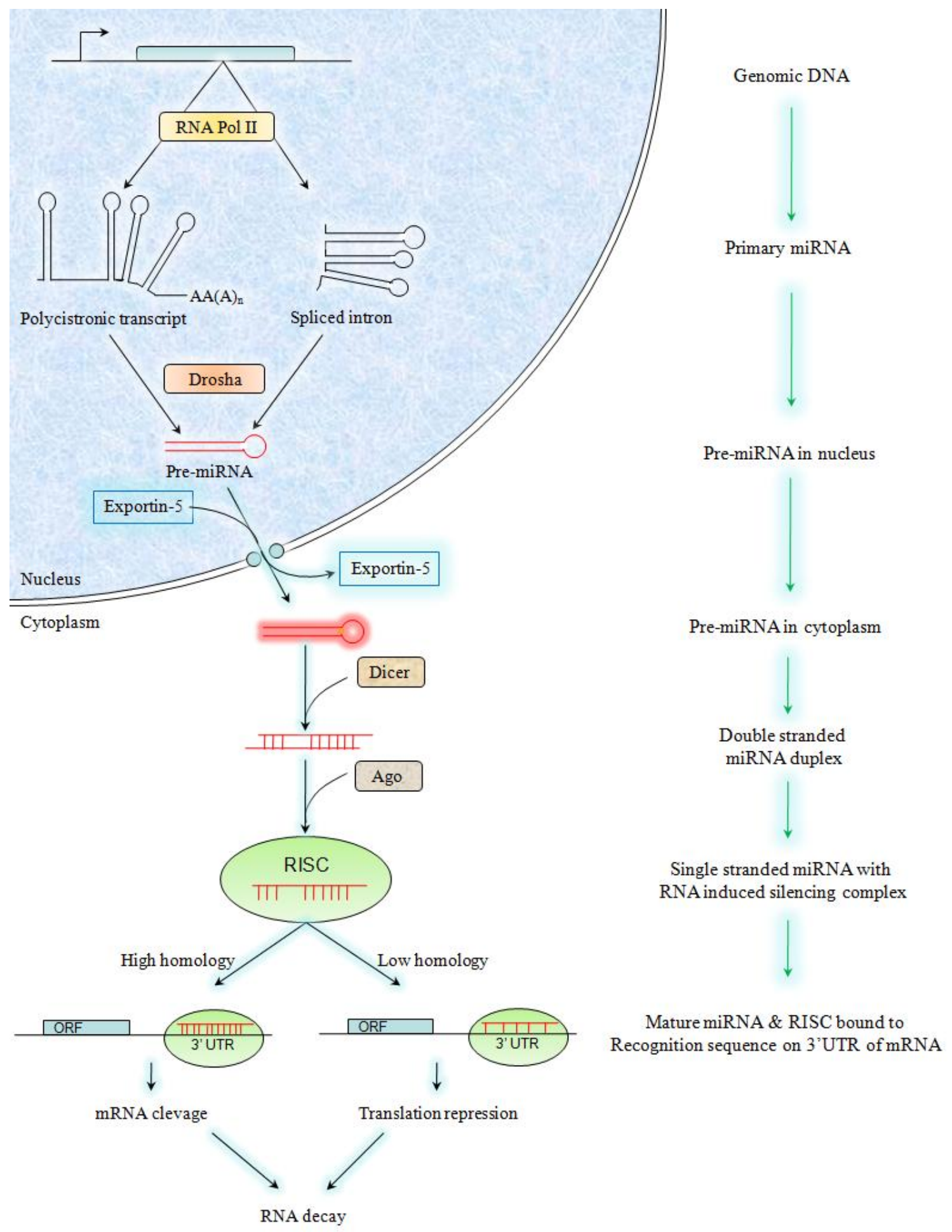

Figure 1 Mechanism of synthesis and processing of microRNAs 


\section{Functions}

In $C$ elegans, several microRNAs have been shown to regulate early and late developmental timing (Lin et al. 2003; Wightman et al. 1993). They have been ascribed a function in controlling left/right neuronal asymmetry (Chang et al. 2004). In $D$. melanogaster miRNAs are thought to play a role in programmed cell death and fat metabolism (Xu et al. 2003). They are deemed responsible for insulin secretion (Poy et al. 2004), heamatopoitic lineage differentiation (Chen et al. 2004), myocyte differentiation and proliferation in heart (Zhao et al. 2005) and developmental patterning in mice (Yekta et al. 2004). MicroRNAs mediate AU rich element mediated RNA instability and deadenylation mediated RNA decay in different cell lines (Jeske et al. 2006; Wu et al. 2006). MicroRNAs also mediate antiviral defense in human cells (Lecellier et al. 2005). Several studies established microRNA expression signatures in different types of cancer (reviewed in (Gregory and Shiekhattar 2005; Kusenda et al. 2006; Meltzer 2005). For example, miR-21 targets a tumor suppressor gene tropomyosin and acts as an antiapoptotic factor in brain cancer cells (Chan et al. 2005; Zhu et al. 2007). With such diverse functions for microRNAs, it is clear that we are beginning to appreciate numerous functions performed by these tiny RNA molecules.

\section{Roles in early development}

Various miRNAs have been identified that are involved in developmental timing in worms (Ambros 2004; Kloosterman and Plasterk 2006). Several observations showed that microRNAs are essential for normal development of vertebrates (Bernstein et al. 2003; Houbaviy et al. 2003; Kanellopoulou et al. 2005; Wienholds et al. 2003). Deletion of Dicer, an enzyme required for processing of all microRNAs results in abnormal 
development and brain morphogenesis in zebrafish (Giraldez et al. 2006). The hypotheses that microRNAs have specific functions are supported by tissue-specific and temporal expression pattern of several microRNAs (Aboobaker et al. 2005; Chen et al. 2005; Watanabe et al. 2005; Xu et al. 2006).

It is well documented that dicer mutant mouse embryos do not survive after axis formation but Dicer mutant zebrafish embryos do (Wienholds and Plasterk 2005). However, what has escaped attention is the fact that there is a difference in developmental timing of EGA in these two species and there could be a relationship between EGA and microRNAs. Interestingly, the deformities in dicer mutants begin to occur at the time of EGA in both mice (1-2 cells stage) and zebrafish (mid-blastula) (Bernstein et al. 2003; Giraldez et al. 2005). Two recent studies by Giraldez et al. (2006) and $\mathrm{Wu}$ et al. (2006) showed that microRNAs direct rapid deadenylation of maternal mRNAs and direct them toward degradation. They also observed that miR-430 is abundantly expressed at the time of degradation of maternal mRNAs during EGA. They showed that when dicer is deleted, degradation of maternal mRNAs is delayed and morphogenesis is postponed. So it was concluded that miR-430 is responsible for degradation of maternal mRNAs at EGA (Weigel and Izaurralde 2006).

However, since it is critical to have recognition sequence on the 3'UTR of an mRNA to be directed for degradation by microRNAs, and not all degraded mRNAs have recognition sequence for miR-430, it is obvious that there might be more than one microRNAs involved in this process. This hypothesis is also supported by the fact that the deformities caused by deficiency of Dicer (devoid of all miRNAs) were not completely recovered when embryos were injected with only miR-430 (Giraldez et al. 
2005). Bioinformatics tools can be utilized to predict targets and candidate microRNAs involved in degradation of maternal mRNAs if the genomic sequence information is available. Since limited genomic information is available for rainbow trout, project III (chapter 3) was designed to clone and sequence microRNAs expressed during embryonic stages and investigate their expression pattern to identify other candidate microRNAs involved in this process. 


\section{Chapter 1 : Identification of OORP-T, a novel oocyte- specific gene encoding a protein with a conserved oxysterol binding protein domain in rainbow trout}

Ramachandra RK ${ }^{1}$, Lankford $\mathrm{SE}^{2}$, Weber $\mathrm{GM}^{2}$, Rexroad CE, 3rd ${ }^{2}$, Yao J ${ }^{1} .2007$

Mol Reprod Dev 74(4):502-511

${ }^{1}$ Division of Animal and Nutritional Sciences, West Virginia University, Morgantown, WV 26506-6108

${ }^{2}$ National Center for Cool and Cold Water Aquaculture, Kearneysville, WV 25430 


\section{Abstract}

Genes specifically expressed in oocytes are important for the development of oocytes and early embryos. By analyzing ESTs from a rainbow trout oocyte cDNA library, we identified a novel EST sequence that does not show homology to any sequences in the GenBank. Analysis of tissue distribution by RT-PCR revealed that this gene was only expressed in unfertilized oocytes. Sequencing of the EST clone identified a cDNA of $3163 \mathrm{bp}$. Northern blot analysis showed the novel gene has a single transcript of $3.4 \mathrm{~kb}$. Additional 5' sequence was obtained by 5' RACE, extending the novel cDNA to $3333 \mathrm{bp}$. Analysis of the full length cDNA identified an open reading frame encoding a protein of 564 amino acids. The novel protein contains a conserved oxysterol binding protein (OSBP) domain at the $\mathrm{C}$ terminus that is characteristic of OSBP-related proteins implicated in lipid metabolism. Therefore, we named the novel gene as Oocyte-specific Oxysterol binding protein Related-Protein of Trout (OORP-T). In situ hybridization showed that the OORP-T mRNA appears to be confined to the cytoplasm of vitellogenic oocytes. Transcription of OORP-T appears to start during pre-vitellogenesis and increases steadily, reaching its peak in the late vitellogenic stage. OORP-T transcript is abundantly present in unfertilized eggs but the level drops significantly in day 2 embryos and continues to decline in day 7 embryos after which it remains low. We propose that OORP-T may play an important role in the utilization of yolk derived lipid products during oocyte development and early stages of embryonic development in rainbow trout.

\section{Introduction}

Genes specifically expressed in the oocyte play important roles in oogenesis, ovarian folliculogenesis, fertilization and early embryonic development (Dean 2002). Key oocyte-specific genes known to be vital in folliculogenesis include Factor In the 
Germline alpha (Figla), Growth Differentiation Factor 9 (GDF9) and Bone Morphogenetic Protein 15 (BMP-15). The essential roles of these genes in follicular development have been demonstrated primarily by their targeted deletion in mice and molecular genetic approaches in farm species (Dong et al. 1996; Galloway et al. 2000; Soyal et al. 2000; Yan et al. 2001). Following fertilization of an oocyte, the first important developmental transition is the activation of the embryonic genome, during which transcripts expressed from the zygotic/embryonic genome replace the maternal transcripts that direct initial development. Several oocyte-specific genes have been identified to be crucial for the initial development of embryos before embryonic genome activation. Such genes are called maternal effect genes that include Maternal Antigen That Embryos Require (MATER), Nucleoplasmin 2 (NPM2) and Zygote Arrest 1 (Zar1). Targeted disruption of these genes in mice resulted in the arrest of early embryonic development (Burns et al. 2003; Tong et al. 2000; Wu et al. 2003).

In fish, accumulation of the maternal transcripts and proteins, which occurs mostly at late stages of oocyte maturation, is accompanied by vitellogenesis, a process characterized by hepatic production and massive deposition of yolk lipoproteins within the oocytes, providing the nutritional reserves necessary for embryogenesis (Tyler and Sumpter 1996). Genes involved in this process as well as in the utilization of these reserves during early development are essential for normal development of embryos in fish.

To date, attempts to determine and characterize the factors influencing folliculogenesis and embryonic development in fish have been sparse. It is of great interest to identify and characterize novel oocyte-specific genes to understand the fish 
developmental biology. In an attempt to characterize the oocyte transcriptome in rainbow trout, we have recently constructed a normalized cDNA library from rainbow trout oocytes and generated $\sim 20,000$ expressed sequence tags (ESTs) from this library (Yao et al. 2005). A significant number of novel EST sequences have been identified, of which some appear to be absent in other somatic libraries. Here, we report the identification and cloning of a novel gene specifically expressed in trout oocytes based on an EST clone derived from the library. The predicted protein contains a conserved oxysterol binding protein (OSBP) domain at the $\mathrm{C}$ terminus that is characteristic of OSBP-related proteins (ORPs) known to be involved in lipid metabolism. Based on the protein structure and the expression patterns of this novel gene, we propose an important role of this gene in yolk lipid usage during oocyte development and early embryonic development of rainbow trout.

\section{Materials and methods}

\section{Collection of Samples}

Ovarian samples at different stages of development were collected from female rainbow trout. The stages of ovarian development were classified based on oocyte diameter as described by (Tyler et al. 1994). The stages of ovarian follicles are: early previtellogenic $(\mathrm{Vg}, \leq 0.5 \mathrm{~mm})$, pre- $\mathrm{Vg}(\leq 0.65 \mathrm{~mm})$, early- $\mathrm{Vg}(0.65-1.1 \mathrm{~mm})$, mid-Vg $(1.1-$ $2.1 \mathrm{~mm})$ and late- $\mathrm{Vg}(2.1-4.0 \mathrm{~mm})$. All stage follicles were histologically verified for land marks of the appropriate stage (early and late pre- $\mathrm{Vg} \leq 5 \%$ of follicles in cortical alveolar stage, early $\mathrm{Vg} \geq 25 \%$ of follicles in cortical alveolar stage, mid and late $\mathrm{Vg} \geq$ $50 \%$ in cortical alveolar stage), and the assignment to early, mid or late was done by taking both size and histology into account. To produce embryos, eggs were fertilized 
and incubated at $13{ }^{\circ} \mathrm{C}$ in a flow through system using a photoperiod of $12 \mathrm{~h}$ light $-12 \mathrm{~h}$ dark. Unfertilized eggs and developing embryos were collected at day 2, 7, 12, 16 and 22 after fertilization. Various tissues including spleen, kidney, muscle, liver, heart, eye, stomach, brain, skin, ovary and testis were also collected from adult fish. All samples were quick frozen in liquid nitrogen and stored at $-80^{\circ} \mathrm{C}$ until RNA extraction.

\section{RNA Preparation}

Total RNA was isolated using TRIzol reagent (Invitrogen, Carlsbad, CA) according to manufacturer's protocol and treated with DNase (Promega, Madison, WI) to avoid genomic DNA contamination. PolyA+ RNA was purified from total RNA using biotinylated oligo d (T) probe and streptavidin attached magnetic beads from the PolyATtract mRNA Isolation System (Promega, Madison, WI).

\section{RT-PCR}

Two $\mu \mathrm{g}$ of DNAse-treated total RNA from various trout tissues were reverse transcribed to first-strand cDNA using oligo $(\mathrm{dT})_{18}$ primer and Superscript II reverse transcriptase (Invitrogen, Carlsbad, CA). Negative control reverse transcription reactions without the enzyme were carried out to confirm no genomic DNA contamination. Firststrand cDNA was used as template for PCR amplification of a $297 \mathrm{bp}$ fragment for the novel gene using gene-specific primers (forward: GGACGTGTCTTCCTACCAACA and reverse: GACCTGGACTTCTTGGGTTTC). The PCR condition (reaction mixture of $25 \mu \mathrm{L}$ ) included a 5 min denaturation at $94{ }^{\circ} \mathrm{C}$ followed by 35 cycles of $94{ }^{\circ} \mathrm{C}$ for $30 \mathrm{sec}$, $59{ }^{\circ} \mathrm{C}$ for $45 \mathrm{sec}$ and $72{ }^{\circ} \mathrm{C}$ for $30 \mathrm{sec}$, and a final extension at $72{ }^{\circ} \mathrm{C}$ for $10 \mathrm{~min}$. Trout $\beta$ actin gene was used as internal control to verify RNA quality. 


\section{5' RACE}

To extend the 5' end of the cDNA sequence, 5'RACE was performed using the $2^{\text {nd }}$ generation $5^{\prime} / 3^{\prime}$ RACE kit (Roche Diagnostics, Indianapolis, IN) following manufacturer's protocol. Two micrograms of total RNA from mature oocytes were reverse transcribed to cDNA using a gene-specific primer (SP-1: ACAGCTGTCTGGGTCATGAGT) followed by 2 rounds of nested PCR using genespecific primers (SP2: TGTAACCAGGCTGACACCTTC and SP3: AACTCAGACGGTGTTGGTGCA) in conjunction with $\mathrm{d}(\mathrm{T})$ anchor primers provided by the kit. The specific product from the second PCR was purified from an agarose gel using the Qiagen gel extraction kit (Qiagen, Valencia, CA) and cloned using TOPO ${ }^{\circledR}$ TA cloning kit (Invitrogen, Carlsbad, CA).

\section{Preparation of Digoxigenin (DIG)-Labeled RNA Probe}

DIG-labeled RNA probes used for Northern blot analysis and in situ hybridization were synthesized using a DIG RNA labeling kit (Roche Diagnostics, Indianapolis, IN). A plasmid containing a 500-bp fragment of the OORP-T cDNA was used as a template to synthesize both anti-sense and sense RNA probes by in vitro transcription. The transcriptions were performed from $1 \mu \mathrm{g}$ of linearized plasmid using either T7 (antisense) or SP6 (sense) RNA polymerases.

\section{Northern Blot Analysis}

One $\mu \mathrm{g}$ of mRNA from unfertilized mature oocytes was separated by electrophoresis on a $1 \%$ denaturing agarose gel containing $2.2 \mathrm{M}$ formaldehyde (Sambrook and Russell 2001b) along with a RNA marker (Promega, Madison, WI) and transferred to Hybond $\mathrm{N}+$ nylon membrane (Amarsham Biosciences, Piscataway, NJ). 
After UV cross linking, the membrane was pre-hybridized in DIG Easy Hyb solution (Roche Diagnostics, Indianapolis, IN) for 1 hour and then hybridized in the same solution containing $75 \mathrm{ng} / \mathrm{ml}$ of DIG-labeled anti-sense RNA probe overnight at $68{ }^{\circ} \mathrm{C}$. Following stringent washes (2x 15 min with 2 X SSC, $0.1 \%$ SDS at room temperature and $2 \times 15 \mathrm{~min}$ with $0.1 \mathrm{X}$ SSC, $0.1 \%$ SDS at $68{ }^{\circ} \mathrm{C}$ ), the membrane was incubated in blocking solution for $30 \mathrm{~min}$ followed by incubation with 1:10,000 diluted (in blocking solution) alkaline phosphatase conjugated anti-DIG antibody (Roche Diagnostics, Indianapolis, IN) for 30 min at room temperature. After 2 washes in washing buffer, the hybridized probe was detected with the chemiluminescent substrate CSPD (Roche Diagnostics, Indianapolis, IN). Blocking solution and washing solution were from a DIG wash and block buffer set (Roche Diagnostics, Indianapolis, IN).

\section{In-Situ Hybridization}

Paraformaldehyde-fixed ovary samples were embedded in paraffin, sectioned (5 $\mu \mathrm{m}$ ), and mounted onto glass slides. Paraffin sections were de-paraffinized by immersion in xylene (3x $5 \mathrm{~min}$ ) and then rehydrated through descending ethanol concentrations (3x with $100 \%$, and $1 \mathrm{x}$ with $90 \%, 80 \%, 70 \%$ and $50 \%$ ethanol, 3 min each) followed by immersion in PBS for $10 \mathrm{~min}$. Sections were then digested with proteinase $\mathrm{K}(2 \mu \mathrm{g} / \mathrm{ml})$ for $15 \mathrm{~min}$ at $37{ }^{\circ} \mathrm{C}$ and acetylated in $0.25 \%(\mathrm{v} / \mathrm{v})$ acetic anhydride in $0.1 \mathrm{M}$ triethanolamine ( $\mathrm{pH}$ 8.0). After washing with 4x SSC (2x $10 \mathrm{~min})$ followed by incubation in $50 \%(\mathrm{v} / \mathrm{v})$ deionized formamide in $2 \mathrm{x} \mathrm{SSC}$ at $42{ }^{\circ} \mathrm{C}$ for $30 \mathrm{~min}$, the sections were hybridized overnight at $42^{\circ} \mathrm{C}$ in a humidified chamber with $0.5 \mu \mathrm{g} / \mathrm{ml}$ DIG-labeled RNA probe in hybridization buffer containing 50\% deioned formamide, $10 \%(\mathrm{w} / \mathrm{v})$ dextran sulfate, 1x Denhardt's solution, $200 \mu \mathrm{g} / \mathrm{ml}$ yeast tRNA, $0.6 \mathrm{M} \mathrm{NaCl}, 10 \mathrm{mM}$ Tris-HCl, 
(pH7.4), 1 mM EDTA (pH8.0). After hybridization, the slides were treated with RNase A (20 $\mu \mathrm{g} / \mathrm{ml}$ ) for $30 \mathrm{~min}$ at $37{ }^{\circ} \mathrm{C}$ and washed with $0.1 \mathrm{x} \mathrm{SSC}$ at $42^{\circ} \mathrm{C}(3 \mathrm{x} 20 \mathrm{~min})$. Hybridized probes were detected with an alkaline phosphatase conjugated anti-DIG antibody (Roche Diagnostics, Indianapolis, IN) and alkaline phosphatase reaction was developed with NBT/BCIP (Roche Diagnostics, Indianapolis, IN).

\section{Quantitative Real Time PCR}

The expression of OORP-T mRNA during folliculogenesis and early embryonic development was measured using quantitative real time PCR. Two $\mu \mathrm{g}$ of DNAse-treated total RNA from each follicular stage $(\mathrm{n}=5)$ and embryonic stage $(\mathrm{n}=5$ pools, 5 embryos/pool) were converted to cDNA using Superscript II reverse transcriptase (Invitrogen, Carlsbad, CA). Real time PCR primers for OORP-T (forward: ACCAGCGGTGGAAGAATAAGT and reverse: AAACCTCGGGAGAGTGACATT) and the endogenous control gene, histone H2A (forward: TCCCCAAGAAGACTGAGAAGG and reverse: TTTGTTGAGCTAGGTGGTTGG) were designed based on the corresponding cDNA sequences (rainbow trout histone H2A: TC85036 in TIGR database) using Primer3 software (http://frodo.wi.mit.edu/cgibin/primer3/primer3_www.cgi). Quantitative PCR was performed in duplicate for each cDNA sample on a Bio-Rad iCycler iQ Real-Time PCR Detection System using iQ ${ }^{\mathrm{TM}}$ SYBR ${ }^{\circledR}$ Green Supermix (Bio-Rad, Hercules, CA) in $25-\mu 1$ reaction volumes containing $300 \mathrm{nM}$ of each primer and cDNA derived from $0.1 \mu \mathrm{g}$ of total RNA. Standard curves for both OORP-T and the endogenous control were constructed using 10 fold serial dilutions of the corresponding plasmid. Standard curves were run on the same plate with the samples. Threshold lines were adjusted to intersect amplification lines in the linear 
portion of the amplification curve and cycles to threshold $(\mathrm{Ct})$ were recorded. For each sample, the quantity of OORP-T mRNA and the reference gene mRNA (histone H2A) was determined from the appropriate standard curve. The quantity of OORP-T mRNA was then divided by the quantity of the reference gene to obtain a normalized value. Oneway analysis of variance (ANOVA) was performed on normalized gene expression values using JMP 5.1 (SAS Institute, Cary, NC). The expression of OORP-T mRNA was then expressed as relative fold changes.

\section{Results}

\section{Identification and cloning of OORP-T cDNA}

Analysis of ESTs from a rainbow trout oocyte cDNA library identified many novel sequences that do not show significant homologies to sequences of any known genes or ESTs deposited in the GenBank database. A number of novel ESTs that were present in the oocyte library but absent in libraries from other tissues were selected for analysis of expression patterns in multiple tissues by RT-PCR. One of them appears to be oocyte-specific as it was abundantly expressed only in mature oocytes and late vitellogenic ovary but not in other tissues (Fig. 1.1A). The EST clone was retrieved from our library and the complete insert of the clone was sequenced by primer walking. The insert size of the cDNA clone is $3163 \mathrm{bp}$ as determined by DNA sequencing. To determine the transcript size of this novel gene and verify whether it has any splice variants, Northern blot analysis was performed on mature oocytes. As shown in Fig. 1.1B, this novel gene has a single transcript corresponding to a size of around $3.4 \mathrm{~kb}$ and no splice variants could be detected. Apparently, the EST clone does not have the full length cDNA sequence of this gene. A 5'RACE experiment was performed to clone the 
missing sequence at the 5' end of the cDNA. An additional $170 \mathrm{bp} 5$ ' sequence was obtained, thus producing a transcript of $3333 \mathrm{bp}$ in length. The complete cDNA sequence has been deposited in the NCBI database with the accession number: DQ630461.

\section{Sequence analysis of OORP-T cDNA and its encoded protein}

Analysis of the novel cDNA sequence revealed that it contains a 12-bp 5'untranslated region (5'-UTR), an open reading frame (ORF) of $1692 \mathrm{bp}$ and 3' untranslated region (3'-UTR) of 1626b (Fig. 1.2). There are 4 typical polyadenylation signal sequences (AATAA) and 2 cytoplasmic polyadenylation elements (TTTTTAT) in the relatively long 3'-UTR. The open reading frame of the cDNA codes for a protein of 564 amino acids with a predicted molecular weight of 63,154 Daltons. Searching of the NCBI Conserved Domain database revealed that the novel protein contains a conserved oxysterol-binding protein domain (OSBP) at its carboxy terminus (aa 365-556). Proteinprotein BLAST analysis (blastp) showed that the protein shares approximately $35 \%$ to $39 \%$ sequence homology with members of the mammalian oxysterol-binding proteinrelated proteins (ORPs). Since the novel gene is exclusively expressed in oocytes, we named the novel protein as Oocyte-specific Oxysterol binding protein Related-Protein of Trout (OORP-T). Phylogenetic analysis of OORP-T with 12 members of the human ORP family showed OORP-T is close to human ORP family subgroup 3 which includes ORP3, 6 and 7 in terms of sequence homology (data not shown). Multiple amino acid sequence alignment of OORP-T against human ORP3, 6 and 7 showed that sequences around the OSBP fingerprint domain (EQVSHHPP) at the $\mathrm{C}$ terminus are highly conserved among OORP-T and human ORP3, 6 and 7 (Fig. 1.3). However, OORP-T lacks the $\mathrm{N}$ terminal 
Plextrin Homology $(\mathrm{PH})$ domain which is present in ORP3, 6, 7 as well as other ORPs except for ORP2 and ORP9.

\section{Quantitative analysis of OORP-T mRNA expression during folliculogenesis and embryonic development}

To investigate the ovarian mRNA expression of OORP-T during folliculogenesis in rainbow trout, ovarian samples collected from 5 developmental stages of follicles [early pre-vitellogenic $(\mathrm{Vg})$, late pre- $\mathrm{Vg}$, early $\mathrm{Vg}$, mid $\mathrm{Vg}$, and late $\mathrm{Vg}$ ] were subjected to quantitative real time PCR analysis. The expression of OORP-T in early pre-Vg stage ovaries is extremely low and barely detectable. Transcription of OORP-T appears to begin in late pre- $\mathrm{Vg}$ stage and steadily increases during development, reaching a peak at late Vg stage (Fig. 1.4A). This expression pattern suggests a role of OORP-T during mid and late vitellogenesis when yolk deposition is at its peak in rainbow trout.

The expression pattern of OORP-T during embryonic development is shown in Fig. 1.4B. Clearly, the OORP-T transcript is highly abundant in unfertilized oocytes (day 0 ). The expression level drops significantly 2 days post fertilization (day 2) and continues to decline in day 7 embryos. The expression level of OORP-T remains low until day 22. This expression pattern of OORP-T during embryogenesis may suggest that this novel protein is required for early embryonic development before embryonic genome activation. Studies in zebrafish suggest this transition occurs at midblastula development (Pelegri 2003) which is approximately 2 days post fertilization in rainbow trout.

\section{Localization of OORP-T mRNA in ovarian follicles}

Dig-labeled sense and anti-sense RNA probes, prepared by in vitro transcription from a 500 bp OORP-T fragment, were used to perform in situ hybridization on trout 
ovarian sections. OORP-T mRNA appears to be confined to the cytoplasm of large, midvitellogenic (Fig. 1.5A) and early-vitellogenic (Fig. 1.5C) oocytes (blue coloration). No specific signals are present in the oocyte nucleus. There appear to be less or no detectable signals in the pre-vitellogenic oocytes (Black arrows in Fig. 5C). This result agrees with the real time PCR data showing peak transcription of the OORP-T gene in vitellogenic follicles and no or little transcription of the OORP-T gene in oocytes at early stages of development (Early pre-Vg and Pre-Vg). No specific hybridization signal was detected in oocytes of different stages in the ovarian section hybridized with the sense (control) RNA probe (Mid-vitellogenic, Fig 1.5B and early vitellogenic, Fig. 1.5D).

\section{Discussion}

In this study, we identified and characterized a novel gene specifically expressed in rainbow trout oocytes. To our knowledge, this is the first report of an oocyte-specific gene in rainbow trout. The cDNA sequence of this gene contains a relatively long 3'UTR. There are 4 typical polyadenylation signal sequences present in this region. Alternative use of these signals could result in multiple transcripts. However, our Northern blot analysis clearly shows a single transcript of $3.4 \mathrm{~kb}$ which is consistent with the size of the cDNA sequence. This indicates that the novel gene uses predominantly the last AATAA signal near the 3 'end of the sequence for termination of transcription. In growing oocytes, some maternal mRNAs, such as c-mos (Gebauer et al. 1994) and cyclin B1 (Tay et al. 2000), undergo deadenylation in the cytoplasm where they are packaged into messenger ribonucleoprotein (mRNP) particles. During oocyte maturation, cytoplasmic polyadenylation extends their poly(A) tail, which is associated with their

timely translation (Paynton and Bachvarova 1994; Sheets et al. 1994). The presence of 2 typical U-rich cytoplasmic polyadenylation elements (UUUUUAU) in the 3'-UTR of 
OORP-T indicates that this gene may have controlled translation during oocyte maturation and early embryonic development.

OORP-T contains a functional OSBP domain which is present in OSBP and its related proteins, ORPs. OSBP is the first protein of the ORP family identified as a receptor for oxysterols (Taylor and Kandutsch 1985) that are potent signaling lipids attributed to play important roles in cellular cholesterol homeostasis, cell differentiation, apoptosis, cellular calcium uptake and membrane structure (Olkkonen and Levine 2004). To date, 12 members of ORP family have been identified in humans (Lehto et al. 2001). Several ORP genes are present in S. cerevisiae (7 homologs), D. melanogaster, and C. elegans suggesting that the ORP family has a vital role in eukaryotic kingdom (Lehto et al. 2001).

Even though deletion of individual ORP had no phenotypically distinct effect, simultaneous deletion of all 7 ORP genes in yeasts resulted in lethality, indicating that ORPs are essential for life (Beh et al. 2001). It also indicates that ORPs have overlapping non-essential function but together they perform at least one vital role. Several ORPs have been demonstrated to bind phosphoinositide lipids directly (Levine and Munro 1998; Li et al. 2002) and transport protein and lipid (ceramide in particular) between subcellular membranes (Levine 2004; Loewen et al. 2003; Wyles et al. 2002). Recent studies proved that OSBP is involved in transportation of cholesterol (Im et al. 2005). The study also indicated that many compounds other than sterols may be transported by ORPs. ORPs are also known to be involved in sphingomyelin synthesis, protein secretion, glycerolipid metabolism (Lagace et al. 1997; Lagace et al. 1999; Li et al. 2002).Given the importance of ORPs in lipid metabolism/transport and the presence of 
abundant OORP-T transcripts in mid-late vitellogenic follicles through early stage embryos, it could be speculated that OORP-T might play important roles in mobilization, transportation and metabolism of yolk lipids. The lipids may be mobilized and transported as nutrients or be metabolized into regulatory lipids. Sphingomyelin and ceramide have been shown to mediate steroid-induced resumption of meiosis in oocytes of amphibians (Morrill and Kostellow 1999; Strum et al. 1995) and evidence suggests yolk platelet lipids may serve as a source of the lipids (Buschiazzo and Alonso 2005). A role in synthesis and regulation of corticosteroids and sex steroids during follicular development and early embryogenesis could also be expected.

Characteristic of all members of ORP family identified so far is the OSBP domain which is conserved even in ORP homologs of D. melanogaster, yeast and C. elegans. Even though the overall similarity within the OSBP domain between OORP-T and other ORPs is strikingly high, the OSBP fingerprint sequence EQV $\underline{S} H H P P$ of all ORPs is replaced by EQVEHHPP of trout OORP. The uncharged polar amino acid, Serine, is replaced by another uncharged polar amino acid Cysteine which contains sulfur. Cysteine is unique among all 20 amino acids in that it has a thiol group that can form a disulfide bond with another cysteine leading to a variety of structural and functional implications (Voet et al. 2005). This sulfur containing amino acid may confer unique functions to OORP-T which distinguishes OORP-T from ORPs.

For many of the oxysterol regulatory processes, it is important that ORPs are localized on specific cell organelles like Golgi apparatus or endoplasmic reticulum. Most ORP members have an N-terminal Plextrin Homology (PH) domain which specifies Golgi localization of ORPs. Studies by (Lagace et al. 1997) and (Levine and Munro 
1998) suggested that PH domain is required and sufficient to target the OSBP to Golgi apparatus. In addition, many of ORPs contain recently described FFAT motif that leads to endoplasmic reticulum localization (Loewen et al. 2003). OORP-T lacks both of these motifs indicating that it is structurally and functionally different from the known ORP members. No signal peptides or organelle localization motifs are present in OORP-T indicating that it is a cytoplasmic protein. Indeed, our in situ hybridization experiment has confirmed that OORP-T is localized in the cytoplasm of mature oocytes. It is hard to distinguish cellular components in the mature oocytes because of huge amount of yolk present. However, since OORP-T does not have the PH domain, it is highly unlikely that OORP-T localizes on Golgi apparatus. However we can not exclude the possibility that OORP-T does localize on Golgi apparatus or on endoplasmic reticulum by some other mechanism as suggested (Wyles et al. 2002).

OORP-T is expressed specifically in trout oocytes while all ORP genes are ubiquitously expressed (Lehto et al. 2001). As shown by phylogenetic analysis, OORP-T is closely related to members of human ORP family subfamily 3 (ORP3, 6 and 7). No specific roles of this subfamily have been reported. However, members of this subfamily show tissue-specific transcriptional regulation. For instance, ORP3 and ORP7 are most abundant in the kidney and gastrointestinal tract, respectively, whereas expression of ORP6 is highest in the skeletal muscle and the brain (Lehto et al. 2001). The oocyte specificity of OORP-T adds another line of evidence suggesting that OORP-T is functionally different from the ORPs.

In summary, OORP-T is an oocyte-specific gene expressed abundantly in midlate vitellogenic follicles and early stage embryos. The protein contains a conserved 
OSBP domain; therefore it may share similar functions as the ORPs in lipid metabolism. However, the unique structure of OORP-T (substitution of Serine by Cysteine in the OSBP fingerprint domain, lack of PH domain and FFAT motif) and its oocyte-specific expression suggest a distinct and important role for OORP-T in trout oogenesis and early embryonic development. 


\section{Figures}

A

M Sp Ki Mu Li He Ey St Br Sk Ov Te Oo

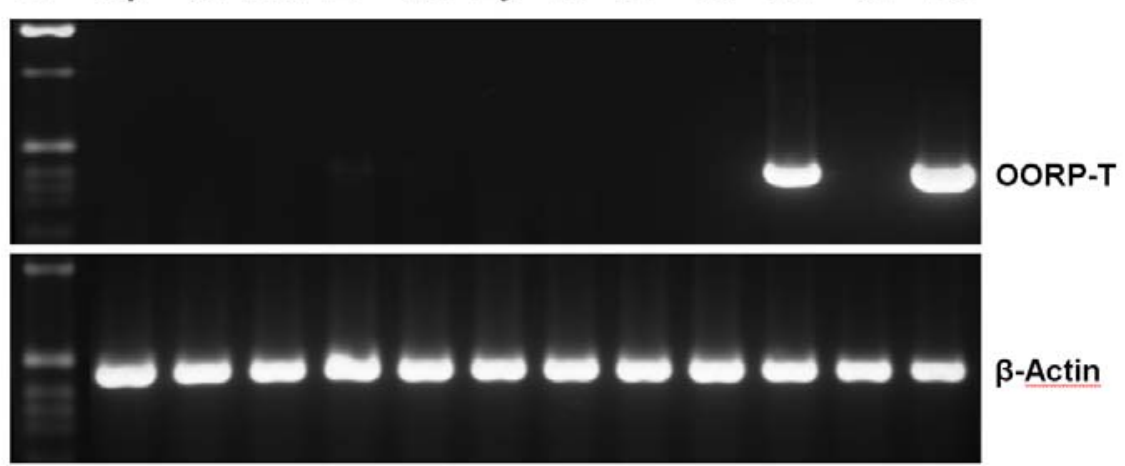

B

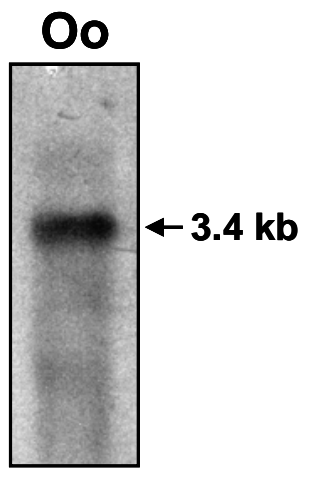

Figure 1-1 Expression of OORP-T mRNA in rainbow trout tissues. A. RT-PCR analysis of tissue distribution of OORP-T mRNA. Tissues examined were: spleen (SP), kidney (Ki), muscle (Mu), liver (Li), heart (He), eye (Ey), stomach (St), brain (Br), skin (Sk), ovary (Ov), testis (Te) and mature oocyte (Oo). Trout $\beta$-actin was used as a control for RNA quality. B. Northern blot analysis of OORP-T mRNA. mRNA from unfertilized eggs was used in the analysis and the blot was hybridized with a DIG-labeled anti-sense RNA probe generated by in vitro transcription of a 500-bp OORP-T fragment. 


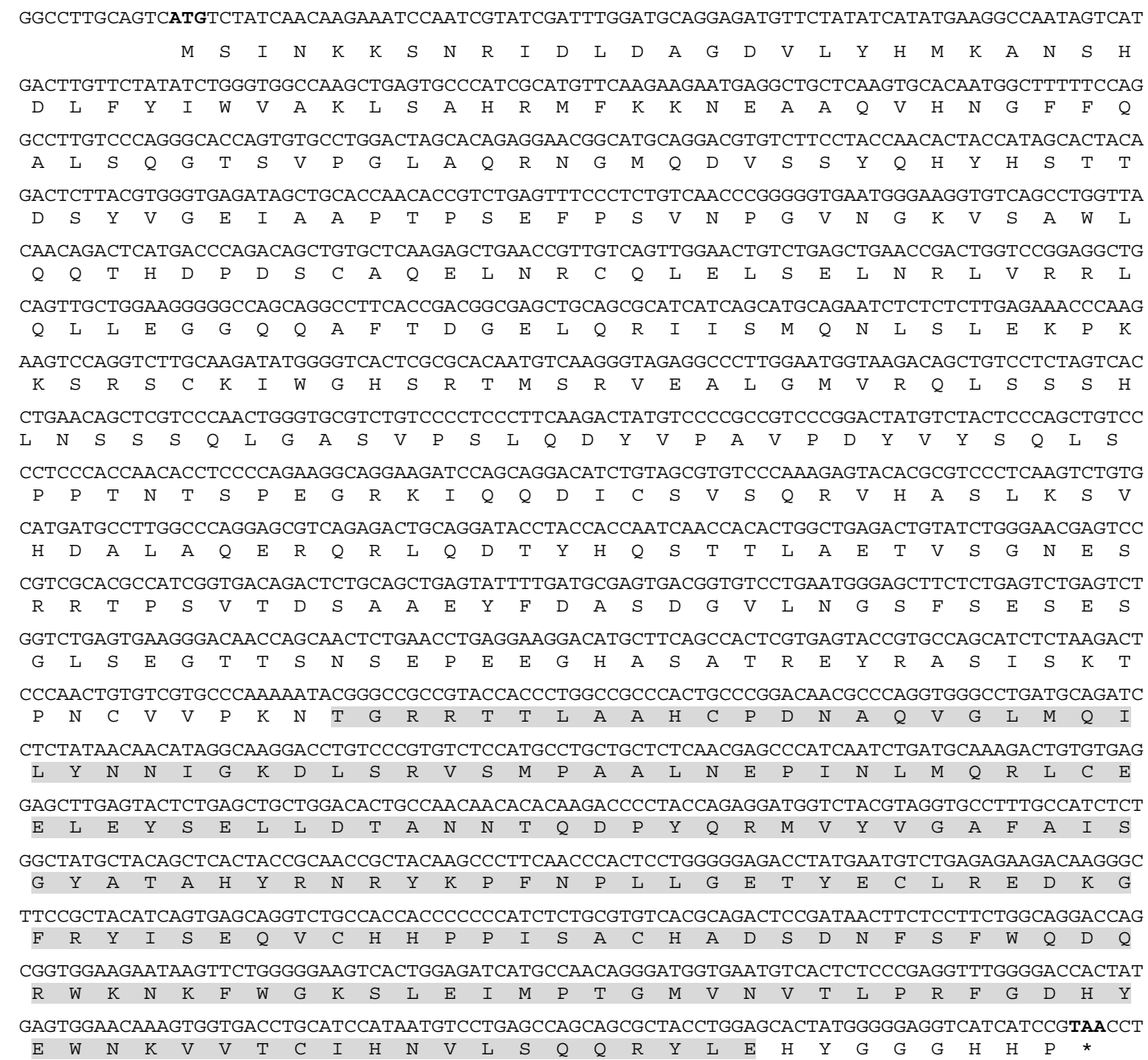
GCTCGACCAGACTGGGAGTGTTATCCACCGGTTTGGGGGGCTGTGGCATGAGGGGCATCTTCTGTGACACCTTGCCCACTCCACAGTGTA TCTGGAAAGCCAAATTCCCAGCCCAAGGACTACTACCTGTACTACGGCTTCTCAAGCTTCACACTAGAGCTGAACGAGCTCACCCCAGGC CTGAAGCCTCTTCTGCCCCCCACAGACTCACGCCTTCGTCCTGACCAGAGGATGCTGGAGGATGGGAGGGTGGATGACTGTGACAAGTTT AAAGAAGAAGTGGAAGACATGCAGAGGGAGCGGAGGAAACAACTGGCTAAGAAAGGACAGGAGCACACGCCGCGCTTCTTTAAGAAAGCC ATGGATTCCTCTGGGAGGGATGTGTGGCTGACCAATGGAACCTATTGGAAAGTCCGAGAGAACCCGGGCTTTGCTAACACCAAAAACCTG GAACTATGGTGAATAAACAGACCGACTGGGGCCATTTGTTGGAATTGGTGAAGGCATCGATGAACCGTCCTGAGGTCCCACCTTCCATCA TTGCCATCTGATTTGCACTCCCTCCCTGGCTGCTTCATGGGAAACCTCTGGGGAAAGTCTGGAAACGACTTGCATCCACTGAAACGTCAA GTTGAAAATAGTTCCCAGAATGTGTAGTGTCACCTGTTCCGCCACCTGGAAAGGATAAATAGACTTTTCTCTCATACTCGCATTTAGTCC ATTGCAATGTATTTATGGTCATTCCCCATTTGTGTACATTTATGTTATCCTGTCAAGATGTATTTGCTTTCTAGAGGGCTGGAAGTGTGA GGTTAATTTGCTCAGGTCAAGACATTTACTGTGACTAATCTTCAGATATTGTAAAGGTAGAAAAATGTGTATTTAATACTCCCGGAGCTC CTAACTCAATCTTTTTGCGTCATCACTCAATTTTCACACGTCTCTCTAAGTCATCTATGCATGATTTGTGGATCCTAAGTTAGGATTAAG CCCATTTTATGAATTATTGTTGAATCATATTTATTTCAGTGGCATTGGTGTGTTCAAACATTCCTTTCTCCTACCTGAGTGTTTTAGTAA GTCAAACAATTTGACATGGGAATGGAACCTATAACAGTCTGTCATTTAGGGTGCACATAAACTACTTTTTATAATGTAAGTGTTGTATTT TTGATTAGATTTTTAGTGAACAATAATAATGCTGTTACTTGTGATTTAACAAATTGCTCTTGAAAGGGGTTACCAAGGCAACTGGTTGCA TAATGAGTCTGTGTTAATAAAGTATATTTTATGATTGAGTATAATTAAATTATAATCAAGCTATACTTAATATCAACATGTCTAATATAC AGTACAATGGGTATGTGGGTATTATTCAGTTTATAATTTTGAGGTTGTCTTTTTTTTATTTTATTTTTTACTTTGGTTTGAGATTCAATT TAAACAGTTGTGATTATGAAATGTTAATTCATGAATAAAACACAGTAAAAGACAATTAAAGCCACCTTTTAATAAATTAAAAAAAAAAAA AAA

Figure 1-2 Full-length cDNA and deduced amino acid sequences of rainbow trout OORP-T. The cDNA has an ORF encoding a protein of 564 amino acids. The protein contains a conserved oxysterol binding protein (OSBP) domain at the $\mathrm{C}$ terminus (shaded). Polyadenylation signals (AATAA) are shown in bold and the cytoplasmic polyadenylation elements (TTTTTAT) are both underlined and bolded. The cDNA sequence has been deposited in the NCBI database with the accession number: DQ630461. 


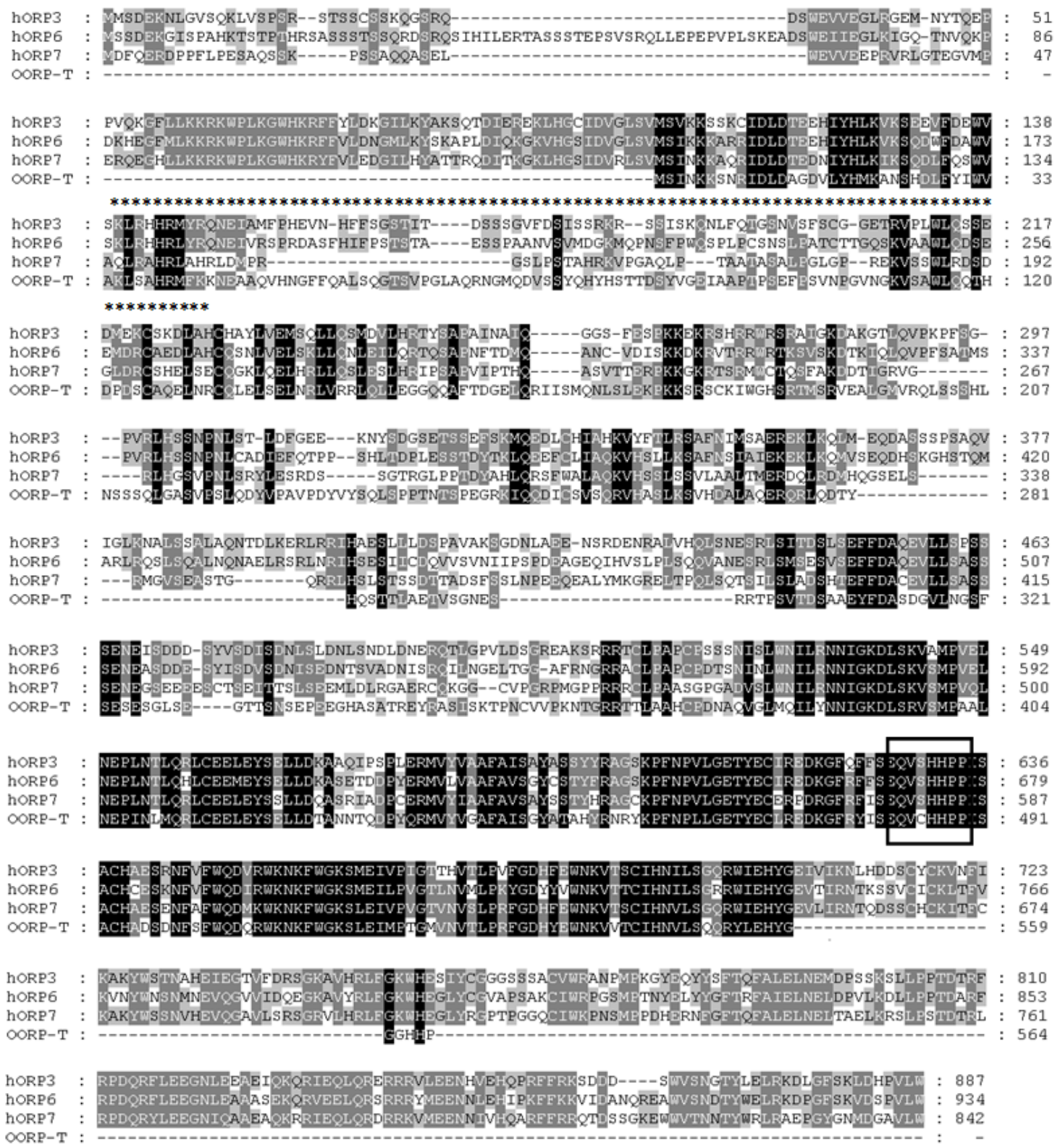

Figure 1-3 Multiple alignment of the deduced amino acid sequence of rainbow trout OORP-T with members of human ORP subfamily 3 (hORP3: AY008315, hORP6: AF323728; ORP7, AF323729) by ClustalW analysis (http://www.ebi.ac.uk/clustalw). The PH domain is indicated by stars. The OSBP fingerprint domain is boxed. 

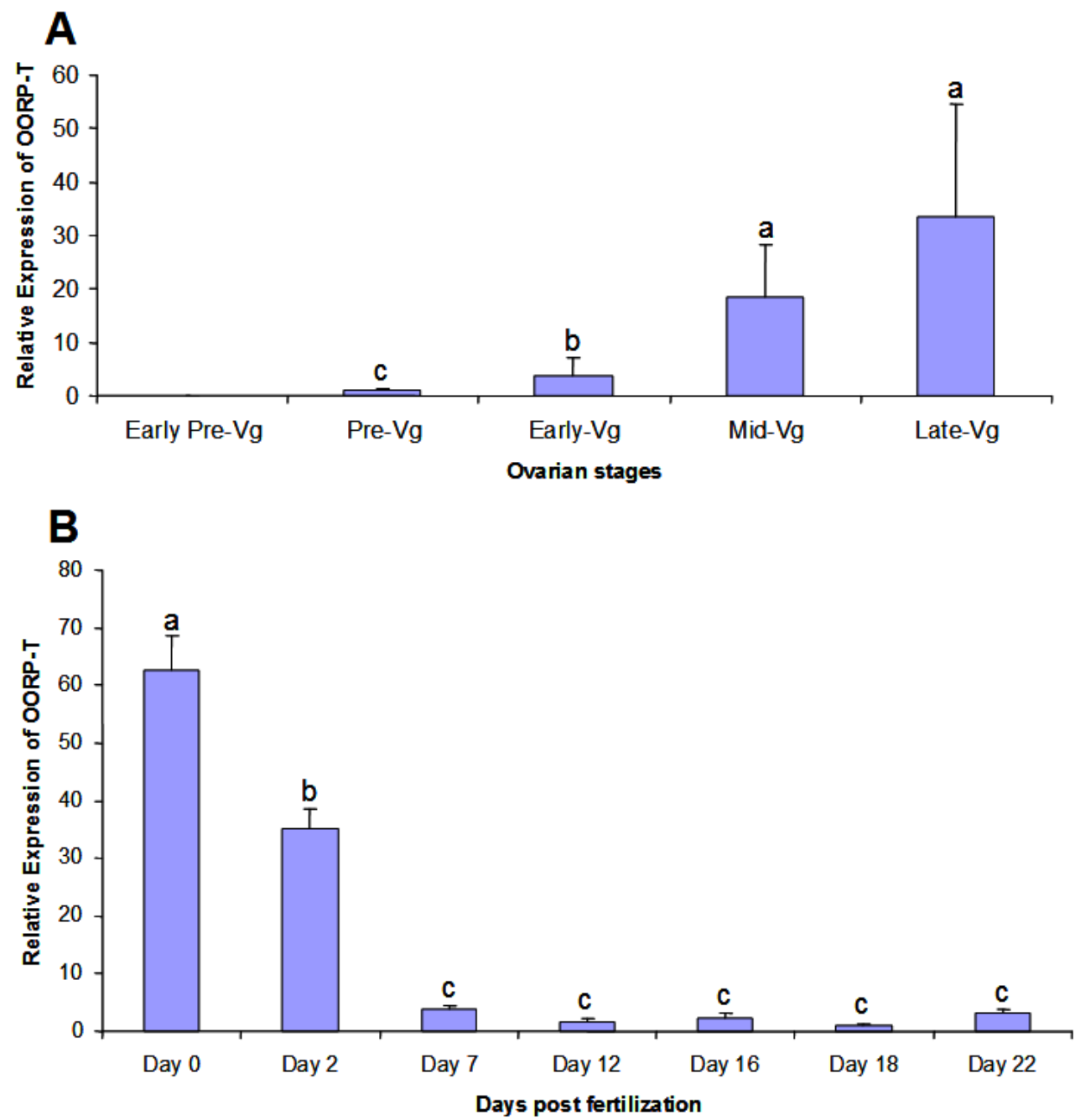

Figure 1-4 Quantitative analysis of OORP-T mRNA expression during ovarian and embryonic development by real time PCR. A. Relative expression of OORP-T mRNA during ovarian development. Different stages of ovarian follicles analyzed include: early pre-vitellogenesis (Early pre-Vg), pre-vitellogenesis (Pre-Vg), early-vitellogenesis (Early-Vg), mid vitellogenesis (Mid-Vg) and late vitellogenesis (Late-Vg). B. Relative expression of OORP-T mRNA during embryonic development. Embryonic stages analyzed include day 0 (unfertilized eggs), 2, 7, 12, 16 and 22 embryos. The quantity of OORP-T mRNA was normalized to trout histone H2A. The means of the normalized gene expression values for each stage of ovary/embryo were calculated and expressed as relative fold changes. Different letters indicate significant difference $(\mathrm{P}<0.05)$. 

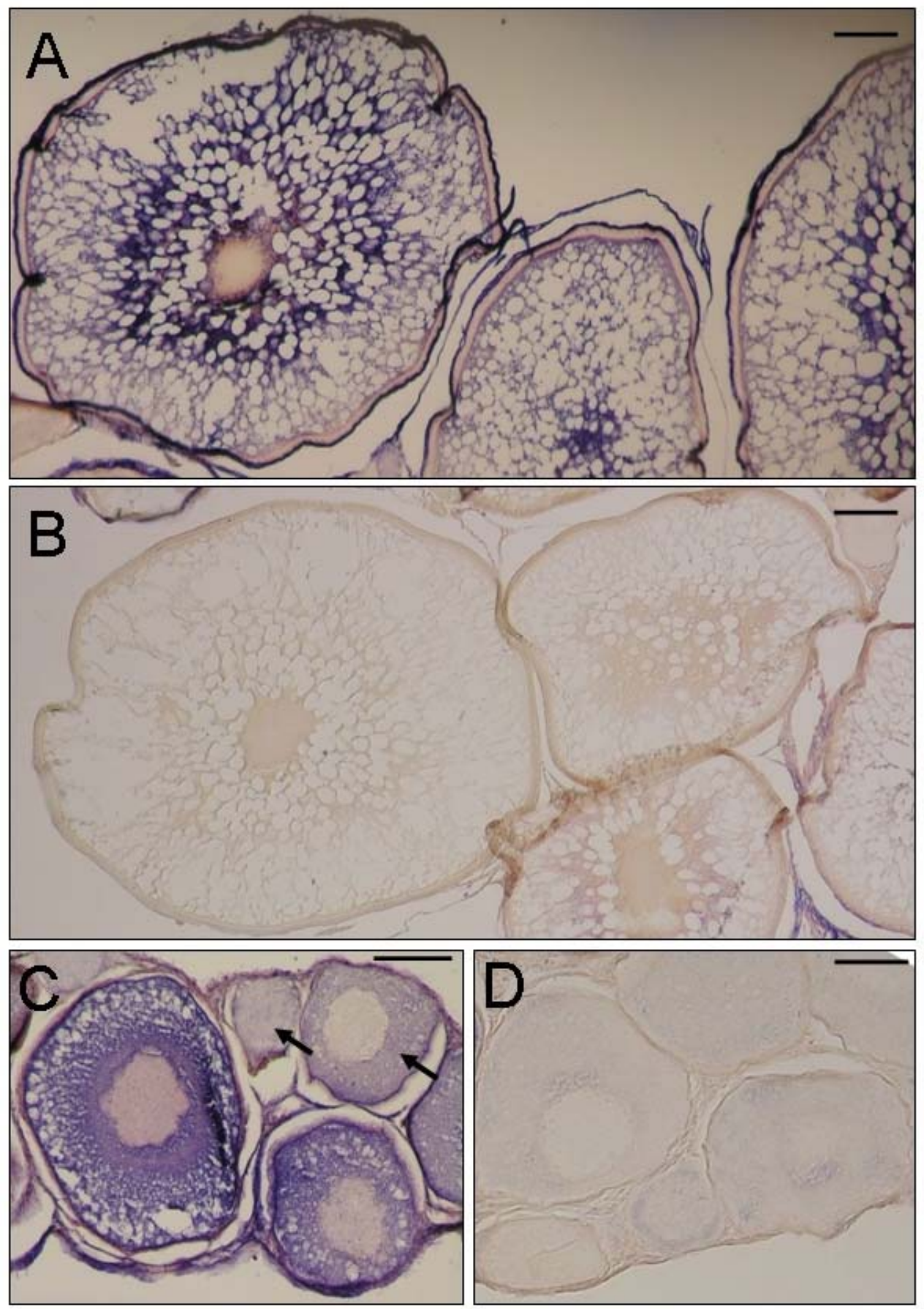

Figure 1-5 Localization of OORP-T mRNA in ovarian follicles by in situ hybridization. Midvitellogenic (A) and early-vitellogenic (C) ovarian section hybridized with DIG-labeled anti-sense RNA probe. B and D are ovarian sections (Mid and early vitellogenic ovary respectively) hybridized with sense RNA probe (negative control). Arrows in Fig. $\mathrm{C}$ indicate pre-vitellogenic oocytes. Bar = $100 \mu \mathrm{m}$ 


\section{Chapter 2 : Expression of key transcription factors during early embryogenesis in rainbow trout (Oncorhynchus mykiss)}

Raghuveer K. Ramachandra ${ }^{1}$, Caird E. Rexroad $\mathrm{III}^{2}$ and Jianbo Yao ${ }^{1 *}$.

(Under peer-review)

${ }^{1}$ Division of Animal and Nutritional Sciences, West Virginia University, Morgantown, WV 26506-6108

${ }^{2}$ National Center for Cool and Cold Water Aquaculture, Kearneysville, WV 25430 


\section{Abstract}

Early embryonic development is a complex process that requires regulated expression of numerous genes. The maternal-zygotic transition (MZT) is the first major transition in early development leading to the activation of the embryonic genome. Effective transcription machinery, including transcription factors, must be available during the MZT for it to occur. Therefore, measuring the transcript abundance of key transcription factors, prior to and after MZT, can provide important clues about the roles of transcription factors in this process. In this study, we quantitatively measured mRNA abundance of 9 selected transcription factors (Figla, P300, YY1, HMGA1, HMGB1, HMGN1, ATF-1, TEAD2 and OCT-4) in unfertilized eggs and early stage embryos from day 1 through day 7 post fertilization using quantitative real time PCR. Our results demonstrate that significant amounts of mRNA for all transcription factors studied are present in unfertilized eggs and day 1 embryos, and the expression of all transcription factors reaches minimum levels in day 2 embryos. While some transcription factors remain at low levels of expression throughout later stages of development, others show significant increase of expression following embryonic genome activation. The expression patterns of these transcription factors are suggestive of their roles in MZT as well as in early development in rainbow trout. 


\section{Introduction}

Accumulation of maternal transcripts in the oocyte during its growth and final maturation is necessary to sustain life until the embryo develops its own machinery to meet subsequent transcriptional needs. This shift from stored maternal factors to synthesized embryonic signals is called the maternal-zygotic transition (MZT). It takes

place in several bursts with a small scale initiation followed by global activation. Major activation occurs at the 1- to 2-cell stage in mice (Schultz 1993), 4- to 8-cell stage in humans (Telford et al. 1990) and 8- to 16-cell stage in cattle (Memili and First 1999). However in amphibians and teleosts, this transition takes place after 10-12 asynchronous cell cycles at the mid-blastula stage (Aizawa et al. 2003; Kane and Kimmel 1993; Newport and Kirschner 1982). Hence in teleosts and amphibians, this process is called the mid-blastula transition. The MZT is considered to be an important milestone in an embryo's life and requires precise and timely coordinated expression of numerous genes.

Initiation of transcription in transcriptionally silent embryos prior to the MZT requires factors involved in chromatin remodeling. Histone acetylation and de-acetylation have been shown to be key regulatory switches for transcription (Stein et al. 1997). In addition, proper chromatin architecture is necessary to facilitate transcription of selected genes. High Mobility Group (HMG) proteins are members of a unique family of gene regulatory proteins called architectural transcription factors (Grosschedl et al. 1994) and HMG activity is suspected to produce a transcription-friendly conformation of the chromatin (Bianchi and Beltrame 2000). Once the chromatin conformation permits the access of transcription factors, these factors must be present to initiate the transcription. They may act either by influencing RNA polymerase II or by binding to promoters of downstream genes. Some transcription factors are specific to particular genes, while 
others are general transcription factors promoting transcription of a set of downstream genes.

Transcription factors play important roles in many biological processes. Early embryonic development is a complex process that involves timely and quantitative control of gene transcription. The importance of transcription factors in embryonic development has been demonstrated in several previous studies (Fujiwara et al. 1996; Koutsourakis et al. 1999; Marin et al. 1997). In rainbow trout (Oncorhynchus mykiss), the developmental expression pattern of an important transcription factor, FoxF1, has been described (Hidaka et al. 2004). However, quantitative measurements of gene expression profiles of transcription factors during rainbow trout embryonic development have not been reported. In this study, we evaluated 9 selected transcription factors for their expression patterns during early embryonic development in rainbow trout. These factors were chosen based on their suspected roles in early transcription during embryogenesis (Table 1). Quantitative real time PCR was used to determine the relative mRNA abundance of these transcription factors in unfertilized eggs and embryos of day 1 through day 7 post fertilization. Our results show that all embryonic stages observed contain detectable amounts of mRNA for all transcription factors studied, and 6 transcription factors (Figla, P300, YY1, HMGA1, ATF1 and OCT-4) share similar expression patterns while the other 3 (HMGB1, HMGN1 and TEAD2) show another pattern of expression. This study represents the first attempt to determine the expression of key transcription factors in rainbow trout early embryos and indicates possible roles of transcription factors in and around the MZT during early embryogenesis in rainbow trout. 


\section{Materials and methods \\ Animals and embryos}

Fishes were reared under standard farming conditions. Rainbow trout eggs from a commercial farm were fertilized and incubated at $13{ }^{\circ} \mathrm{C}$ in a flow through system using a $12 \mathrm{~h}$ light cycle. Unfertilized eggs (day 0 ) and developing embryos were collected at day $1,2,3,4,5,6$ and 7 post-fertilization. All samples were quick frozen in liquid nitrogen and stored at $-80^{\circ} \mathrm{C}$ until RNA extraction.

\section{RNA and cDNA preparation}

Total RNA was isolated using TRIzol (Invitrogen, Carlsbad, CA) according to manufacturer's protocol. Total RNA was treated with DNase (Promega, Madison, WI) to avoid genomic DNA contamination. Two $\mu \mathrm{g}$ of DNAse-treated total RNA from each stage ( $\mathrm{n}=5$ pools, 5 embryos/pool) were converted to cDNA using Superscript II reverse transcriptase (Invitrogen, Carlsbad, CA).

\section{Quantitative real time PCR}

Quantitative real time PCR was carried out as described (Ramachandra et al. 2007). Briefly, primers were designed based on the corresponding cDNA sequences in TIGR database (http://compbio.dfci.harvard.edu/tgi/) using Primer3 software (http://frodo.wi.mit.edu/cgi-bin/primer3/primer3_www.cgi) and listed in Table 2-2. Two $\mu \mathrm{g}$ of DNAse-treated total RNA from each embryonic stage ( $\mathrm{n}=5$ pools, 5 embryos/pool) were converted to cDNA using Superscript II reverse transcriptase (Invitrogen, Carlsbad, CA). Quantitative PCR was carried out using the Bio-Rad iCycler iQ Real-Time PCR Detection System using $\mathrm{iQ}^{\mathrm{TM}}$ SYBR ${ }^{\circledR}$ Green Supermix (Bio-Rad, Hercules, CA). Standard curves for all genes and an endogenous control (Histone H2a) were constructed 
using 10 fold serial dilutions of the corresponding plasmid. The quantity of each gene was divided by the quantity of the control gene to obtain a normalized value. The expression of transcription factor mRNA was then expressed as relative fold changes. Specificity of amplification is confirmed by melt curve analysis using iCycler software (Bio-Rad). Histone H2A was chosen as the endogenous control as it shows stable expression during rainbow trout embryonic development (data not shown). This gene has

also been reported to be consistently expressed in bovine embryos during early development (Robert et al. 2002).

\section{Statistical analysis}

One-way analysis of variance (ANOVA, Tukey's HSD comparison) and paired ttest were performed on normalized gene expression values using JMP 5.1 (SAS Institute, Cary, NC). Differences between groups were reported significant (denoted by a different alphabet in figures) with confidence level of $95 \%(\mathrm{p}=0.05)$.

\section{Results and discussion}

Our real time PCR data show that detectable quantities of mRNA for all transcription factors studied are present in unfertilized eggs and all embryonic stages (Fig. 2.1 and Fig. 2.2). Significant amounts of mRNA for all transcription factors are present in unfertilized eggs and day 1 embryos, and the expression for all transcription factors reaches minimum levels in day 2 embryos. Of the 9 transcription factors studied, Figla, P300, YY1, HMGA1, OCT-4 and ATF-1 show similar patterns of expression, i.e. they remain at low levels of expression throughout the late stage development following the decrease in day 2 embryos (Fig. 2.1), whereas the other 3 transcription factors, 
HMGN1, HMGB1 and TEAD2, show increased expression in late stage embryos following the drop in day 2 embryos (Fig. 2.2).

The presence of abundant maternal transcripts for the transcription factors in unfertilized mature eggs could mean that these transcription factors play a role during the initial development prior to the MZT. The mRNA levels for all genes start to decline in embryos 2 days post-fertilization, which is the expected time of mid-blastula transition in rainbow trout. Recruitment of the mRNA by the translation machinery and subsequent degradation could be the explanation for reduction of mRNA in day 2 embryos.

Figla is a germ cell specific transcription factor (Huntriss et al. 2002; Liang et al. 1997) which is required for ovarian follicle formation (Soyal et al. 2000). Expression of this gene in embryonic development has not been reported in other species. Although the role of this factor in late stage development of embryos is not clear, the presence of abundant transcripts of this gene in unfertilized eggs and day 1 embryos leads us to believe that this gene might be involved in embryonic genome activation in addition to its known function in folliculogenesis and zona pellucida formation. P300, YY1, HMGA1 and OCT-4 are all important transcription factors involved in many biological processes. P300 has acetyltransferase activity and helps in making the tightly packed chromosome accessible for transcription factors (Vo and Goodman 2001). YY1 is a multifunctional protein with four zinc fingers at the $\mathrm{C}$-terminus and it activates transcription by binding to many other factors (Donohoe et al. 1999; Lee et al. 1993a). OCT-4 is implicated in maintaining the pluripotency of embryos (Morrison and Brickman 2006). HMGA1 is a member of HMGA proteins that participate in a wide variety of nuclear processes and act as architectural transcription factors that regulate the expression of numerous genes 
(Reeves 2001). In rainbow trout, although the mRNA levels for these 4 genes did not reach the levels in the unfertilized eggs and day 1 embryos following embryonic genome activation (day 2), they maintained steady levels of expression throughout the late stages of development (Fig. 2.1). In a bovine study, characterizing the expression patterns of multiple transcription factors during early embryogenesis, Vigneault et al. (2004) demonstrated that the expression of these 4 transcription factors was at the lowest levels in 8-cell stage embryos, which is the expected time of embryonic genome activation in cattle. Our data is in good agreement with this finding showing the lowest mRNA levels for these factors in day 2 embryos, the estimated time of the MZT in rainbow trout. The expression pattern of ATF-1 is rather unique compared to the patterns of other factors during early embryonic development in cattle (Vigneault et al. 2004). It shows no significant decrease at the 8-cell stage and maintains the same level of expression before and after MZT. This expression pattern for ATF-1 was not observed in rainbow trout. Inherent differences between mammals and teleosts could explain this discrepancy. However, the use of in vitro produced embryos in the bovine study could also be a source of variation since differences do exist between in vivo and in vitro derived embryos (Lonergan et al. 2003a; Lonergan et al. 2003b).

Both HMGN1 and HMGB1 are non-histone chromosomal proteins that facilitate transcription through relaxing the compaction of chromatin (Bianchi and Beltrame 1998; Bustin 2001). TEAD2 is a member of the highly conserved TEAD/TEF transcription factor family and is expressed in mouse embryos immediately after fertilization (Kaneko et al. 1997). The expression of these 3 genes increases in rainbow trout early embryos following the decrease during MZT. Apparently, they are derived from zygotic 
transcription and presumably play a role in activating transcription of other genes during late development of the embryos. Increased expression for these 3 genes in bovine embryos following embryonic genome activation has also been observed (Vigneault et al. 2004).

In summary, we have shown that abundant amounts of mRNA for all 9 transcription factors examined in this study are present in mature rainbow trout oocytes and embryos prior to MZT, suggesting that maternal transcripts for transcription factors are stored in mature oocytes and translated when needed for the MZT. Significant amounts of mRNA for 8 of the 9 transcription factors (all except for Figla) are found in early embryos (day 3 to day 7) following embryonic genome activation, suggesting that they continue to play a role during early embryogenesis after the embryonic genome is activated. 


\section{Tables and figures}

Table 2-1 . Relevant information about transcription factors evaluated

\begin{tabular}{|c|c|c|}
\hline $\begin{array}{l}\text { Gene } \\
\text { Name }\end{array}$ & Relevance in this study & References \\
\hline Figla & $\begin{array}{l}\text { Germline specific transcription factor known to } \\
\text { regulate zona pellucida genes. So far attributed only to } \\
\text { folliculogenesis and zona pellucida formation. }\end{array}$ & $\begin{array}{l}\text { (Liang et al. 1997; } \\
\text { Soyal et al. 2000) }\end{array}$ \\
\hline P300 & $\begin{array}{l}\text { Structurally related to CREB binding protein (CBP). } \\
\text { Co-activates transcription by binding to hundreds of } \\
\text { other transcription factors }\end{array}$ & $\begin{array}{l}\text { (Vo and } \\
\text { Goodman 2001) }\end{array}$ \\
\hline YY1 & $\begin{array}{l}\text { Transcriptional activator. Binds to many other factors } \\
\text { to enhance transcription. Its localization from } \\
\text { cytoplasm to nucleus is correlated to MZT in mice. }\end{array}$ & $\begin{array}{l}\text { (Lee et al. 1993a), } \\
\text { (Donohoe et al. } \\
\text { 1999) }\end{array}$ \\
\hline HMGN1 & $\begin{array}{l}\text { Non-histone chromosomal protein called architectural } \\
\text { protein. When bound to chromatin, they reduce } \\
\text { compaction facilitating transcription. Knock down in } \\
\text { mice delays development and reduces total RNA } \\
\text { production. }\end{array}$ & $\begin{array}{l}\text { (Bustin 2001; } \\
\text { Bustin et al. 1995; } \\
\text { Mohamed et al. } \\
\text { 2001) }\end{array}$ \\
\hline HMGA1 & $\begin{array}{l}\text { Another architectural protein that bind to AT rich } \\
\text { regions of chromatin. Recruits transcription initiation } \\
\text { machinery to transcription initiation site by forming } \\
\text { huge complexes. }\end{array}$ & $\begin{array}{l}\text { (Reeves and } \\
\text { Beckerbauer } \\
\text { 2001) }\end{array}$ \\
\hline HMGB1 & $\begin{array}{l}\text { Non-histone chromosomal protein that binds linker } \\
\text { DNA between nucleosomes and disrupts the chromatin } \\
\text { by inducing sharp bends that facilitate transcription. }\end{array}$ & $\begin{array}{l}\text { (Bianchi and } \\
\text { Beltrame 1998) }\end{array}$ \\
\hline TEAD2 & $\begin{array}{l}\text { Contains a conserved TEA DNA binding domain and } \\
\text { is expressed at high levels during pre-implantation } \\
\text { development in mice. }\end{array}$ & $\begin{array}{l}\text { (Kaneko et al. } \\
1997 \text { ) }\end{array}$ \\
\hline ATF-1 & $\begin{array}{l}\text { Related to CREB both structurally and functionally. } \\
\text { Responds to various growth factors to promote } \\
\text { transcription. }\end{array}$ & $\begin{array}{l}\text { (Hai and Hartman } \\
\text { 2001) }\end{array}$ \\
\hline OCT-4 & $\begin{array}{l}\text { Correlated to pleuripotency of cells and it has also } \\
\text { been shown to participate in the expression of } \\
\text { numerous pluripotent cell genes }\end{array}$ & $\begin{array}{l}\text { (Ovitt and Scholer } \\
\text { 1998) }\end{array}$ \\
\hline
\end{tabular}


Table 2-2 Primers used for quantitative real time PCR

\begin{tabular}{|c|c|c|c|}
\hline $\begin{array}{l}\text { Gene } \\
\text { Name }\end{array}$ & $\begin{array}{l}\text { TIGR TC } \\
\text { number }\end{array}$ & Primer Sequence & $\begin{array}{l}\text { Product } \\
\text { Length } \\
\text { (bp) }\end{array}$ \\
\hline \multirow[b]{2}{*}{ Figla } & \multirow{2}{*}{ TC72755 } & For 5'-GCAACTTCTGATGGGATGTGT-3' & \multirow{2}{*}{133} \\
\hline & & Rev 5'- CTCCAAACCCTGTAGTCACCA-3' & \\
\hline \multirow{2}{*}{ P300 } & \multirow{2}{*}{ TC88246 } & For 5' -AGTCCTTTCCCTACAGGACGA-3' & \multirow{2}{*}{99} \\
\hline & & Rev 5'-CTGAACCGTACTCCTGCACAT-3' & \\
\hline \multirow{2}{*}{ YY1 } & \multirow{2}{*}{ TC93486 } & For 5' -CTATGGAGGGGGAATTCTCTG-3' & \multirow{2}{*}{139} \\
\hline & & Rev 5' -AGCTTCTTCCCCGTCATGTAT-3' & \\
\hline \multirow{2}{*}{ HMGN1 } & \multirow{2}{*}{ TC70379 } & For 5' -ATCCTCCATCTGGTTGGTCTT-3' & \multirow{2}{*}{127} \\
\hline & & Rev 5'-AGAGAAGGCTGTGAACGACAA-3' & \\
\hline \multirow{2}{*}{ HMGA1 } & \multirow{2}{*}{ TC82112 } & For 5'-GTATGGAGCGGGACATGAGTA-3' & \multirow{2}{*}{92} \\
\hline & & Rev 5' -CCTCTGCTTCTTCCCAAACTC-3' & \\
\hline \multirow{2}{*}{ HMGB1 } & \multirow{2}{*}{ TC86880 } & For 5' - CTCTGCAGCTGAGGAGAAGAA-3' & \multirow{2}{*}{110} \\
\hline & & Rev 5' - AGGCCGTATCCACTCTACCAT-3' & \\
\hline \multirow{2}{*}{ TEAD2 } & \multirow{2}{*}{ TC80298 } & For 5'-GGAGTATGCACGGTTTGAGAA-3' & \multirow{2}{*}{109} \\
\hline & & Rev 5' -CTTCTCTGGCAGGTGTTTGAG-3' & \\
\hline \multirow{2}{*}{ ATF-1 } & \multirow{2}{*}{ TC71207 } & For 5' -TGGTCATGACTTCCCCTGTAG-3' & \multirow{2}{*}{150} \\
\hline & & Rev 5'-CCACACGATTCTCCAGACATT-3' & \\
\hline \multirow{2}{*}{ OCT-4 } & \multirow{2}{*}{ TC85975 } & For 5' -CTTTTTCTGCCTGCAGATGTC-3' & \multirow{2}{*}{11} \\
\hline & & Rev 5'-GTATGGGTGTGTTTGCATGTG-3' & \\
\hline \multirow{2}{*}{$\begin{array}{l}\text { Histone } \\
\mathrm{H} 2 \mathrm{a}\end{array}$} & \multirow{2}{*}{ TC85036 } & For 5' -TCCCCAAGAAGACTGAGAAGG-3' & \multirow{2}{*}{114} \\
\hline & & Rev 5'-TTTGTTGAGCTAGGTGGTTGG-3' & \\
\hline
\end{tabular}


A

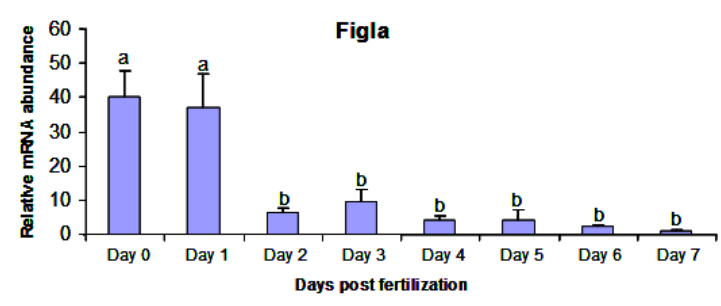

B

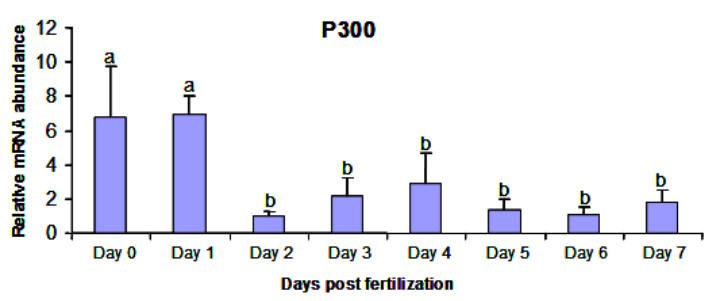

C

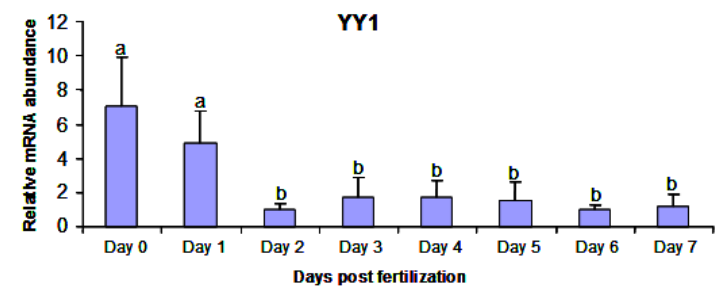

D

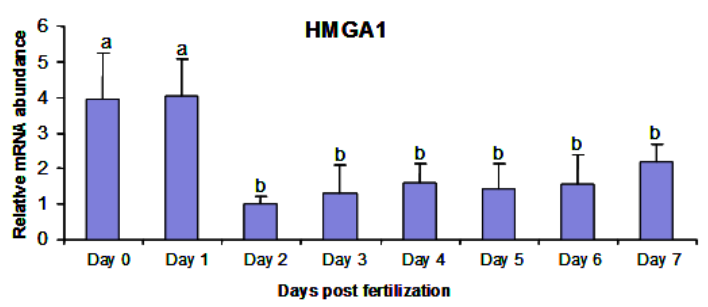

E

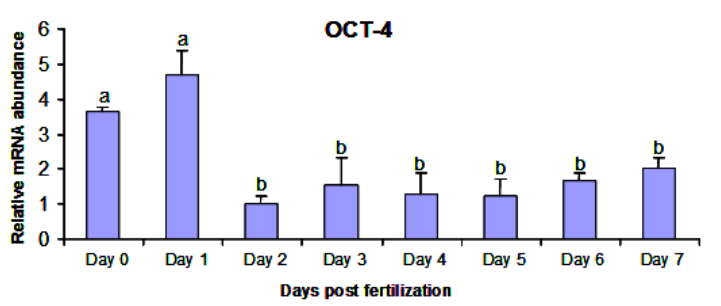

F

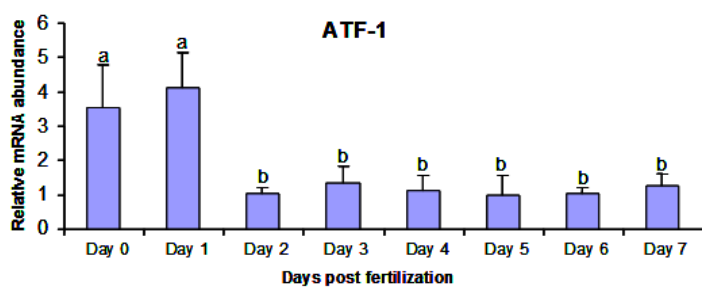

Figure 2-1 Relative abundance of Figla (A), P300 (B) and YY1 (C), HMGA1 (D), OCT-4 (E) and ATF-1 (F) mRNA in rainbow trout unfertilized eggs (day 0) and embryos from day 1 through day 7 post fertilization. The mRNA levels for each gene were normalized to Histone H2a. The means of the normalized gene expression values for each stage of embryo were calculated and expressed as relative fold changes (mean \pm S.D., $n=5$ ). Different letters indicate significant difference between groups $(P<0.05)$. 
A

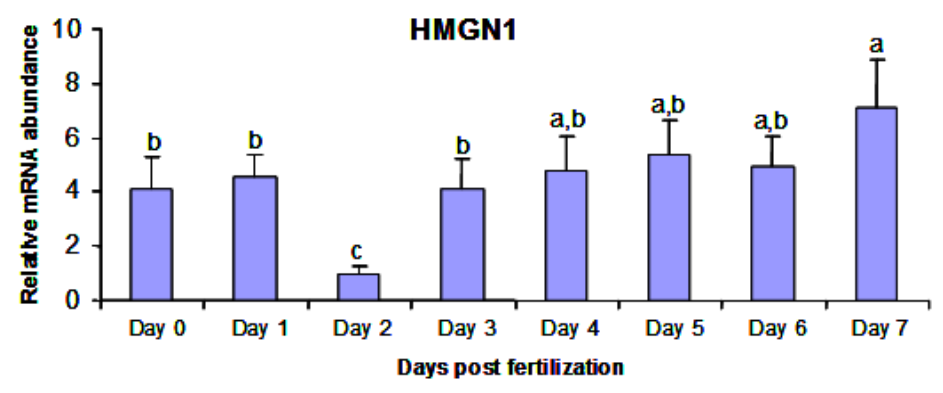

B

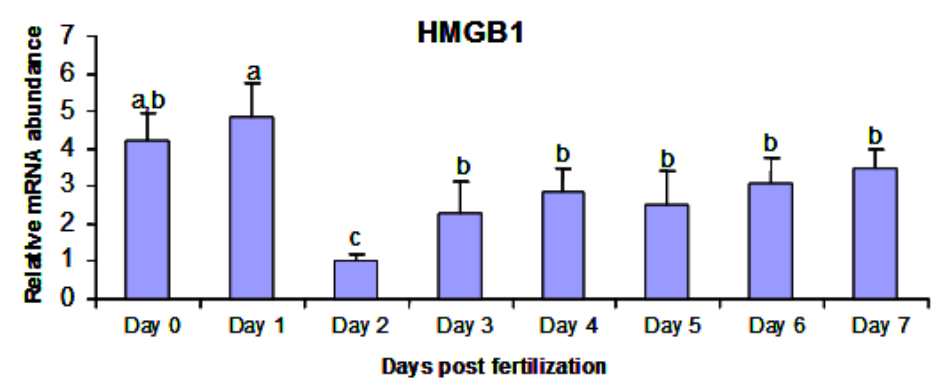

C

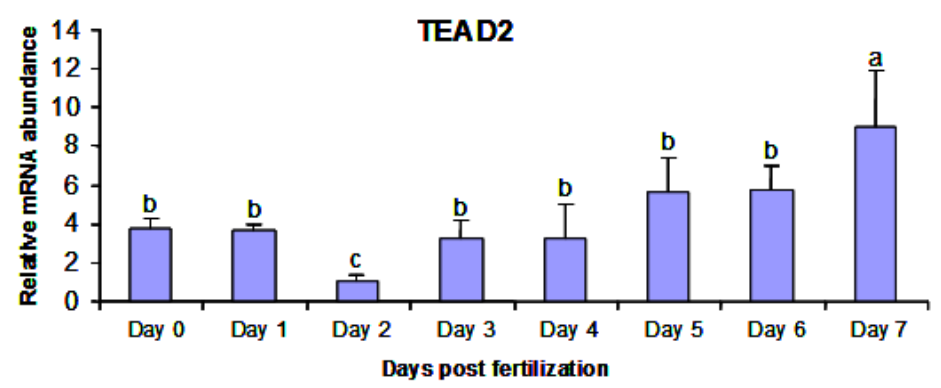

Figure 2-2 Real time PCR analysis of relative abundance of HMGN1 (A) HMGB1 (B) and TEAD2 (C) mRNA in rainbow trout unfertilized eggs (day 0 ) and embryos from day 1 through day 7 post fertilization. The mRNA levels for each gene were normalized to Histone H2a. The means of the normalized gene expression values for each stage of embryo were calculated and expressed as relative fold changes (mean \pm S.D., $n=5$ ). Different letters indicate significant difference between groups $(\mathrm{P}<0.05)$. 


\title{
Chapter 3 : Cloning and characterization of microRNAs during early embryonic development in rainbow trout (Oncorhynchus mykiss)
}

\author{
Raghuveer K. Ramachandra ${ }^{1}$, Scott $\mathrm{Gahr}^{2}$, Caird E. Rexroad $\mathrm{III}^{2}$ and Jianbo Yao ${ }^{1}$. \\ (Pre-submission) \\ ${ }^{1}$ Division of Animal and Nutritional Sciences, West Virginia University, Morgantown, \\ WV 26506-6108 \\ ${ }^{2}$ National Center for Cool and Cold Water Aquaculture, Kearneysville, WV 25430
}




\section{Abstract}

Current literature and our results on expression pattern of oocyte specific genes and transcription factors suggest a global but highly regulated maternal mRNA degradation at the time of embryonic genome activation (EGA). We hypothesized that microRNAs (miRNAs), naturally occurring 19-21bp long post-transcriptional regulators, are involved in this degradation process. We analyzed the expression pattern of dicer, an enzyme required for the processing of microRNAs. Dicer is abundantly expressed until 24 hours post-fertilization and gets down-regulated afterwards. This supports the hypothesis that dicer processes mature miRNAs during these stages and these miRNAs in turn degrade maternal mRNAs. To identify candidate microRNAs involved in this process, we constructed a miRNA library from a pool of oocytes and early stage embryos stages ( 0 hour post-fertilization through 72 hours post-fertilization). Sequencing analysis of clones showed that there are at least 15 miRNAs expressed during these stages, 4 of which are novel to rainbow trout. We carried out quantitative real-time PCR to learn more about their expression pattern. Our results show that microRNAs miR-100t, miR21t, miR-21, miR-23, miR-26 and miR-92a are up-regulated when maternal RNAs are degraded. Stat3, a transcription factor which is involved in activating the transcription of microRNAs is also abundantly expressed in early rainbow trout embryos. Taken together, these results and literature on functions of stat3 indicate that up-regulated microRNAs, some induced by stat3, could be responsible for degradation of maternal mRNAs in early embryos. 


\section{Introduction}

The embryo remains dependent on maternally stored mRNAs for its transcriptional needs until its own transcription machinery is functional. The time of this transcriptional independence, called embryonic genome activation (EGA), varies greatly with species. While it occurs by the 2 cell stage in mice (Bolton et al. 1984), it does not take place until mid-blastula in teleosts (Kane and Kimmel 1993) and amphibians (Slevin et al. 2005). There could be at least three reasons why the embryonic genome is not able to transcribe mRNAs before EGA namely (i) Epigenetic and chromatin mediated repression, (ii) insufficient transcription machinery and (iii) lack of sufficient time for the chromosome to transcribe while it is undergoing rapid cell divisions (Schier 2007). In fish, the maternal-zygotic transition is characterized by asynchronous cell division, lengthening of cell cycles and cell motility (Kane and Kimmel 1993). After this activation, the embryo becomes increasingly dependent on its own transcription to exhaust maternally derived mRNAs. It was recently shown that it is critical to degrade inherited mRNAs to achieve normal morphogenesis and morphogenesis is delayed if maternally derived mRNAs are not degraded (Giraldez et al. 2006). So, it seems reasonable to expect a tightly controlled regulatory mechanism in nature to degrade maternal mRNAs at the time of embryonic genome activation.

We previously showed that several transcription factors (Ramachandra et al., 2007 unpublished) and oocyte specific genes (Ramachandra et al. 2007) are degraded during/around the time of embryonic genome activation in rainbow trout. Apart from the involvement of Tata binding protein (TBP) during the activation of mRNA degradation machinery at the maternal-zygotic transition (Ferg et al. 2007), our knowledge about other requirements are limited. Mechanisms by which this degradation is accomplished 
had escaped scientific attention until recently. It was shown by Giraldez et al. (2006) that microRNA miR-21 are involved in this activation of degradation process.

MicroRNAs are small, 19-23 bp long non-coding RNAs that bind to their respective recognition sequence on 3' un-translated region (UTR) of an mRNA and direct it to either degradation in the case of high complimentarity or translational repression in the case of partial complimentarity (Cullen 2006). Interestingly, a microRNA can bind to its recognition sequence on the 3' UTR of up to 200 genes and each mRNA could have recognition sequence for more than one microRNAs (Wienholds and Plasterk 2005). The microRNA model is well suited to explain maternal mRNA degradation because microRNAs degrade mRNAs in a specific and large scale manner which is the case in EGA. The absence of all microRNAs caused by the deficiency of Dicer, an enzyme that is required for processing microRNAs, results in severe early embryonic deformities and faulty brain morphogenesis (Giraldez et al. 2006). The same study also showed that miR430 rapidly de-adenylates maternal mRNAs resulting in their degradation. However, when maternal zygotic dicer mutants were injected with miR-430, the brain morphogenesis phenotype was not completely recovered indicating that there could be other microRNAs involved in this process.

Due to the lack of genomic information in rainbow trout and to avoid errors caused by computational algorithms, we designed this experiment to identify and characterize all microRNAs potentially regulating this degradation process during these embryonic stages in rainbow trout. Here we present data to show that dicer, and several microRNAs are abundantly expressed at the time of maternal mRNA degradation. Signal transducer and activator of transcription3 (Stat3), which activates transcription of 
microRNAs is also abundant in these stages indicating its role in inducing microRNA expression and thereby directing maternal mRNAs for degradation.

\section{Materials and methods}

\section{Animals and embryos}

Fishes were reared under standard farming conditions. Rainbow trout eggs from a commercial farm (Laurel Hill Trout farm, Somerset, PA) were fertilized and incubated at $13^{\circ} \mathrm{C}$ in a flow through system using a $12 \mathrm{~h}$ light cycle. Unfertilized eggs ( 0 hours postfertilization-hpf) and developing embryos were collected at 12(4-8 blastomeres), 24 (blastodisc formation), 36 (onset of interphase lengthening), 48 (blastoderm thickening) and 72 (blastoderm flattening) hours post fertilization and frozen in liquid nitrogen and stored at $-80^{\circ} \mathrm{C}$ until total RNA isolation.

\section{Quantitative Real-time PCR for dicer and stat3}

Total RNA was isolated using TRIzol (Invitrogen, Carlsbad, CA) as instructed by the manufacturer. Total RNA was used as template for quantitative real time PCR as described before (Ramachandra et al. 2007). Primers were designed based on the CoreNucleotide sequence (AY523839 for Dicer and U60333 for Stat3) in NCBI database (http://www.ncbi.nlm. nih.gov/) using Primer3 software (http://frodo.wi.mit.edu/cgibin/primer3/primer3_www.cgi -dicer forward: AGG AGG CAG TGC TAC CCT AAA, dicer reverse: AAG TTG AGT TCG TCA GGC AGA, stat3 Forward GCT GGA CAA CAT CAT TGA CCT and stat3 reverse GTG ACT GCC TCC CTC CTT ACT). Two $\mu \mathrm{g}$ of DNAse-treated total RNA from each embryonic stage ( $\mathrm{n}=5$ pools, 5 embryos/pool) were converted to cDNA using Superscript II reverse transcriptase (Invitrogen, Carlsbad, CA). Quantitative PCR was carried out using Bio-Rad iCycler iQ Real-Time PCR 
Detection System using iQ ${ }^{\mathrm{TM}}$ SYBR ${ }^{\circledR}$ Green Supermix (Bio-Rad, Hercules, CA). Standard curves for dicer/stat3 and endogenous control (Histone H2a) were constructed using 10 fold serial dilutions of the cDNA pool. The quantity of dicer/stat3 was divided by the quantity of the control gene (Histone 2A- forward: TCC CCA AGA AGA CTG AGA AGG and reverse: TTT GTT GAG CTA GGT GGT TGG- TC85036 in TIGR database- www.tigr.org) to obtain a normalized value. The expression of dicer/stat3 mRNA was then expressed as relative fold changes. Specificity of amplification is confirmed by melting curve analysis using iCycler software (Bio-Rad, Hercules, CA).

\section{MicroRNA Cloning}

Total RNA was isolated using TRIzol ${ }^{\mathrm{TM}}$ (Invitrogen, Carlsbad, CA) using manufacturer's instructions. Total RNA from oocyte ( 0 hours post-fertilization) and early embryos (12, 24, 36, 48, 72, 96 and 120 hours post-fertilization) were pooled. A small RNA cloning kit, miRCat ${ }^{\mathrm{TM}}$ (IDT DNA, Coralville, IA), was used with some modifications for cloning microRNAs (fig 3.1). In brief, $500 \mu \mathrm{g}$ of total RNA was size fractionated using 12\% denaturing polyacrylamide gel electrophoresis (PAGE) as described by (Sambrook and Russell 2001a). Excised gels were homogenized in water and heated for 15 minutes at $70^{\circ} \mathrm{C}$ to solubilize small RNA and a 3' linker (5' phosphorylated) was ligated to the small RNA fraction in the absence of ATP. This was again size fractionated using $12 \%$ PAGE and 5' linkers were ligated in the presence of ATP. This mixture was then reverse transcribed using a primer on a 3' linker and PCR amplified using primers on both linkers. Amplified products were Ban I digested and concatemerized and polished with taq polymerase and TA-cloned using TOPO TA cloning kit (Invitrogen, Carlsbad, CA). Transfected bacterial cells were plated and grown 
overnight. Individual colonies were picked and screened for presence of insert using colony PCR. Clones with inserts were sequenced and sequence data was analyzed by BLAST search on Sanger database (http://microrna.sanger.ac.uk/) and named based on the homology to published microRNAs based on the universal nomenclature (Ambros et al. 2003).

\section{Quantitative Real-time PCR for microRNAs}

Total RNA was prepared using TRIzolTM (Invitrogen, Carlsbad, CA) according to manufacturer's instructions. The expression of microRNAs during early embryonic development was measured using quantitative real-time PCR. Two $\mu \mathrm{g}$ of DNAse-treated total RNA from each embryonic stage ( $\mathrm{n}=5$ pools, 5 embryos/pool) were added with several As using polyA polymerase and then converted to cDNA using an oligo dT anchored reverse primer (NCode ${ }^{\mathrm{TM}}$ miRNA First-Strand cDNA Synthesis and qRT-PCR Kits, Invitrogen, Carlsbad, CA). Real-time PCR primers for the microRNAs are tabulated in table 1. Histone H2A was used as endogenous control gene, (forward: TCC CCA AGA AGA CTG AGA AGG and reverse: TTT GTT GAG CTA GGT GGT TGG) (rainbow trout histone H2A: TC85036 in TIGR database- www.tigr. org). All primers were designed using Primer3 software (http://frodo.wi.mit.edu/cgibin/primer3/primer3_www.cgi). Quantitative PCR was performed in duplicate for each cDNA sample on a Bio-Rad iCycler iQ Real-Time PCR Detection System using NCode ${ }^{\mathrm{TM}}$ miRNA qRT-PCR Kit (Invitrogen, Carlsbad, CA) or iQ ${ }^{\mathrm{TM}}$ SYBR ${ }^{\circledR}$ Green Supermix (Bio-Rad, Hercules, CA) in $25-\mu 1$ reaction volumes containing $300 \mathrm{nM}$ of each primer and cDNA derived from $0.1 \mu \mathrm{g}$ of total RNA. Standard curves for all microRNAs and the endogenous control were constructed using 10 fold serial dilutions of a pool of 
cDNAs from all stages. Standard curves were run on the same plate with the samples. Threshold lines were adjusted to intersect amplification lines in the linear portion of the amplification curve and cycles to threshold $(\mathrm{Ct})$ were recorded. For each sample, the quantity of microRNA and the reference gene mRNA (histone H2A) was determined from the appropriate standard curve. The quantity of microRNA was then divided by the quantity of the reference gene to obtain a normalized value.

\section{Statistical analysis}

One-way analysis of variance (ANOVA, Tukey's HSD comparison) and paired ttest were performed on normalized gene expression values using JMP 5.1 (SAS Institute, Cary, NC). Differences between groups were reported significant (denoted by a different alphabet in figures or a star [*] if one group is significantly different from all others) with confidence level of $95 \%(\mathrm{p}=0.05)$. The expression of microRNAs was then expressed as relative fold changes.

\section{Bioinformatics analysis}

Sequences were analyzed for any homology to published microRNAs by doing BLAST search in the Sanger database (microRNA.sanger.ac.uk). Multiple sequence alignments were carried out using BioEdit (http://www.mbio.ncsu.edu/BioEdit/ bioedit.html).

\section{Results and discussion}

\section{Expression pattern of Dicer}

Dicer is the RNase III enzyme with two catalytic subunits (Bernstein et al. 2001; Bernstein et al. 2003) involved in processing of all microRNAs (Bernstein et al. 2003; Yang et al. 2005). Since processing of all microRNAs requires Dicer, if our hypothesis 
that microRNAs are involved in maternal mRNA degradation during early embryonic development was true, dicer must be present during these stages. So we decided to investigate the expression pattern of dicer in rainbow trout during early embryonic development. We found that dicer is abundantly expressed in embryos until the early blastula stage (24 hours post-fertilization) as shown by real-time PCR in Fig 3.2. Like all other maternally inherited mRNAs (Bashirullah et al. 1999; Hamatani et al. 2004; Vigneault et al. 2004), dicer gets down-regulated at the time of mid-blastula transition (between 24 and 48 hours post-fertilization- fig 3.2). The fact that dicer is present at the time of degradation of maternal mRNAs suggests that microRNAs are processed at that time and thus they may be involved in the degradation of maternal mRNAs.

Giraldez et al. (2005) showed that Dicer regulates brain morphogenesis in zebrafish through the action of microRNAs (Giraldez et al. 2005). The same study also showed that the deformities begin approximately at mid-blastula which is the time when embryonic genome activation takes place in zebrafish (Giraldez et al. 2005; Kane and Kimmel 1993). In the case of mice, dicer deficient mice embryos start to show deformities as early as 1 cell stage (Tang et al. 2007; Yang et al. 2005). Interestingly in mice, embryonic genome activation takes place at 1-2 cells stage (Bultman et al. 2006). Based on all these observations it is clear that degradation of maternal mRNAs is essential for embryonic genome activation (Giraldez et al. 2006; Weigel and Izaurralde 2006) and microRNAs are involved in this degradation (Bernstein et al. 2003; Giraldez et al. 2005; Giraldez et al. 2006; Tang et al. 2007; Yang et al. 2005).

The deformities caused by absence of all microRNAs (due to the lack of their processing enzyme Dicer) are rescued to some extent if one microRNA, miR-430a is 
injected into embryos (Giraldez et al. 2005). However, the phenotype is not quite rescued completely indicating that other microRNAs are also required for normal embryonic development (Giraldez et al. 2005). Therefore we constructed a microRNA library from a pool of oocytes and early embryos to identify other candidate microRNAs involved in this process.

\section{MicroRNA library construction and sequencing}

We are the first to characterize microRNAs in rainbow trout. A schematic diagram of the method used to construct miRNA library is depicted in fig 3.1. Out of 150 clones sequenced, 32 clones had significant similarities with published microRNAs (Sanger database Version 10.0 (Griffiths-Jones et al. 2006)). All names were assigned based on the homology between the cloned sequence and published microRNA sequences in the Sanger database (table 3.1) using internationally accepted uniform nomenclature (Ambros et al. 2003). Fifteen unique microRNAs were identified from rainbow trout that were conserved across several species (table 3.1). Four microRNAs were novel in rainbow trout in that their sequence had high homology with published microRNAs but differed in at least 1 base pair. Since we obtained more than one copies of the same sequence in the library, it is highly unlikely that these are sequencing errors so we annotated them as omy-miR-100t, omy-miR-21t, omy-miR-125t and omy-miR126t (omy standing for onchorynchus mykiss and names end with $t$ for trout, Table 3.1 and fig 3.3). These microRNAs that are specific to the rainbow trout (omy-miR-100t, omy-miR-21t, omy-miR-125t and omy-miR-126t) are of special interest because of their unique sequence and possibly unique targeting mechanisms. These miRNAs differ in at least one base pair and this difference might have profound impact on target recognition 
and post-transcriptional regulation. Omy-miR-21t has G to A mismatch with miR-21 of cows at position 16 but this mismatch seems to be common to all fishes (miR-21 of zebrafish, fugu and pufferfish, see fig 3.3a). MiR-21 from all these three fishes are $23 \mathrm{bp}$ long whereas in humans and mice, miR-21 is only $22 \mathrm{bp}$ long. However, the A to G mismatch between trout and other fishes at position 22 is absent between trout and mammals (fig 3.3a). In case of omy-miR-100t, there is a $\mathrm{U}$ to $\mathrm{C}$ single base pair mismatch at position 17 and this seems to be specific to rainbow trout (fig $3.3 \mathrm{~b}$ ). So is the case with omy-miR-125t, only that the mismatch is $\mathrm{C}$ to $\mathrm{U}$ at positions 11 and 12 (fig 3.3c). Presence of closely related miR-125b identical to miR-125b of other species (table 3.1 ), and $125 \mathrm{t}$ which is specific to rainbow trout, suggests another layer of complexity in post-transcriptional regulation by microRNAs. Omy-miR-126t sequence is identical to that of chicken, mammals and fish up to position 20, but has an A to G one-base pair mismatch at position 21 as compared to chicken miR-126 (fig 3.3d). These mismatches may not have profound influence on target recognition and mRNA degradation because they are not in the seed sequence (first 6-8bp from 5' end) but they are likely to fine-tune the expression of their targets (Brennecke et al. 2005).

\section{Expression pattern of microRNAs}

Despite our repeated efforts, we were able to amplify only 6 microRNAs out of 15 microRNAs cloned from rainbow trout oocytes and embryos using quantitative realtime PCR. Nine other microRNAs were presumably too low in abundance to be detected by real-time PCR.

Out of 4 microRNAs that are novel in rainbow trout (omy-miR-21t, omy-miR$100 t$ my-miR-125t and omy-miR-126t), only omy-miR-21t and omy-miR-100t could be 
amplified using real-time RT-PCR. Both of these two novel microRNAs have a similar expression pattern (fig 3.4a and 3.4b for miR-100t and miR-21t respectively). Abundance increases from 0 hours post-fertilization until $24 \mathrm{hpf}$ and decreases and stays low thereafter. A significant increase in abundance during early embryonic development suggests an important role in the early development of rainbow trout.

Omy-miR-21 was the most abundant microRNA in our library. The expression pattern of this miRNA supports the hypothesis that several microRNAs might be involved in degradation of maternal effect genes during early embryonic development (fig 3.4c). This pattern is in agreement with that of the zebrafish embryos at similar developmental stages (Chen et al. 2005). MiR-21 is one of the most ubiquitous microRNAs being implicated as an anti-apoptotic factor (Chan et al. 2005; Si et al. 2007) and an oncogene (Zhu et al. 2007). Suppression of miR-21 causes down-regulation of apoptosis related proteins like bcl2 leading to increased apoptosis ( $\mathrm{Si}$ et al. 2007). However in HeLa cells, inhibition of miR-21 causes a profound increase in cell growth (Cheng et al. 2005). Rapidly dividing embryos mimic cancer cells but in rainbow trout, miR-21 is down regulated when the active large scale division begins (fig 3.4c). It is possible that expression of miR-21 is essential to coordinate the cell division/cell growth in early embryos. High abundance of miR-21 at the time of maternal mRNAs degradation supports our initial hypothesis.

MiR-23 is known to target important genes in neuronal development (Kawasaki and Taira 2003). It is present in adult fish tissues and frog ovaries (Lagos-Quintana et al. 2001) and neuronal cells (Smirnova et al. 2005). Mir-23 is also known to down-regulate cell growth when inhibited in cell lines (Cheng et al. 2005). In rainbow trout embryos, 
miR-23 is abundantly expressed up to 24 hours post fertilization but is down regulated afterwards (fig 3.4d). With limited understanding of the functions of this microRNA in early embryonic development, the importance of this pattern is not clear. Nevertheless, miR-23 follows the characteristic up-regulation of microRNAs at the time of embryonic genome activation.

The transcript level of miR-26 is abundant only at $12 \mathrm{hpf}$ indicating a specific role for this miRNA at a small window during development (fig 3.4e). MiR-26 is induced under hypoxic conditions and reduces pro-apoptotic signals (Kulshreshtha et al. 2007). Expression of miR-26 gains relevance because fish eggs undergo fertilization and embryonic development in aquatic environments where dissolved oxygen is often in short supply, Mir-26 also produces caspase inhibitory effects (Fabbri et al. 2007) which could have important consequences in early metabolism of stored glycoproteins in trout embryos.

Mir-92 is previously shown to be ubiquitously expressed in adult tissues and embryonic stem cells indicating that it controls some basic cell functions common to stem cells and other adult tissues (Houbaviy et al. 2003). Expression of miR-92 is universal in early fish embryos and becomes restricted to highly proliferative tissues late in development (Ason et al. 2006). Polycystronic expression of miR-17-92 is associated with some types of cancers (He et al. 2005; Venturini et al. 2007). Transgenic overexpression of this cluster promotes cell proliferation and prevents differentiation in lung epithelial progenitor cells ( $\mathrm{Lu}$ et al. 2007). In rainbow trout, the expression of miR-92 is relatively high at 12 hours post-fertilization, which is the time of the first few divisions 
(fig 3.4f). We suggest that miR-92 is involved in making an embryo competent of proliferation and it might also play a role in keeping these early cells un-differentiated.

\section{Expression pattern of stat 3}

It was recently shown that activation of microRNA-21 is necessary for the survival of myeloma cells (Loffler et al. 2007). This induction is mediated by a conserved enhancer and signal transducer and activator of transcription 3 (stat3) is involved in this process. Stat3 proteins are transcription factors that virtually activate transcription and they become functional with tyrosine phosphorylation by various cytokines (Bromberg and Chen 2001; Kretzschmar et al. 2004). Expression of miR-21 is indirectly but strictly dependent on stat3 (Loffler et al. 2007). In rainbow trout, stat3 transcript level is abundant when the miR-21 begins to accumulate as shown in figure $3.4 \mathrm{c}$ and 3.5 . Between 24 and 48 hours post-fertilization, the abundance of stat 3 transcripts decrease and so does the miR-21 abundance (Fig 3.4c). It is possible that stat3 is involved in activation of other microRNAs and thereby regulating degradation of maternal mRNAs in early embryos.

\section{Conclusions}

In this study we present cloning and expression pattern of microRNAs from rainbow trout. Four novel microRNAs are reported here emphasizing species specific distribution and potential functions of microRNAs. We were able to amplify all six microRNAs at 12-24 hpf consistent with a role in degradation of maternal mRNAs. Stat3 is also abundantly expressed at the time of expression of microRNAs in rainbow trout embryos indicating a possible role for stat3 in early embryonic development. Therefore we suggest that the activation of stat3 leads to the activation of several microRNAs, 
including miR-21. We also conclude that these microRNAs play a major role in degrading maternal mRNAs at the time of embryonic genomic activation. 


\section{Table and figures}

Table 3-1 Rainbow trout microRNAs. Sequences, length, primers used for real time PCR and conservation across species.

\begin{tabular}{|l|l|c|l|l|l|}
\hline \multicolumn{1}{|c|}{ miRNA $^{1}$} & \multicolumn{2}{|c|}{ Sequence } & Size & \multicolumn{1}{c|}{ Real Time Primer Sequence } & \multicolumn{1}{c|}{ Conserved in other species. $^{2}$} \\
\hline omy-miR-21 & UAGCUUAUCAGACUGGUGUUGGC & 23 & TAGCTTATCAGACTGGTGTTGGC & dre, fru, tni \\
\hline omy-miR-21t & UAGCUUAUCAGACUGGUGUUGAC & 23 & TAGCTTATCAGACTGGTGTTGAC & See fig 3A \\
\hline omy-miR-23a & AUCACAUUGCCAGGGAUUUCCA & 22 & ATCACATTGCCAGGGATTTCA & dre, fru, tni, bta \\
\hline omy-miR-26a & UUCAAGUAAUCCAGGAUAGGCU & 22 & TTCAAGTAATCCAGGATAGGCT & $\begin{array}{l}\text { dre, ssc, ptr, ggo, lla, mml, ppa, fru, tni, } \\
\text { bta }\end{array}$ \\
\hline omy-miR-30d & UGUAAACAUCCCCGACUGGAAG & 22 & TGTAAACATCCCCGACTGGAAG & $\begin{array}{l}\text { bta, hsa, mmu, rno, gga dre, ptr, ggo, } \\
\text { mne, ppa, fru, tni, xtr }\end{array}$ \\
\hline omy-miR-92a & UAUUGCACUUGUCCCGGCCUGU & 22 & TATTGCACTTGTCCCGGCCTGT & $\begin{array}{l}\text { dre, ggo, lme, age, ppa, ppy, ptr, mml, } \\
\text { sla, lla, mne, fru, tni, bta }\end{array}$ \\
\hline omy-miR-100t & AACCCGUAGAUCCGAAUUUGU & 21 & AACCCGTAGATCCGAATTGT & See fig 3B \\
\hline omy-miR-125a & UCCCUGAGACCCUUAACCUGUG & 22 & TCCCTGAGACCCTTAACCTGTG & dre, fru, tni, xtr \\
\hline omy-miR-125b & UCCCUGAGACCCUAACUUGUGA & 22 & TCCCTGAGACCCTAACTTGTGA & $\begin{array}{l}\text { dre, dme, hsa, rno, gga, dps, aga, dre, } \\
\text { ssc, ggo, ppa, ssc, age, ppy, ptr, mml, } \\
\text { sla, lla, mne, lca, fru, tni, bta, xtr, mdo }\end{array}$ \\
\hline omy-miR-125t & UCCCUGAGACUUUAACUUGUGA & 22 & TCCCTGAGACTTTAACTTGTGA & See fig 3C \\
\hline omy-miR-126t & UCGUACCGUGAGUAAUAAUGCAC & 23 & TCGTACCGTGAGTAATAATGCAC & See fig 3D \\
\hline omy-miR-126* & CAUUAUUACUUUUGGUACGCG & 21 & CATTATTACTTTTGGTACGCG & mmu, hsa, rno, gga, dre, xtr \\
\hline omy-miR-200b & UAAUACUGCCUGGUAAUGAUGAU & 23 & TAATACTGCCTGGTAATGATGAT & gga, xtr \\
\hline omy-miR-214* & GCCUGUCUACACUUGCUGUGC & 21 & GCCTGTCTACACTTGCTGTGC & mmu, has \\
\hline omy-miR-455 & UAUGUGCCCUUGGACUACAUCG & 22 & TATGTGCCCTTGGACTACATCG & dre, fru, tni, gga, xtr \\
\hline
\end{tabular}

\footnotetext{
${ }^{1}$ MiRNA annotations were based upon universally accepted nomenclatures as published in

2 Annotations: aga- Anopheles gambiae, age- Ateles geoffroyi, dme- Drosophila melanogaster, dps- Drosophila pseudoobscura, fruFugu rubripes, ggo-Gorilla gorilla, lca- Lemur catta, lla- Lagothrix lagotricha, lla-Lagothrix lagotricha, lme- Lemur catta, mdoMonodelphis domestica, mml- Macaca mulatta, mml- Macaca mulatta, mne- Macaca nemestrina, ppa- Pan paniscus, ppy- Pongo pygmaeus, ptr-Pan troglodytes, ptr-Pan troglodytes, ptr-Pongo pygmaeus, rno-Rattus norvegicus, sla-Saguinus labiatus, ssc-Sus scrofa, tni-Tetraodon nigroviridis.
} 


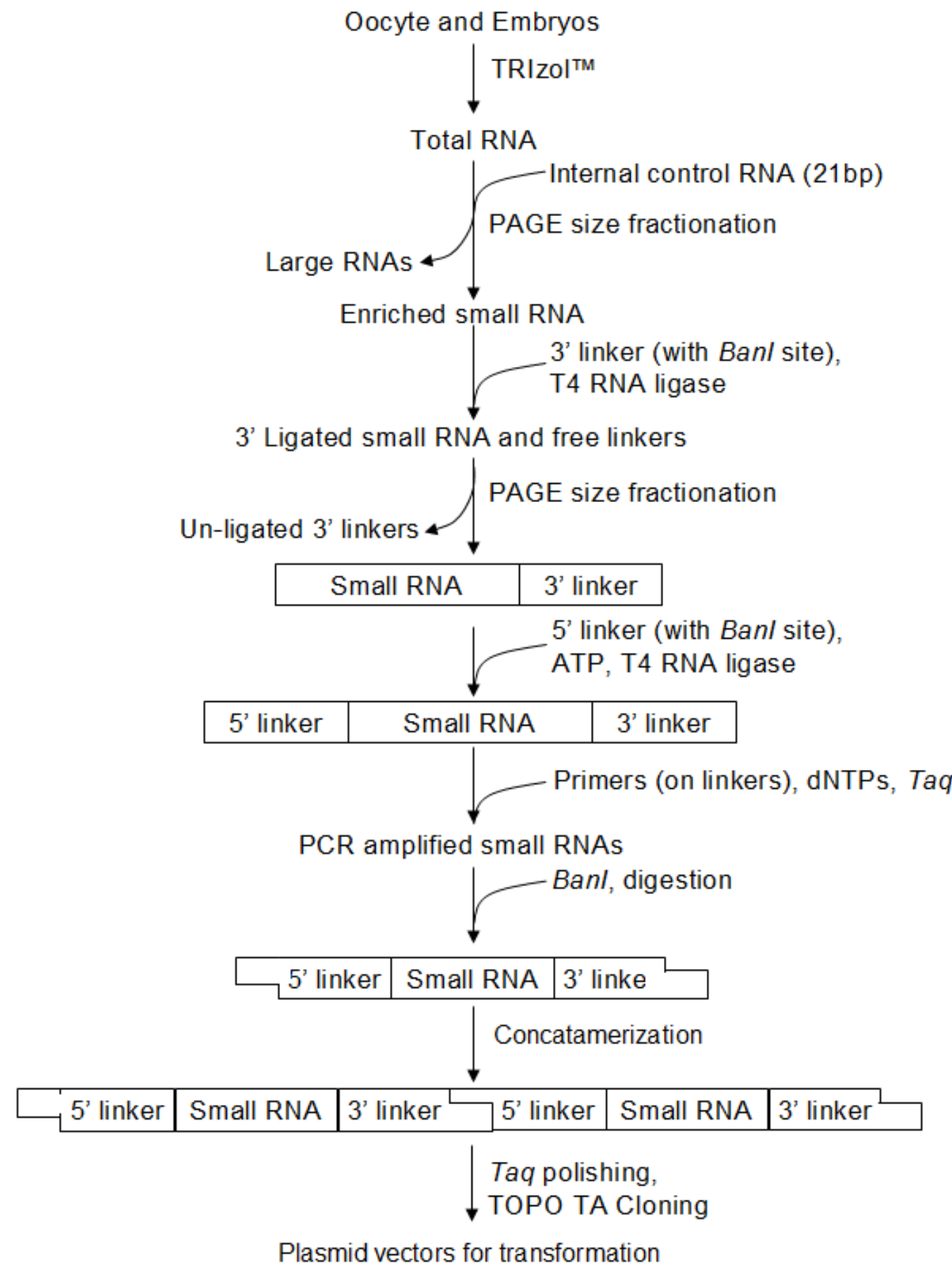

Figure 3-1 Schematic diagram showing method used to clone small RNAs. MirCat TM (IDT DNA Technologies, Coralville IA) microRNA cloning kit was used with modifications. 


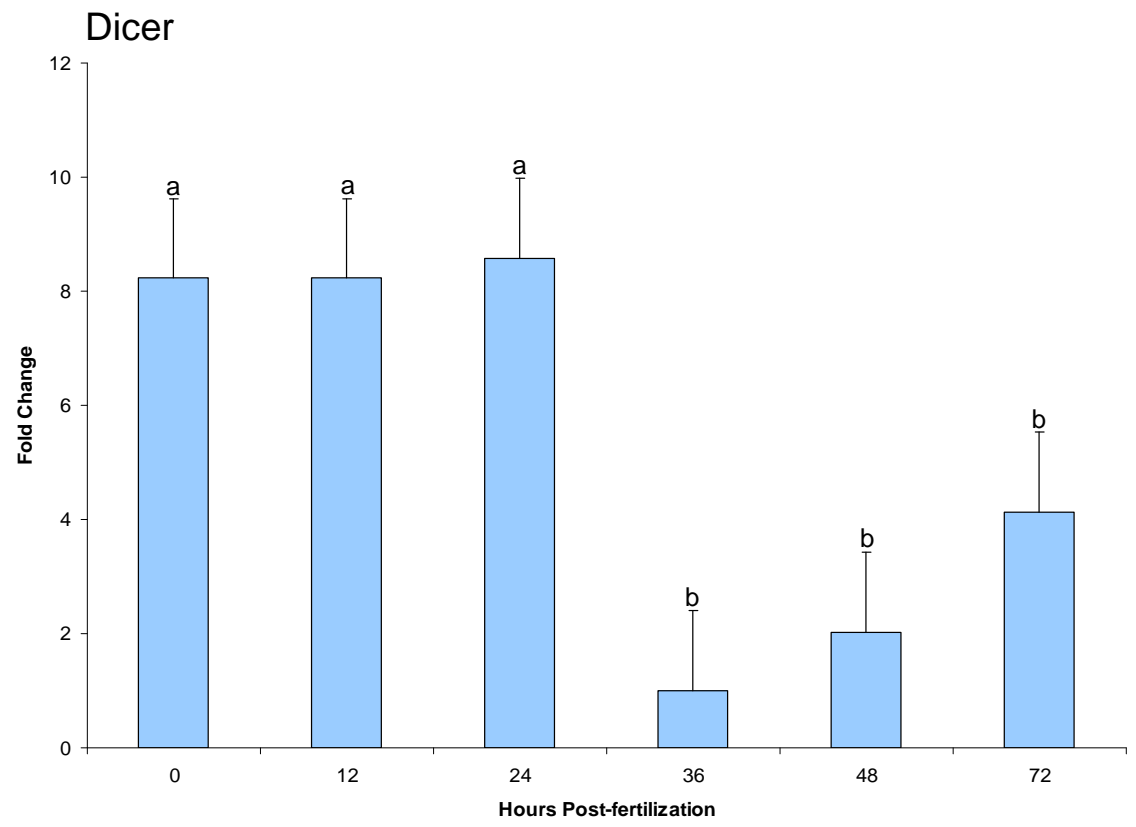

Figure 3-2 Expression pattern (fold change) of Dicer transcripts as shown by real-time PCR. Stages examined are indicated hours post-fertilization $(0,12,24,36,48$ and $72 \mathrm{hpf})$. Quantity of dicer mRNA was normalized to histone $2 \mathrm{a}$. The means of the normalized gene expression values for oocyte/each stage of embryo were calculated and expressed as relative fold changes \pm sem. Different letters indicate significant difference $(P<0.05)$. 


\begin{tabular}{|c|c|}
\hline $\begin{array}{l}\text { A } \\
\text { omy-miR-21t } \\
\text { bta-miR-21 } \\
\text { dre-miR-21 } \\
\text { fru-miR-21 } \\
\text { tni-miR-21 } \\
\text { mu-miR-21 } \\
\text { hsa-miR-21 }\end{array}$ & $\begin{array}{l}1-1-1-1-\cdots \\
\text { UAGCUUAUCAGACUGGUGUUGACU } \\
\text { UAGCUUAUCAGACUGAUGUUGACU } \\
\text { UAGCUUAUCAGACUGGUGUUGGC } \\
\text { UAGCUUAUCAGACUGGUGUUGGC } \\
\text { UAGCUUAUCAGACUGGUGUUGGC } \\
\text { UAGCUUAUCAGACUGAUGUUGA } \\
\text { UAGCUUAUCAGACUGAUGUUGA }\end{array}$ \\
\hline $\begin{array}{l}\text { B } \\
\text { omy-miR-100t } \\
\text { hsa-miR-100 } \\
\text { mmu-miR-100 } \\
\text { dre-miR-100 } \\
\text { tni-miR-100 } \\
\text { xtr-miR-100 }\end{array}$ &  \\
\hline $\begin{array}{l}\text { C } \\
\text { omy-miR-125t } \\
\text { mmu-miR-125b } \\
\text { hsa-miR-125b } \\
\text { fru-miR-125b } \\
\text { tni-miR-125b } \\
\text { dre-miR-125b } \\
\text { dre-miR-125c }\end{array}$ & 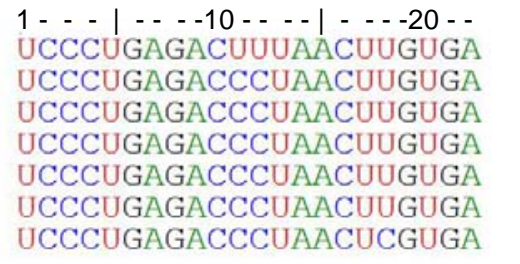 \\
\hline $\begin{array}{l}\text { D } \\
\text { omy-miR-126t } \\
\text { qqa-miR-126 } \\
\text { mmu-miR-126-3p } \\
\text { hsa-miR-126 } \\
\text { dre-miR-126 } \\
\text { fru-miR-126 } \\
\text { tni-miR-126 }\end{array}$ & $\begin{array}{l}1--1-\cdots-10-\cdots \\
\text { UCGUACCGUGAGUAAUAAUGCAC } \\
\text { UCGUACCGUGAGUAAUAAUGCGC } \\
\text { UCGUACCGUGAGUAAUAAUGC } \\
\text { UCGUACCGUGAGUAAUAAUGC } \\
\text { UCGUACCGUGAGUAAUAAUGC } \\
\text { UCGUACCGUGAGUAAUAAUGC } \\
\text { UCGUACCGUGAGUAAUAAUGC }\end{array}$ \\
\hline
\end{tabular}

Figure 3-3 Alignment of novel rainbow trout microRNAs. Highly homologous miRNAs from other species are aligned using BioEdit program. 

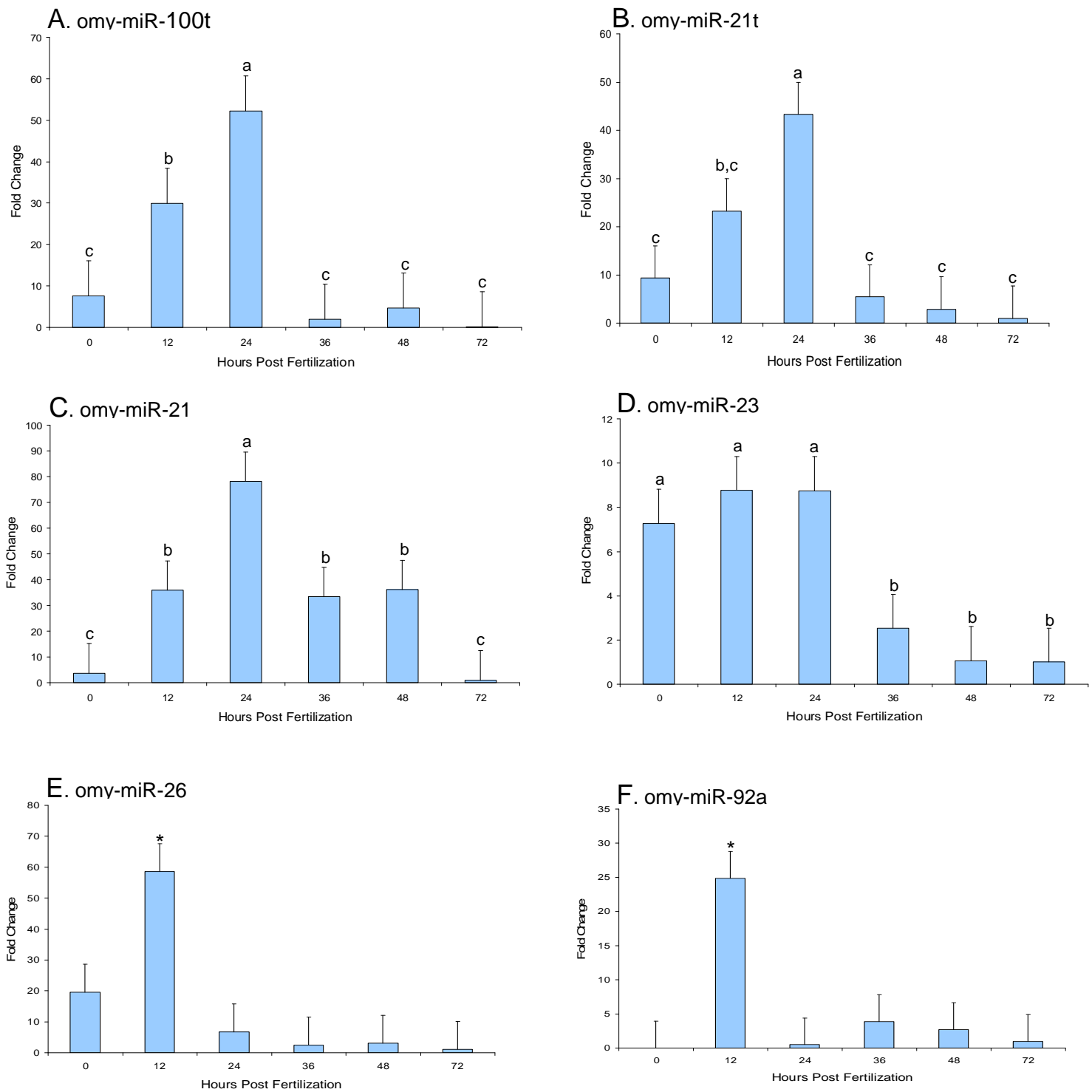

Figure 3-4 Expression patterns (fold change) of microRNAs as shown by real-time PCR. Stages examined are indicated as hours post-fertilization $(0,12,24,36,48$ and $72 \mathrm{hpf})$. Quantity of each microRNA was normalized to histone $2 \mathrm{a}$. The means of the normalized gene expression values for oocyte/each stage of embryo were calculated and expressed as relative fold changes \pm sem (A: omymiR-100t, B: omy-miR-21t, C: omy-miR-21, D: omy-miR-23, E: omy-miR-26 and F: omy-miR-92a). Different letters indicate significant difference at $\mathbf{P}<0.05$ ) and star $(*)$ indicates significant difference from all other stages at $\mathbf{p}<0.05$. 


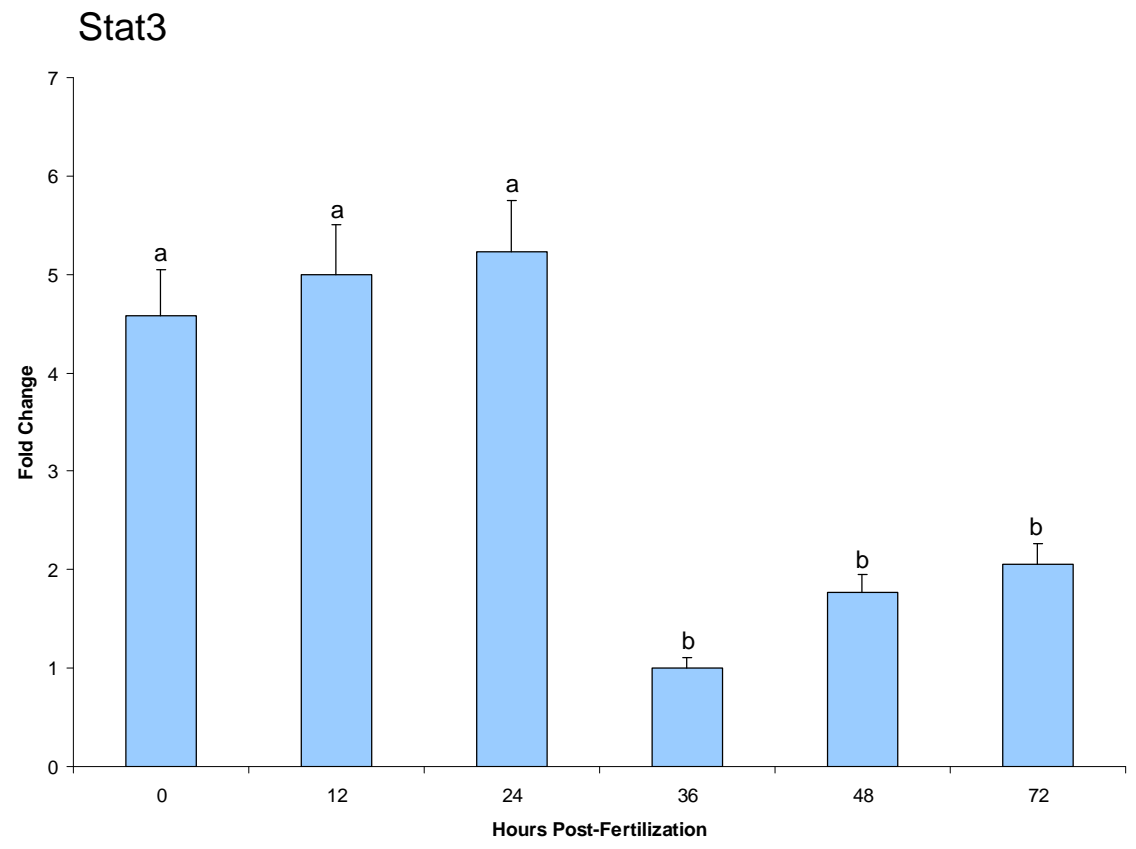

Figure 3-5 Expression pattern (fold change) of Stat3 transcripts as shown by real-time PCR. Stages examined are indicated hours post-fertilization $(0,12,24,36,48$ and $72 \mathrm{hpf})$. Quantity of Stat3 mRNA was normalized to histone $2 \mathrm{a}$. The means of the normalized gene expression values for oocyte/each stage of embryo were calculated and expressed as relative fold changes \pm sem. Different letters indicate significant difference $(P<0.05)$. 


\section{CONCLUSIONS}

Historically, it is accepted that the interaction between the oocyte and surrounding somatic cells is required for normal reproduction (see review). Oocyte signals from instruct surrounding cells to allow normal maturation, ovulation, fertilization and embryonic development. Apart from a few identified genes, this oocyte-to-somatic cell interaction remains elusive. So it was the objective of the first project to identify novel genes expressed in rainbow trout oocyte and characterize them to help us better understand oocyte-somatic interaction. We identified OORP-T, a novel oocyte specific gene containing oxysterol binding domain that is accumulated in oocytes during vitellogenesis and persistent until embryonic genome activation. With lipid stored as food for the embryo and with steroidal hormones acting, OORP-T might make a significant contribution to the normal development of rainbow trout embryos.

Dependence on maternal mRNAs ends after the embryonic genome is capable of synthesizing transcripts on its own. Reasons for the absence of transcription before embryonic genome activation are not well understood. One possible reason could be the absence of sufficient transcription machinery prior to that stage. To evaluate this hypothesis, we quantitatively measured the abundance of several transcription factors and architectural proteins during embryonic genome activation in rainbow trout. Our results show that mRNAs of all transcription factors and architectural proteins measured were present in detectable amounts before the activation. It is therefore possible that other mechanisms might regulate the availability of these factors for transcription.

We also observed that all the transcripts were degraded at the time of activation, even if they are produced later on. We hypothesized that this large-scale, but specific 
degradation, is regulated by microRNAs. MicroRNAs bind to their recognition sequences on 3' un-translated regions of the target genes and mediate degradation or translational repression. We measured transcript levels of Dicer, an enzyme required for procession of all microRNAs during development. We found that Dicer is abundantly expressed during the time of genome activation indicating that microRNAs are processed during these stages. Since no genomic sequence is available for rainbow trout, we constructed a microRNA library from a pool of oocytes and early embryos. We identified 15 unique microRNAs from rainbow trout, four of which are specific to rainbow trout. We performed quantitative real time PCR to characterize the expression pattern of these microRNAs and found that all the microRNAs we could amplify were present before/during genome activation. Our results show that Stat3, an activator of transcription that is known to induce the expression of miR-21, is expressed during early developmental stages in rainbow trout. We propose that stat3 mediates the expression of miR-21 and possibly other microRNAs thereby inducing the degradation of maternal mRNAs during embryonic genome activation. 


\section{LIST OF REFERENCES}

Aboobaker AA, Tomancak P, Patel N, Rubin GM, Lai EC. 2005. Drosophila microRNAs exhibit diverse spatial expression patterns during embryonic development. Proc Natl Acad Sci U S A 102(50):18017-18022.

Aizawa K, Shimada A, Naruse K, Mitani H, Shima A. 2003. The medaka midblastula transition as revealed by the expression of the paternal genome. Gene Expr Patterns 3(1):43-47.

Ambros V. 2004. The functions of animal microRNAs. Nature 431(7006):350-355.

Ambros V, Bartel B, Bartel DP, Burge CB, Carrington JC, Chen X, Dreyfuss G, Eddy SR, Griffiths-Jones S, Marshall M, Matzke M, Ruvkun G, Tuschl T. 2003. A uniform system for microRNA annotation. RNA 9(3):277-279.

Ason B, Darnell DK, Wittbrodt B, Berezikov E, Kloosterman WP, Wittbrodt J, Antin PB, Plasterk RH. 2006. Differences in vertebrate microRNA expression. Proc Natl Acad Sci U S A 103(39):14385-14389.

Bailey GS, Williams DE, Hendricks JD. 1996. Fish models for environmental carcinogenesis: the rainbow trout. Environ Health Perspect 104 Suppl 1:5-21.

Barad O, Meiri E, Avniel A, Aharonov R, Barzilai A, Bentwich I, Einav U, Gilad S, Hurban P, Karov Y, Lobenhofer EK, Sharon E, Shiboleth YM, Shtutman M, Bentwich Z, Einat P. 2004. MicroRNA expression detected by oligonucleotide microarrays: system establishment and expression profiling in human tissues. Genome Res 14(12):2486-2494.

Bashirullah A, Halsell SR, Cooperstock RL, Kloc M, Karaiskakis A, Fisher WW, Fu W, Hamilton JK, Etkin LD, Lipshitz HD. 1999. Joint action of two RNA degradation pathways controls the timing of maternal transcript elimination at the midblastula transition in Drosophila melanogaster. EMBO J 18(9):2610-2620.

Baskerville S, Bartel DP. 2005. Microarray profiling of microRNAs reveals frequent coexpression with neighboring miRNAs and host genes. RNA 11(3):241-247.

Bauskin AR, Franken DR, Eberspaecher U, Donner P. 1999. Characterization of human zona pellucida glycoproteins. Mol Hum Reprod 5(6):534-540.

Beh CT, Cool L, Phillips J, Rine J. 2001. Overlapping functions of the yeast oxysterolbinding protein homologues. Genetics 157(3):1117-1140.

Bentwich I. 2005. Prediction and validation of microRNAs and their targets. FEBS Lett 579(26):5904-5910.

Bentwich I, Avniel A, Karov Y, Aharonov R, Gilad S, Barad O, Barzilai A, Einat P, Einav U, Meiri E, Sharon E, Spector Y, Bentwich Z. 2005. Identification of hundreds of conserved and nonconserved human microRNAs. Nat Genet 37(7):766-770.

Berezikov E, van Tetering G, Verheul M, van de Belt J, van Laake L, Vos J, Verloop R, van de Wetering M, Guryev V, Takada S, van Zonneveld AJ, Mano H, Plasterk R, Cuppen E. 2006. Many novel mammalian microRNA candidates identified by extensive cloning and RAKE analysis. Genome Res 16(10):1289-1298.

Bernstein E, Caudy AA, Hammond SM, Hannon GJ. 2001. Role for a bidentate ribonuclease in the initiation step of RNA interference. Nature 409(6818):363366. 
Bernstein E, Kim SY, Carmell MA, Murchison EP, Alcorn H, Li MZ, Mills AA, Elledge SJ, Anderson KV, Hannon GJ. 2003. Dicer is essential for mouse development. Nat Genet 35(3):215-217.

Bewley CA, Gronenborn AM, Clore GM. 1998. Minor groove-binding architectural proteins: structure, function, and DNA recognition. Annu Rev Biophys Biomol Struct 27:105-131.

Bianchi ME, Beltrame M. 1998. Flexing DNA: HMG-box proteins and their partners. Am J Hum Genet 63(6):1573-1577.

Bianchi ME, Beltrame M. 2000. Upwardly mobile proteins. Workshop: the role of HMG proteins in chromatin structure, gene expression and neoplasia. EMBO Rep 1(2):109-114.

Bleil JD, Beall CF, Wassarman PM. 1981. Mammalian sperm-egg interaction: fertilization of mouse eggs triggers modification of the major zona pellucida glycoprotein, ZP2. Dev Biol 86(1):189-197.

Bleil JD, Wassarman PM. 1980. Synthesis of zona pellucida proteins by denuded and follicle-enclosed mouse oocytes during culture in vitro. Proc Natl Acad Sci U S A 77(2):1029-1033.

Bohnsack MT, Czaplinski K, Gorlich D. 2004. Exportin 5 is a RanGTP-dependent dsRNA-binding protein that mediates nuclear export of pre-miRNAs. RNA 10(2):185-191.

Bolton VN, Oades PJ, Johnson MH. 1984. The relationship between cleavage, DNA replication, and gene expression in the mouse 2-cell embryo. J Embryol Exp Morphol 79:139-163.

Brennecke J, Stark A, Russell RB, Cohen SM. 2005. Principles of microRNA-target recognition. PLoS Biol 3(3):e85.

Bromberg J, Chen X. 2001. STAT proteins: signal tranducers and activators of transcription. Methods Enzymol 333:138-151.

Buccione R, Schroeder AC, Eppig JJ. 1990a. Interactions between somatic cells and germ cells throughout mammalian oogenesis. Biol Reprod 43(4):543-547.

Buccione R, Vanderhyden BC, Caron PJ, Eppig JJ. 1990b. FSH-induced expansion of the mouse cumulus oophorus in vitro is dependent upon a specific factor(s) secreted by the oocyte. Dev Biol 138(1):16-25.

Bultman SJ, Gebuhr TC, Pan H, Svoboda P, Schultz RM, Magnuson T. 2006. Maternal BRG1 regulates zygotic genome activation in the mouse. Genes Dev 20(13):1744-1754.

Burns KH, Viveiros MM, Ren Y, Wang P, DeMayo FJ, Frail DE, Eppig JJ, Matzuk MM. 2003. Roles of NPM2 in chromatin and nucleolar organization in oocytes and embryos. Science 300(5619):633-636.

Buschiazzo J, Alonso TS. 2005. Effect of meiotic maturation on yolk platelet lipids from Bufo arenarum oocytes. J Exp Zoolog A Comp Exp Biol 303(9):813-822.

Bustin M. 2001. Chromatin unfolding and activation by $\operatorname{HMGN}\left({ }^{*}\right)$ chromosomal proteins. Trends Biochem Sci 26(7):431-437.

Bustin M, Trieschmann L, Postnikov YV. 1995. The HMG-14/-17 chromosomal protein family: architectural elements that enhance transcription from chromatin templates. Semin Cell Biol 6(4):247-255. 
Cai X, Hagedorn CH, Cullen BR. 2004. Human microRNAs are processed from capped, polyadenylated transcripts that can also function as mRNAs. RNA 10(12):19571966.

Canipari R, Epifano O, Siracusa G, Salustri A. 1995. Mouse oocytes inhibit plasminogen activator production by ovarian cumulus and granulosa cells. Dev Biol 167(1):371-378.

Chan JA, Krichevsky AM, Kosik KS. 2005. MicroRNA-21 is an antiapoptotic factor in human glioblastoma cells. Cancer Res 65(14):6029-6033.

Chang S, Johnston RJ, Jr., Frokjaer-Jensen C, Lockery S, Hobert O. 2004. MicroRNAs act sequentially and asymmetrically to control chemosensory laterality in the nematode. Nature 430(7001):785-789.

Chen CZ, Li L, Lodish HF, Bartel DP. 2004. MicroRNAs modulate hematopoietic lineage differentiation. Science 303(5654):83-86.

Chen L, Russell PT, Larsen WJ. 1993. Functional significance of cumulus expansion in the mouse: roles for the preovulatory synthesis of hyaluronic acid within the cumulus mass. Mol Reprod Dev 34(1):87-93.

Chen L, Zhang H, Powers RW, Russell PT, Larsen WJ. 1996. Covalent linkage between proteins of the inter-alpha-inhibitor family and hyaluronic acid is mediated by a factor produced by granulosa cells. J Biol Chem 271(32):19409-19414.

Chen PY, Manninga H, Slanchev K, Chien M, Russo JJ, Ju J, Sheridan R, John B, Marks DS, Gaidatzis D, Sander C, Zavolan M, Tuschl T. 2005. The developmental miRNA profiles of zebrafish as determined by small RNA cloning. Genes Dev 19(11):1288-1293.

Cheng AM, Byrom MW, Shelton J, Ford LP. 2005. Antisense inhibition of human miRNAs and indications for an involvement of miRNA in cell growth and apoptosis. Nucleic Acids Res 33(4):1290-1297.

Combelles CM, Carabatsos MJ, Kumar TR, Matzuk MM, Albertini DF. 2004. Hormonal control of somatic cell oocyte interactions during ovarian follicle development. Mol Reprod Dev 69(3):347-355.

Cooke HJ, Lee M, Kerr S, Ruggiu M. 1996. A murine homologue of the human DAZ gene is autosomal and expressed only in male and female gonads. Hum Mol Genet 5(4):513-516.

Cullen BR. 2006. Viruses and microRNAs. Nat Genet 38 Suppl:S25-30.

D'Alessandris C, Canipari R, Di Giacomo M, Epifano O, Camaioni A, Siracusa G, Salustri A. 2001. Control of mouse cumulus cell-oocyte complex integrity before and after ovulation: plasminogen activator synthesis and matrix degradation. Endocrinology 142(7):3033-3040.

Davis GH, McEwan JC, Fennessy PF, Dodds KG, McNatty KP, O WS. 1992. Infertility due to bilateral ovarian hypoplasia in sheep homozygous (FecXI FecXI) for the Inverdale prolificacy gene located on the X chromosome. Biol Reprod 46(4):636640.

Dean J. 2002. Oocyte-specific genes regulate follicle formation, fertility and early mouse development. J Reprod Immunol 53(1-2):171-180.

Dong J, Albertini DF, Nishimori K, Kumar TR, Lu N, Matzuk MM. 1996. Growth differentiation factor-9 is required during early ovarian folliculogenesis. Nature 383(6600):531-535. 
Donohoe ME, Zhang X, McGinnis L, Biggers J, Li E, Shi Y. 1999. Targeted disruption of mouse Yin Yang 1 transcription factor results in peri-implantation lethality. Mol Cell Biol 19(10):7237-7244.

el-Fouly MA, Cook B, Nekola M, Nalbandov AV. 1970. Role of the ovum in follicular luteinization. Endocrinology 87(2):286-293.

Elvin JA, Clark AT, Wang P, Wolfman NM, Matzuk MM. 1999. Paracrine actions of growth differentiation factor-9 in the mammalian ovary. Mol Endocrinol 13(6): 1035-1048.

Elvin JA, Yan C, Matzuk MM. 2000a. Growth differentiation factor-9 stimulates progesterone synthesis in granulosa cells via a prostaglandin E2/EP2 receptor pathway. Proc Natl Acad Sci U S A 97(18):10288-10293.

Elvin JA, Yan C, Matzuk MM. 2000b. Oocyte-expressed TGF-beta superfamily members in female fertility. Mol Cell Endocrinol 159(1-2):1-5.

Eppig JJ. 2001. Oocyte control of ovarian follicular development and function in mammals. Reproduction 122(6):829-838.

Eppig JJ, Wigglesworth K, Pendola F, Hirao Y. 1997. Murine oocytes suppress expression of luteinizing hormone receptor messenger ribonucleic acid by granulosa cells. Biol Reprod 56(4):976-984.

Etkin LD, Balcells S. 1985. Transformed Xenopus embryos as a transient expression system to analyze gene expression at the midblastula transition. Dev Biol 108(1):173-178.

Fabbri M, Ivan M, Cimmino A, Negrini M, Calin GA. 2007. Regulatory mechanisms of microRNAs involvement in cancer. Expert Opin Biol Ther 7(7):1009-1019.

Familiari G, Relucenti M, Heyn R, Micara G, Correr S. 2006. Three-dimensional structure of the zona pellucida at ovulation. Microsc Res Tech 69(6):415-426.

Ferg M, Sanges R, Gehrig J, Kiss J, Bauer M, Lovas A, Szabo M, Yang L, Straehle U, Pankratz MJ, Olasz F, Stupka E, Muller F. 2007. The TATA-binding protein regulates maternal mRNA degradation and differential zygotic transcription in zebrafish. EMBO J.

Fujiwara Y, Browne CP, Cunniff K, Goff SC, Orkin SH. 1996. Arrested development of embryonic red cell precursors in mouse embryos lacking transcription factor GATA-1. Proc Natl Acad Sci U S A 93(22):12355-12358.

Furman A, Rotmensch S, Kohen F, Mashiach S, Amsterdam A. 1986. Regulation of rat granulosa cell differentiation by extracellular matrix produced by bovine corneal endothelial cells. Endocrinology 118(5):1878-1885.

Galloway SM, McNatty KP, Cambridge LM, Laitinen MP, Juengel JL, Jokiranta TS, McLaren RJ, Luiro K, Dodds KG, Montgomery GW, Beattie AE, Davis GH, Ritvos O. 2000. Mutations in an oocyte-derived growth factor gene (BMP15) cause increased ovulation rate and infertility in a dosage-sensitive manner. Nat Genet 25(3):279-283.

Gebauer F, Xu W, Cooper GM, Richter JD. 1994. Translational control by cytoplasmic polyadenylation of c-mos mRNA is necessary for oocyte maturation in the mouse. Embo J 13(23):5712-5720.

Giraldez AJ, Cinalli RM, Glasner ME, Enright AJ, Thomson JM, Baskerville S, Hammond SM, Bartel DP, Schier AF. 2005. MicroRNAs regulate brain morphogenesis in zebrafish. Science 308(5723):833-838. 
Giraldez AJ, Mishima Y, Rihel J, Grocock RJ, Van Dongen S, Inoue K, Enright AJ, Schier AF. 2006. Zebrafish MiR-430 promotes deadenylation and clearance of maternal mRNAs. Science 312(5770):75-79.

Grad Y, Aach J, Hayes GD, Reinhart BJ, Church GM, Ruvkun G, Kim J. 2003. Computational and experimental identification of C. elegans microRNAs. Mol Cell 11(5):1253-1263.

Gregory RI, Shiekhattar R. 2005. MicroRNA biogenesis and cancer. Cancer Res 65(9):3509-3512.

Griffiths-Jones S. 2004. The microRNA Registry. Nucleic Acids Res 32(Database issue):D109-111.

Griffiths-Jones S, Grocock RJ, van Dongen S, Bateman A, Enright AJ. 2006. miRBase: microRNA sequences, targets and gene nomenclature. Nucleic Acids Res 34(Database issue):D140-144.

Grosschedl R, Giese K, Pagel J. 1994. HMG domain proteins: architectural elements in the assembly of nucleoprotein structures. Trends Genet 10(3):94-100.

Hai T, Hartman MG. 2001. The molecular biology and nomenclature of the activating transcription factor/cAMP responsive element binding family of transcription factors: activating transcription factor proteins and homeostasis. Gene 273(1):111.

Hamatani T, Carter MG, Sharov AA, Ko MS. 2004. Dynamics of global gene expression changes during mouse preimplantation development. Dev Cell 6(1):117-131.

Hammond SM. 2005. Dicing and slicing: the core machinery of the RNA interference pathway. FEBS Lett 579(26):5822-5829.

Handel MA, Eppig JJ. 1998. Sexual dimorphism in the regulation of mammalian meiosis. Curr Top Dev Biol 37:333-358.

Hanrahan JP, Gregan SM, Mulsant P, Mullen M, Davis GH, Powell R, Galloway SM. 2004. Mutations in the genes for oocyte-derived growth factors GDF9 and BMP15 are associated with both increased ovulation rate and sterility in Cambridge and Belclare sheep (Ovis aries). Biol Reprod 70(4):900-909.

Hayashi M, McGee EA, Min G, Klein C, Rose UM, van Duin M, Hsueh AJ. 1999. Recombinant growth differentiation factor-9 (GDF-9) enhances growth and differentiation of cultured early ovarian follicles. Endocrinology 140(3):12361244.

He L, Thomson JM, Hemann MT, Hernando-Monge E, Mu D, Goodson S, Powers S, Cordon-Cardo C, Lowe SW, Hannon GJ, Hammond SM. 2005. A microRNA polycistron as a potential human oncogene. Nature 435(7043):828-833.

Hidaka Y, Tanaka S, Suzuki M. 2004. Sequence and expression of the rainbow trout winged helix/forkhead transcription factor FoxF1. Gene Expr Patterns 5(1):29-34.

Hikosaka A, Takaya K, Jinno M, Kawahara A. 2007. Identification and expressionprofiling of Xenopus tropicalis miRNAs including plant miRNA-like RNAs at metamorphosis. FEBS Lett 581(16):3013-3018.

Hirshfield AN. 1986. Patterns of $[3 \mathrm{H}]$ thymidine incorporation differ in immature rats and mature, cycling rats. Biol Reprod 34(1):229-235.

HMG-Homepage J. 2007. High mobility group chromosomal proteins nomenclature homepage. Bar Harbor: The Jackson Laboratories. $p$ http://www.informatics.jax.org/mgihome/nomen/genefamilies/hmgfamily.shtml. 
Houbaviy HB, Murray MF, Sharp PA. 2003. Embryonic stem cell-specific MicroRNAs. Dev Cell 5(2):351-358.

Huntriss J, Gosden R, Hinkins M, Oliver B, Miller D, Rutherford AJ, Picton HM. 2002. Isolation, characterization and expression of the human Factor In the Germline alpha (FIGLA) gene in ovarian follicles and oocytes. Mol Hum Reprod 8(12):1087-1095.

Hutvagner G. 2005. Small RNA asymmetry in RNAi: function in RISC assembly and gene regulation. FEBS Lett 579(26):5850-5857.

Hutvagner G, McLachlan J, Pasquinelli AE, Balint E, Tuschl T, Zamore PD. 2001. A cellular function for the RNA-interference enzyme Dicer in the maturation of the let-7 small temporal RNA. Science 293(5531):834-838.

Hutvagner G, Zamore PD. 2002. A microRNA in a multiple-turnover RNAi enzyme complex. Science 297(5589):2056-2060.

Im YJ, Raychaudhuri S, Prinz WA, Hurley JH. 2005. Structural mechanism for sterol sensing and transport by OSBP-related proteins. Nature 437(7055):154-158.

Jeske M, Meyer S, Temme C, Freudenreich D, Wahle E. 2006. Rapid ATP-dependent deadenylation of nanos mRNA in a cell-free system from Drosophila embryos. J Biol Chem 281(35):25124-25133.

Joyce IM, Clark AT, Pendola FL, Eppig JJ. 2000. Comparison of recombinant growth differentiation factor-9 and oocyte regulation of KIT ligand messenger ribonucleic acid expression in mouse ovarian follicles. Biol Reprod 63(6):16691675.

Joyce IM, Pendola FL, O'Brien M, Eppig JJ. 2001. Regulation of prostaglandinendoperoxide synthase 2 messenger ribonucleic acid expression in mouse granulosa cells during ovulation. Endocrinology 142(7):3187-3197.

Joyce IM, Pendola FL, Wigglesworth K, Eppig JJ. 1999. Oocyte regulation of kit ligand expression in mouse ovarian follicles. Dev Biol 214(2):342-353.

K. Hershberger W. 1992. Genetic variability in rainbow trout populations. Aquaculture 100(1-3):51-71.

Kane DA, Kimmel CB. 1993. The zebrafish midblastula transition. Development 119(2):447-456.

Kaneko KJ, Cullinan EB, Latham KE, DePamphilis ML. 1997. Transcription factor mTEAD-2 is selectively expressed at the beginning of zygotic gene expression in the mouse. Development 124(10):1963-1973.

Kanellopoulou C, Muljo SA, Kung AL, Ganesan S, Drapkin R, Jenuwein T, Livingston DM, Rajewsky K. 2005. Dicer-deficient mouse embryonic stem cells are defective in differentiation and centromeric silencing. Genes Dev 19(4):489-501.

Kanka J. 2003. Gene expression and chromatin structure in the pre-implantation embryo. Theriogenology 59(1):3-19.

Kawasaki H, Taira K. 2003. Hes1 is a target of microRNA-23 during retinoic-acidinduced neuronal differentiation of NT2 cells. Nature 423(6942):838-842.

Kloosterman WP, Plasterk RH. 2006. The diverse functions of microRNAs in animal development and disease. Dev Cell 11(4):441-450.

Koutsourakis M, Langeveld A, Patient R, Beddington R, Grosveld F. 1999. The transcription factor GATA6 is essential for early extraembryonic development. Development 126(9):723-732. 
Kretzschmar AK, Dinger MC, Henze C, Brocke-Heidrich K, Horn F. 2004. Analysis of Stat3 (signal transducer and activator of transcription 3) dimerization by fluorescence resonance energy transfer in living cells. Biochem J 377(Pt 2):289297.

Kulshreshtha R, Ferracin M, Wojcik SE, Garzon R, Alder H, Agosto-Perez FJ, Davuluri R, Liu CG, Croce CM, Negrini M, Calin GA, Ivan M. 2007. A microRNA signature of hypoxia. Mol Cell Biol 27(5):1859-1867.

Kusenda B, Mraz M, Mayer J, Pospisilova S. 2006. MicroRNA biogenesis, functionality and cancer relevance. Biomed Pap Med Fac Univ Palacky Olomouc Czech Repub 150(2):205-215.

Lagace TA, Byers DM, Cook HW, Ridgway ND. 1997. Altered regulation of cholesterol and cholesteryl ester synthesis in Chinese-hamster ovary cells overexpressing the oxysterol-binding protein is dependent on the pleckstrin homology domain. Biochem J 326 ( Pt 1):205-213.

Lagace TA, Byers DM, Cook HW, Ridgway ND. 1999. Chinese hamster ovary cells overexpressing the oxysterol binding protein (OSBP) display enhanced synthesis of sphingomyelin in response to 25-hydroxycholesterol. J Lipid Res 40(1):109116.

Lagos-Quintana M, Rauhut R, Lendeckel W, Tuschl T. 2001. Identification of novel genes coding for small expressed RNAs. Science 294(5543):853-858.

Lagos-Quintana M, Rauhut R, Yalcin A, Meyer J, Lendeckel W, Tuschl T. 2002. Identification of tissue-specific microRNAs from mouse. Curr Biol 12(9):735739.

Lai EC, Tomancak P, Williams RW, Rubin GM. 2003. Computational identification of Drosophila microRNA genes. Genome Biol 4(7):R42.

Lecellier CH, Dunoyer P, Arar K, Lehmann-Che J, Eyquem S, Himber C, Saib A, Voinnet O. 2005. A cellular microRNA mediates antiviral defense in human cells. Science 308(5721):557-560.

Lee JS, Galvin KM, Shi Y. 1993a. Evidence for physical interaction between the zincfinger transcription factors YY1 and Sp1. Proc Natl Acad Sci U S A 90(13):61456149.

Lee RC, Feinbaum RL, Ambros V. 1993b. The C. elegans heterochronic gene lin-4 encodes small RNAs with antisense complementarity to lin-14. Cell 75(5):843854.

Lee Y, Ahn C, Han J, Choi H, Kim J, Yim J, Lee J, Provost P, Radmark O, Kim S, Kim VN. 2003. The nuclear RNase III Drosha initiates microRNA processing. Nature 425(6956):415-419.

Lee Y, Jeon K, Lee JT, Kim S, Kim VN. 2002. MicroRNA maturation: stepwise processing and subcellular localization. EMBO J 21(17):4663-4670.

Lee Y, Kim M, Han J, Yeom KH, Lee S, Baek SH, Kim VN. 2004. MicroRNA genes are transcribed by RNA polymerase II. EMBO J 23(20):4051-4060.

Lehto M, Laitinen S, Chinetti G, Johansson M, Ehnholm C, Staels B, Ikonen E, Olkkonen VM. 2001. The OSBP-related protein family in humans. J Lipid Res 42(8):1203-1213.

Levine T. 2004. Short-range intracellular trafficking of small molecules across endoplasmic reticulum junctions. Trends Cell Biol 14(9):483-490. 
Levine TP, Munro S. 1998. The pleckstrin homology domain of oxysterol-binding protein recognises a determinant specific to Golgi membranes. Curr Biol 8(13):729-739.

Li R, Norman RJ, Armstrong DT, Gilchrist RB. 2000. Oocyte-secreted factor(s) determine functional differences between bovine mural granulosa cells and cumulus cells. Biol Reprod 63(3):839-845.

Li X, Rivas MP, Fang M, Marchena J, Mehrotra B, Chaudhary A, Feng L, Prestwich GD, Bankaitis VA. 2002. Analysis of oxysterol binding protein homologue Kes1p function in regulation of Sec14p-dependent protein transport from the yeast Golgi complex. J Cell Biol 157(1):63-77.

Liang L, Soyal SM, Dean J. 1997. FIGalpha, a germ cell specific transcription factor involved in the coordinate expression of the zona pellucida genes. Development 124(24):4939-4947.

Lin SY, Johnson SM, Abraham M, Vella MC, Pasquinelli A, Gamberi C, Gottlieb E, Slack FJ. 2003. The $\mathrm{C}$ elegans hunchback homolog, hbl-1, controls temporal patterning and is a probable microRNA target. Dev Cell 4(5):639-650.

Liu C, Litscher ES, Mortillo S, Sakai Y, Kinloch RA, Stewart CL, Wassarman PM. 1996. Targeted disruption of the mZP3 gene results in production of eggs lacking a zona pellucida and infertility in female mice. Proc Natl Acad Sci U S A 93(11):54315436.

Loewen CJ, Roy A, Levine TP. 2003. A conserved ER targeting motif in three families of lipid binding proteins and in Opilp binds VAP. Embo J 22(9):2025-2035.

Loffler D, Brocke-Heidrich K, Pfeifer G, Stocsits C, Hackermuller J, Kretzschmar AK, Burger R, Gramatzki M, Blumert C, Bauer K, Cvijic H, Ullmann AK, Stadler PF, Horn F. 2007. Interleukin-6 dependent survival of multiple myeloma cells involves the Stat3-mediated induction of microRNA-21 through a highly conserved enhancer. Blood 110(4):1330-1333.

Lonergan P, Gutierrez-Adan A, Rizos D, Pintado B, de la Fuente J, Boland MP. $2003 \mathrm{a}$. Relative messenger RNA abundance in bovine oocytes collected in vitro or in vivo before and $20 \mathrm{hr}$ after the preovulatory luteinizing hormone surge. Mol Reprod Dev 66(3):297-305.

Lonergan P, Rizos D, Gutierrez-Adan A, Moreira PM, Pintado B, de la Fuente J, Boland MP. 2003b. Temporal divergence in the pattern of messenger RNA expression in bovine embryos cultured from the zygote to blastocyst stage in vitro or in vivo. Biol Reprod 69(4):1424-1431.

Lu Y, Thomson JM, Wang HY, Hammond SM, Hogan BL. 2007. Transgenic overexpression of the microRNA miR-17-92 cluster promotes proliferation and inhibits differentiation of lung epithelial progenitor cells. Dev Biol.

Lund E, Guttinger S, Calado A, Dahlberg JE, Kutay U. 2004. Nuclear export of microRNA precursors. Science 303(5654):95-98.

Marin M, Karis A, Visser P, Grosveld F, Philipsen S. 1997. Transcription factor Sp1 is essential for early embryonic development but dispensable for cell growth and differentiation. Cell 89(4):619-628.

Marmorstein R. 2001. Protein modules that manipulate histone tails for chromatin regulation. Nat Rev Mol Cell Biol 2(6):422-432. 
Meltzer PS. 2005. Cancer genomics: small RNAs with big impacts. Nature 435(7043):745-746.

Memili E, First NL. 1999. Control of gene expression at the onset of bovine embryonic development. Biol Reprod 61(5):1198-1207.

Mohamed OA, Bustin M, Clarke HJ. 2001. High-mobility group proteins 14 and 17 maintain the timing of early embryonic development in the mouse. Dev Biol 229(1):237-249.

Morrill GA, Kostellow AB. 1999. Progesterone induces meiotic division in the amphibian oocyte by releasing lipid second messengers from the plasma membrane. Steroids 64(1-2):157-167.

Morrison GM, Brickman JM. 2006. Conserved roles for Oct4 homologues in maintaining multipotency during early vertebrate development. Development 133(10):20112022.

Newport J, Kirschner M. 1982. A major developmental transition in early Xenopus embryos: I. characterization and timing of cellular changes at the midblastula stage. Cell 30(3):675-686.

Nikolov DB, Burley SK. 1997. RNA polymerase II transcription initiation: a structural view. Proc Natl Acad Sci U S A 94(1):15-22.

Olkkonen VM, Levine TP. 2004. Oxysterol binding proteins: in more than one place at one time? Biochem Cell Biol 82(1):87-98.

Omoto S, Fujii YR. 2006. Cloning and detection of HIV-1-encoded microRNA. Methods Mol Biol 342:255-265.

Otsuka F, Yao Z, Lee T, Yamamoto S, Erickson GF, Shimasaki S. 2000. Bone morphogenetic protein-15. Identification of target cells and biological functions. J Biol Chem 275(50):39523-39528.

Ovitt CE, Scholer HR. 1998. The molecular biology of Oct-4 in the early mouse embryo. Mol Hum Reprod 4(11):1021-1031.

Padmanabhan K, Richter JD. 2006. Regulated Pumilio-2 binding controls RINGO/Spy mRNA translation and CPEB activation. Genes Dev 20(2):199-209.

Pangas SA, Choi Y, Ballow DJ, Zhao Y, Westphal H, Matzuk MM, Rajkovic A. 2006. Oogenesis requires germ cell-specific transcriptional regulators Sohlh1 and Lhx8. Proc Natl Acad Sci U S A 103(21):8090-8095.

Paynton BV, Bachvarova R. 1994. Polyadenylation and deadenylation of maternal mRNAs during oocyte growth and maturation in the mouse. Mol Reprod Dev 37(2):172-180.

Pelegri F. 2003. Maternal factors in zebrafish development. Dev Dyn 228(3):535-554.

Philpott A, Leno GH. 1992. Nucleoplasmin remodels sperm chromatin in Xenopus egg extracts. Cell 69(5):759-767.

Philpott A, Leno GH, Laskey RA. 1991. Sperm decondensation in Xenopus egg cytoplasm is mediated by nucleoplasmin. Cell 65(4):569-578.

Pillai RS. 2005. MicroRNA function: multiple mechanisms for a tiny RNA? RNA 11(12):1753-1761.

Pincus G, Enzmann EV. 1935. The comparative behavior of mammalian eggs in vivo and in vitro: $i$. The activation of ovarian eggs. J Exp Med 62(5):665-675. 
Poy MN, Eliasson L, Krutzfeldt J, Kuwajima S, Ma X, Macdonald PE, Pfeffer S, Tuschl T, Rajewsky N, Rorsman P, Stoffel M. 2004. A pancreatic islet-specific microRNA regulates insulin secretion. Nature 432(7014):226-230.

Rajkovic A, Pangas SA, Ballow D, Suzumori N, Matzuk MM. 2004. NOBOX deficiency disrupts early folliculogenesis and oocyte-specific gene expression. Science 305(5687):1157-1159.

Ramachandra RK, Lankford SE, Weber GM, Rexroad CE, 3rd, Yao J. 2007. Identification of OORP-T, a novel oocyte-specific gene encoding a protein with a conserved oxysterol binding protein domain in rainbow trout. Mol Reprod Dev 74(4):502-511.

Rankin T, Familari M, Lee E, Ginsberg A, Dwyer N, Blanchette-Mackie J, Drago J, Westphal H, Dean J. 1996. Mice homozygous for an insertional mutation in the Zp3 gene lack a zona pellucida and are infertile. Development 122(9):2903-2910.

Rankin T, Talbot P, Lee E, Dean J. 1999. Abnormal zonae pellucidae in mice lacking ZP1 result in early embryonic loss. Development 126(17):3847-3855.

Rankin TL, Coleman JS, Epifano O, Hoodbhoy T, Turner SG, Castle PE, Lee E, GoreLangton R, Dean J. 2003. Fertility and taxon-specific sperm binding persist after replacement of mouse sperm receptors with human homologs. Dev Cell 5(1):3343.

Rankin TL, O'Brien M, Lee E, Wigglesworth K, Eppig J, Dean J. 2001. Defective zonae pellucidae in Zp2-null mice disrupt folliculogenesis, fertility and development. Development 128(7):1119-1126.

Reeves R. 2001. Molecular biology of HMGA proteins: hubs of nuclear function. Gene 277(1-2):63-81.

Reeves R, Beckerbauer L. 2001. HMGI/Y proteins: flexible regulators of transcription and chromatin structure. Biochim Biophys Acta 1519(1-2):13-29.

Reinhart BJ, Slack FJ, Basson M, Pasquinelli AE, Bettinger JC, Rougvie AE, Horvitz HR, Ruvkun G. 2000. The 21-nucleotide let-7 RNA regulates developmental timing in Caenorhabditis elegans. Nature 403(6772):901-906.

Robert C, McGraw S, Massicotte L, Pravetoni M, Gandolfi F, Sirard MA. 2002. Quantification of housekeeping transcript levels during the development of bovine preimplantation embryos. Biol Reprod 67(5):1465-1472.

Rodriguez A, Griffiths-Jones S, Ashurst JL, Bradley A. 2004. Identification of mammalian microRNA host genes and transcription units. Genome Res 14(10A):1902-1910.

Ruggiu M, Speed R, Taggart M, McKay SJ, Kilanowski F, Saunders P, Dorin J, Cooke HJ. 1997. The mouse Dazla gene encodes a cytoplasmic protein essential for gametogenesis. Nature 389(6646):73-77.

Salustri A, Yanagishita M, Hascall VC. 1989. Synthesis and accumulation of hyaluronic acid and proteoglycans in the mouse cumulus cell-oocyte complex during folliclestimulating hormone-induced mucification. J Biol Chem 264(23):13840-13847.

Sambrook J, Russell DW. 2001a. Molecular cloning : a laboratory manual. Cold Spring Harbor, N.Y.: Cold Spring Harbor Laboratory Press. p 3 v. (various pagings).

Sambrook J, Russell DW. 2001b. Molecular Cloning: A Laboratory Manual. New York: Cold Spring Harbour Laboratory Press. pp 7.1-7.88. 
Schier AF. 2007. The maternal-zygotic transition: death and birth of RNAs. Science 316(5823):406-407.

Schultz RM. 1993. Regulation of zygotic gene activation in the mouse. Bioessays 15(8):531-538.

Sheets MD, Fox CA, Hunt T, Vande Woude G, Wickens M. 1994. The 3'-untranslated regions of c-mos and cyclin mRNAs stimulate translation by regulating cytoplasmic polyadenylation. Genes Dev 8(8):926-938.

Si ML, Zhu S, Wu H, Lu Z, Wu F, Mo YY. 2007. miR-21-mediated tumor growth. Oncogene 26(19):2799-2803.

Slevin MK, Lyons-Levy G, Weeks DL, Hartley RS. 2005. Antisense knockdown of cyclin $\mathrm{E}$ does not affect the midblastula transition in Xenopus laevis embryos. Cell Cycle 4(10): 1396-1402.

Smirnova L, Grafe A, Seiler A, Schumacher S, Nitsch R, Wulczyn FG. 2005. Regulation of miRNA expression during neural cell specification. Eur J Neurosci 21(6):14691477.

Soyal SM, Amleh A, Dean J. 2000. FIGalpha, a germ cell-specific transcription factor required for ovarian follicle formation. Development 127(21):4645-4654.

Stein P, Worrad DM, Belyaev ND, Turner BM, Schultz RM. 1997. Stage-dependent redistributions of acetylated histones in nuclei of the early preimplantation mouse embryo. Mol Reprod Dev 47(4):421-429.

Strum JC, Swenson KI, Turner JE, Bell RM. 1995. Ceramide triggers meiotic cell cycle progression in Xenopus oocytes. A potential mediator of progesterone-induced maturation. J Biol Chem 270(22):13541-13547.

Su YQ, Wu X, O'Brien MJ, Pendola FL, Denegre JN, Matzuk MM, Eppig JJ. 2004. Synergistic roles of BMP15 and GDF9 in the development and function of the oocyte-cumulus cell complex in mice: genetic evidence for an oocyte-granulosa cell regulatory loop. Dev Biol 276(1):64-73.

Takada S, Berezikov E, Yamashita Y, Lagos-Quintana M, Kloosterman WP, Enomoto M, Hatanaka H, Fujiwara S, Watanabe H, Soda M, Choi YL, Plasterk RH, Cuppen E, Mano H. 2006. Mouse microRNA profiles determined with a new and sensitive cloning method. Nucleic Acids Res 34(17):e115.

Tang F, Kaneda M, O'Carroll D, Hajkova P, Barton SC, Sun YA, Lee C, Tarakhovsky A, Lao K, Surani MA. 2007. Maternal microRNAs are essential for mouse zygotic development. Genes Dev 21(6):644-648.

Tay J, Hodgman R, Richter JD. 2000. The control of cyclin B1 mRNA translation during mouse oocyte maturation. Dev Biol 221(1):1-9.

Tay J, Richter JD. 2001. Germ cell differentiation and synaptonemal complex formation are disrupted in CPEB knockout mice. Dev Cell 1(2):201-213.

Taylor FR, Kandutsch AA. 1985. Oxysterol binding protein. Chem Phys Lipids 38(12):187-194.

Telford NA, Watson AJ, Schultz GA. 1990. Transition from maternal to embryonic control in early mammalian development: a comparison of several species. Mol Reprod Dev 26(1):90-100.

Thorgaard GH, Bailey GS, Williams D, Buhler DR, Kaattari SL, Ristow SS, Hansen JD, Winton JR, Bartholomew JL, Nagler JJ, Walsh PJ, Vijayan MM, Devlin RH, Hardy RW, Overturf KE, Young WP, Robison BD, Rexroad C, Palti Y. 2002. 
Status and opportunities for genomics research with rainbow trout. Comp Biochem Physiol B Biochem Mol Biol 133(4):609-646.

Tong ZB, Gold L, Pfeifer KE, Dorward H, Lee E, Bondy CA, Dean J, Nelson LM. 2000. Mater, a maternal effect gene required for early embryonic development in mice. Nat Genet 26(3):267-268.

Tyler CR, Nagler JJ, Pottinger TG, Turner MA. 1994. Effects of unilateral ovariectomy on recruitment and growth of follicles in the rainbow trout, Oncorhynchus mykiss. Fish Physiology and Biochemistry 13:309-316.

Tyler CR, Sumpter JP. 1996. Oocyte growth and development in teleosts. Rev Fish Biol Fish 6(3):287 - 318.

Vasudevan S, Seli E, Steitz JA. 2006. Metazoan oocyte and early embryo development program: a progression through translation regulatory cascades. Genes Dev 20(2):138-146.

Venturini L, Battmer K, Castoldi M, Schultheis B, Hochhaus A, Muckenthaler MU, Ganser A, Eder M, Scherr M. 2007. Expression of the miR-17-92 polycistron in chronic myeloid leukemia (CML) CD34+ cells. Blood 109(10):4399-4405.

Vigneault C, McGraw S, Massicotte L, Sirard MA. 2004. Transcription factor expression patterns in bovine in vitro-derived embryos prior to maternal-zygotic transition. Biol Reprod 70(6):1701-1709.

Vitt UA, Hayashi M, Klein C, Hsueh AJ. 2000. Growth differentiation factor-9 stimulates proliferation but suppresses the follicle-stimulating hormone-induced differentiation of cultured granulosa cells from small antral and preovulatory rat follicles. Biol Reprod 62(2):370-377.

Vo N, Goodman RH. 2001. CREB-binding protein and p300 in transcriptional regulation. J Biol Chem 276(17):13505-13508.

Voet D, Voet JG, Pratt CW. 2005. Fundamentals of biochemistry-life at the molecular level: John Wiley \& Sons Inc.

Watanabe T, Takeda A, Mise K, Okuno T, Suzuki T, Minami N, Imai H. 2005. Stagespecific expression of microRNAs during Xenopus development. FEBS Lett 579(2):318-324.

Weigel D, Izaurralde E. 2006. A tiny helper lightens the maternal load. Cell 124(6):11171118.

Wienholds E, Koudijs MJ, van Eeden FJ, Cuppen E, Plasterk RH. 2003. The microRNAproducing enzyme Dicer1 is essential for zebrafish development. Nat Genet 35(3):217-218.

Wienholds E, Plasterk RH. 2005. MicroRNA function in animal development. FEBS Lett 579(26):5911-5922.

Wightman B, Ha I, Ruvkun G. 1993. Posttranscriptional regulation of the heterochronic gene lin-14 by lin- 4 mediates temporal pattern formation in C. elegans. Cell 75(5):855-862.

Worrad DM, Turner BM, Schultz RM. 1995. Temporally restricted spatial localization of acetylated isoforms of histone H4 and RNA polymerase II in the 2-cell mouse embryo. Development 121(9):2949-2959.

Woychik NA, Hampsey M. 2002. The RNA polymerase II machinery: structure illuminates function. Cell 108(4):453-463. 
Wu L, Fan J, Belasco JG. 2006. MicroRNAs direct rapid deadenylation of mRNA. Proc Natl Acad Sci U S A 103(11):4034-4039.

Wu X, Viveiros MM, Eppig JJ, Bai Y, Fitzpatrick SL, Matzuk MM. 2003. Zygote arrest 1 (Zar1) is a novel maternal-effect gene critical for the oocyte-to-embryo transition. Nat Genet 33(2):187-191.

Wyles JP, McMaster CR, Ridgway ND. 2002. Vesicle-associated membrane proteinassociated protein-A (VAP-A) interacts with the oxysterol-binding protein to modify export from the endoplasmic reticulum. J Biol Chem 277(33):2990829918.

Xu H, Wang X, Du Z, Li N. 2006. Identification of microRNAs from different tissues of chicken embryo and adult chicken. FEBS Lett 580(15):3610-3616.

Xu P, Vernooy SY, Guo M, Hay BA. 2003. The Drosophila microRNA Mir-14 suppresses cell death and is required for normal fat metabolism. Curr Biol 13(9):790-795.

Yan C, Wang P, DeMayo J, DeMayo FJ, Elvin JA, Carino C, Prasad SV, Skinner SS, Dunbar BS, Dube JL, Celeste AJ, Matzuk MM. 2001. Synergistic roles of bone morphogenetic protein 15 and growth differentiation factor 9 in ovarian function. Mol Endocrinol 15(6):854-866.

Yang WJ, Yang DD, Na S, Sandusky GE, Zhang Q, Zhao G. 2005. Dicer is required for embryonic angiogenesis during mouse development. J Biol Chem 280(10):93309335.

Yao J, Higgins AD, Rexroad CE. Transcriptome analyses of rainbow trout oocytes; 2005; San Diego, CA.

Yekta S, Shih IH, Bartel DP. 2004. MicroRNA-directed cleavage of HOXB8 mRNA. Science 304(5670):594-596.

Yoshida H, Takakura N, Kataoka H, Kunisada T, Okamura H, Nishikawa SI. 1997. Stepwise requirement of c-kit tyrosine kinase in mouse ovarian follicle development. Dev Biol 184(1):122-137.

Yu J, Hecht NB, Schultz RM. 2001. Expression of MSY2 in mouse oocytes and preimplantation embryos. Biol Reprod 65(4):1260-1270.

Zhao Y, Samal E, Srivastava D. 2005. Serum response factor regulates a muscle-specific microRNA that targets Hand2 during cardiogenesis. Nature 436(7048):214-220.

Zheng P, Dean J. 2007. Oocyte-specific genes affect folliculogenesis, fertilization, and early development. Semin Reprod Med 25(4):243-251.

Zhu S, Si ML, Wu H, Mo YY. 2007. MicroRNA-21 targets the tumor suppressor gene tropomyosin 1 (TPM1). J Biol Chem 282(19):14328-14336. 